TI 2012-121/III

Tinbergen Institute Discussion Paper
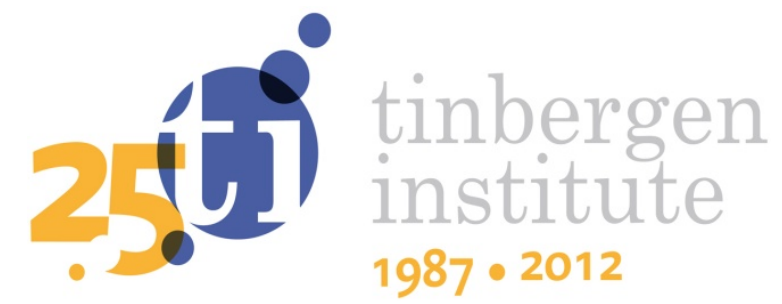

\title{
Speed, Algorithmic Trading, and Market Quality around Macroeconomic News Announcements
}

\author{
Martin L. Scholtus' \\ Dick van Dijk' \\ Bart Frijns²
}

${ }^{\prime}$ Econometric Institute, Erasmus School of Economics, Erasmus University Rotterdam, and Tinbergen Institute;

2 Department of Finance, Auckland University of Technology. 
Tinbergen Institute is the graduate school and research institute in economics of Erasmus University Rotterdam, the University of Amsterdam and VU University Amsterdam.

More TI discussion papers can be downloaded at http://www.tinbergen.nl

Tinbergen Institute has two locations:

Tinbergen Institute Amsterdam

Gustav Mahlerplein 117

1082 MS Amsterdam

The Netherlands

Tel.: +31(0)205251600

Tinbergen Institute Rotterdam

Burg. Oudlaan 50

3062 PA Rotterdam

The Netherlands

Tel.: +31(0)10 4088900

Fax: $+31(0) 104089031$

Duisenberg school of finance is a collaboration of the Dutch financial sector and universities, with the ambition to support innovative research and offer top quality academic education in core areas of finance.

DSF research papers can be downloaded at: http://www.dsf.nl/

Duisenberg school of finance

Gustav Mahlerplein 117

1082 MS Amsterdam

The Netherlands

Tel.: +31(0)20 5258579 


\title{
Speed, Algorithmic Trading, and Market Quality around Macroeconomic News Announcements
}

\author{
Martin Scholtus ${ }^{\mathrm{a}, *}$, Dick van Dijk ${ }^{\mathrm{a}}$, Bart Frijns ${ }^{\mathrm{b}}$ \\ ${ }^{a}$ Econometric Institute and Tinbergen Institute, Erasmus University Rotterdam \\ P.O. Box 1738, 3000 DR Rotterdam, The Netherlands \\ ${ }^{b}$ Auckland University of Technology - Department of Finance, Auckland, New Zealand
}

November 12, 2012

\begin{abstract}
This paper documents that speed is crucially important for high frequency trading strategies based on U.S. macroeconomic news releases. Using order level data of the highly liquid S\&P500 ETF traded on NASDAQ from January 6, 2009, to December 12, 2011, we find that a delay of 300 milliseconds (1 second) significantly reduces returns by $3.08 \%$ (7.33\%) compared to instantaneous execution over all announcements in the sample. This reduction is stronger in case of high impact news and on days with high volatility. In addition, we assess the effect of algorithmic trading on market quality around macroeconomic news. Increases in algorithmic trading activity have a positive (mixed) effect on market quality measures when we use algorithmic trading proxies that capture the top of the orderbook (full orderbook).
\end{abstract}

Keywords: Macroeconomic News, High Frequency Trading, Latency Costs, Market Activity, Event-Based Trading

JEL: E44, G10, G14

${ }^{*}$ Corresponding author.

Email addresses: scholtus@ese.eur.nl (Martin Scholtus), djvandijk@ese.eur.nl

(Dick van Dijk), bart.frijns@aut.ac.nz (Bart Frijns) 


\section{Introduction}

News arrivals in financial markets are a driving force behind asset price changes. In the early days of organized exchange-based trading a telex and telephone, combined with good analytical skills, were enough for a competitive edge. More recently, a basic internet connection would suffice. Nowadays, the first trades based on new information arrive in the market before any human trader can glance at a news feed. How is this possible? First of all, in today's markets about two-thirds of all (NASDAQ) dollar volume traded can be attributed to fully automated, high frequency trading (Brogaard, 2010). Second, the current round-trip latency for these high frequency traders (in case of colocation) is less than 100 microseconds.1 $]^{1}$ Combine this with an ultra low-latency (machine readable) news feed and it is clear that no human market participant is able to compete purely based on speed.

It is not surprising that computers outperform humans in terms of speed. More interesting is that within the universe of high frequency traders large differences exist in trading speed that have a substantial day-to-day impact on performance. Hasbrouck and Saar (2009) and Scholtus and van Dijk (2012) describe the speed differences for interval-based high frequency traders. They find that the fastest group of traders acts in 5 milliseconds (ms), whereas other groups of relatively fast traders can be identified at speed levels of $50 \mathrm{~ms}$ and 150 ms. Scholtus and van Dijk (2012) further find that trading speed significantly affects technical trading rule performance when traders are more than $200 \mathrm{~ms}$ slower compared to instantaneous execution. Furthermore, the economic impact of trading speed on performance increases over time.

This paper makes two important contributions to the literature on high frequency trading around macroeconomic news announcements. First, the main contribution of this paper is to examine the importance of speed on event-based trading profitability around scheduled U.S. macroeconomic news announcements with millisecond precision. This extends the work of Scholtus and van Dijk (2012)

\footnotetext{
${ }^{1}$ http: //www . nasdaqtrader . com/Trader . aspx?id=colo
} 
who analyze the effect of speed using technical trading rules. Speed is most important when there are many traders making the same decisions. Not all market participants, however, obtain identical technical trading signals at the same time. By focusing on speed during macroeconomic news announcements we identify moments when the competition for good quotes is, without a doubt, fierce. Second, we analyze the effect of algorithmic trading activity on market quality during the periods with macro news. This is achieved by providing a detailed analysis of market activity and market quality measures around macroeconomic news arrivals.

We investigate the importance of speed for the profitability of strategies that trade on news releases of 20 different U.S. macroeconomic variables by using the highly liquid State Street S\&P500 Exchange Traded Fund (ETF) traded on NASDAQ. The period under consideration is January 6, 2009 up to December 12, 2011 (736 trading days and 800 macroeconomic news announcements of which 707 occur at different intraday moments). The exact moment the news becomes available in the market is, with millisecond precision, obtained from the SIRCA Global News Database. By randomizing the perfect foresight strategy (obtained based on the value of the S\&P500 index 1 minute after the news release) with predetermined degrees of error we are able to create different trading strategies. For all strategies we measure the importance of speed by comparing the performance of a strategy when signals are executed instantaneously with the performance of the same strategy when signal executions are delayed by a certain amount of time.

We find that trading speed is very important around macroeconomic news announcements, both in economic and statistical terms. For success ratios of $60 \%$ and higher, any delay from $10 \mathrm{~ms}$ up to 1 second leads to a statistically significant decrease in performance. The economic significance of speed increases with the degree to which trade direction is predicted accurately. Traders that can identify the correct trade direction for $80 \%$ of the news announcements experience a reduction in return of $0.26(0.61)$ bps per event when trades are delayed with 
$300 \mathrm{~ms}$ (1 second) compared to instantaneous execution. The corresponding decline over all 707 announcements is $1.86 \%$ for a $300 \mathrm{~ms}$ delay and $4.31 \%$ for a delay of 1 second. In case of a trader with perfect foresight (a success rate of $100 \%$ ), the loss for a delay of $300 \mathrm{~ms}$ (1 second) increases to 0.44 (1.04) bps per event, or $3.08 \%$ (7.33\%) over all 707 announcements. In relative terms (with respect to the total return of a strategy), the loss of a strategy with a success ratio of $80 \%$ that is delayed with 1 second is $12.64 \%$. This is substantially higher than the $2.03 \%$ relative decrease in performance when the execution of intervalbased technical trading strategies is delayed with 1 second Scholtus and van Dijk, 2012). The impact of speed on returns is higher in case of, for example, announcements at 10:00 a.m., on days with high volatility, and for high impact news, with declines in returns for a 1 second delay of 1.94, 1.61, and 2.08 bps per event, respectively.

The impact of algorithmic trading on market quality during macroeconomic news arrivals is analyzed by looking at message activity, spreads, orderbook depth, trading volume, and realized volatility measures ${ }^{2}$ We find that the period around macroeconomic news is characterized by large (quoted) spreads, an increase in volatility, a decrease in depth, and an increase in the algorithmic trading proxies. By means of a regression analysis we find that the effect of algorithmic trading on market quality during news depends on the type of algorithm that is active. For algorithms active in the whole orderbook, increases in algorithmic activity have a mixed effect on market quality. We find a positive effect on, for example, depth and trading volume, whereas for the quoted half-spread and volatility we find a negative effect. During macroeconomic news arrivals, increases in algorithmic trading proxies that focus on the top of the book have a positive effect on all market quality measures, except trading volume.

This paper is related to the rapidly growing literature on high frequency trading, algorithmic trading, and the effect of high speed trading on market quality,

\footnotetext{
${ }^{2}$ We cannot directly observe the activity of algorithmic traders during macroeconomic news announcements. Therefore, we use message activity and several types of fleeting orders as proxies for algorithmic trading activity.
} 
including Erenburg and Lasser (2009), Hasbrouck and Saar (2011), Hendershott,

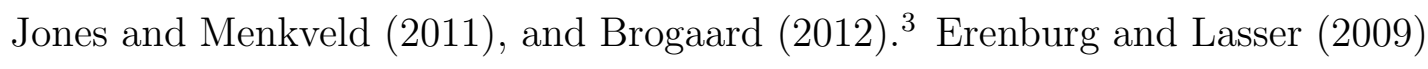
find that 7 out of the 16 different types of macroeconomic announcements lead to an increase in volatility. Furthermore, in the minutes surrounding macroeconomic news there is an increase in the bid-ask spread and order aggressiveness and a decrease in several measures of orderbook depth. Hasbrouck and Saar (2011) conclude that increases in low latency (high frequency) activity improve market quality measures such as intraday volatility, the quoted spread, and depth. The results of Hasbrouck and Saar (2011) for intraday volatility and depth (spreads) are confirmed by Brogaard (2012) (Hendershott et al. (2011)). In addition, Brogaard (2012) finds, for 200 individual stocks traded on NASDAQ, an increase in high frequency activity within 10 seconds of a macroeconomic news release, which can be attributed to an increase in liquidity taking. We extend these papers by focusing specifically on the effect of an increase in algorithmic trading on market quality during moments with macroeconomic news.

In addition to the aforementioned papers there exists a large literature concerning the effect of macroeconomic news announcements on financial markets. Whereas most early work finds that monetary news has an impact on stock market returns (see Pearce and Roley (1985) and Hardouvelis (1987)), the evidence with respect to real variables, such as industrial production, is mixed (compare Jain (1988) with Pearce and Roley (1985)). However, when accounting for the state of the economy (see McQueen and Roley (1993) and Boyd, Hu and Jagannathan (2005)), looking at sufficiently small intraday intervals (Adams, Mcqueen and Wood (2004) and Andersen, Bollerslev, Diebold and Vega (2007)), or including additional information from news headlines (Birz and Lott Jr., 2011) the stock market does show a price reaction to real macroeconomic news. Macroeconomic news not only affect stock prices, but also, equity volatility Andersen et al., 2007) and intraday price jumps (Evans, 2011). We extent this literature by

\footnotetext{
${ }^{3}$ For a more complete list on papers related to high frequency and algorithmic trading see the literature overview provided in Gomber, Arndt, Lutat and Uhle (2011).
} 
documenting the impact of macroeconomic news announcements on (midpoint) returns, volatility, and other market quality measures with millisecond precision.

The outline of this paper is as follows. Section 2 provides an overview of the S\&P500 ETF and macroeconomic news announcement data. Methods concerning measures of market quality, algorithmic activity, and the importance of speed are provided in Section 3. The results in Section 4 are followed by concluding remarks in Section 5 .

\section{Data}

\subsection{Orderbook Level Data}

In this study we use full orderbook information for the State Street S\&P 500 Exchange Traded Fund (ETF) traded on NASDAQ over the period January 6, 2009 up to December 12, 2011.4 We discard trading days before Christmas or following Thanksgiving as liquidity is low and trading is only possible in the morning. We also remove May 6, 2010, the day of the flash crash. The total number of trading days that remains in the sample period is 736 .

Because NASDAQ does not directly provide the full orderbook we construct this by means of the daily NASDAQ TotalView ITCH files. The TotalView ITCH files contain recordings of a direct data feed product offered by NASDAQ. The data elements in the file are order level data as well as trade messages, administrative messages, and net order imbalance data. We make use of order level data and administrative messages. The order level data consists of messages to add a new order (type A) and messages to modify existing orders (types E, C, X, D, and U) $5^{5}$ The administrative messages provide system event messages (including, for example, start and end of system and market hours), information about

\footnotetext{
${ }^{4}$ From June 5, 2009 to August 31, 2009 it was possible to use flash orders on NASDAQ. Because flash orders are added to the top of the orderbook they can affect, for example, the bid-ask spread. The flash order period is included in the analysis but any results that are potentially affected by the inclusion of flash orders are tested for robustness.

${ }^{5}$ Message type $\mathrm{E}$ and $\mathrm{C}$ are execution messages (where $\mathrm{E}$ is an execution against the price of the limit order originally put in and $\mathrm{C}$ is execution against a different price). Types $\mathrm{X}, \mathrm{D}$, and $\mathrm{U}$ are order cancellations, deletions, and replace messages, respectively.
} 
trading halts and market participant positions. All messages have a time stamp with potential nanosecond precision. However, this precision is not supported by NASDAQ over the whole sample period. Therefore, we use millisecond precision.

\subsection{Macroeconomic News Announcements}

Table 1 provides an overview of the 20 U.S. macroeconomic news announcements considered in this research. The list of intraday macroeconomic announcements as well as the high, low, and consensus forecasts are obtained from Econoday. News impact classifications (high, medium, and low) are based on the categories provided at http://www.forexfactory.com 6

We use the SIRCA global news database to identify the exact millisecond the macroeconomic news is first observed in the market. The SIRCA database consists of the news messages distributed over the Thomson Reuters real time network. For 2 macroeconomic releases we cannot find the correct arrival time in the SIRCA global news database $]^{7}$ Furthermore, the global news database contains news up to November 30, 2011, 23:59:59 p.m. Hence, also for the 8 macro announcements that occur from December 1, 2011 up to December 12, 2011 we cannot obtain the exact moment the news was observed by the market. For all 10 announcements without an exact SIRCA arrival time we use, unless mentioned otherwise, the official announcement time as exact news arrival time.

Of the 736 days in the sample period 520 days have, in total, 800 intraday macroeconomic news announcements that occur between 09:45 a.m. and 03:30 p.m. Of the 800 announcements, 707 take place on unique times. The remaining 93 news releases coincide with other announcements. In case multiple news releases take place at the same official announcement time, the news arrivals are considered as one announcement, for which we assign the time stamp of the

\footnotetext{
${ }^{6}$ Note that ForexFactory employs a news impact scale from 1 (low impact) to 4 (high impact). We consider category 1 and 2 as low impact, category 3 as medium impact, and category 4 as high impact news.

${ }^{7}$ This is the case for the ISM Services announcement on August 4, 2011, 10:00 a.m. and for the FOMC minutes on November 22, 2011, 02:00 p.m.
} 
first announcement that takes place and the impact factor of the highest impact announcement at that moment.

Table 1 shows that the announcements are spread uniformly over the sample period, with 268 (178), 273 (169), and 259 (173) announcements (days with announcements) in 2009, 2010, and 2011, respectively. Most announcements occur at 10:00 a.m. At all other official announcement times only one or two releases take place. The Crude Oil Inventory statements take place weekly, whereas the FOMC meetings are irregularly spaced. All other announcements are released on a monthly basis and occur either 35 or 36 times in the database.

Figure 1 provides an overview of the inverse tangent transformation of the differences in seconds between the official announcement time and actual news arrival as observed in the SIRCA global news database. Positive values indicate an announcement that takes place after the official announcement time. Although, on average, macroeconomic news arrivals are reasonably punctual, large differences exist. Most reliable are the releases of the preliminary and revised University of Michigan Consumer confidence data, whereas the FOMC rate decisions can occur far from the officially scheduled time. Macroeconomic news arrivals before the official announcement time are scarce 8

\subsection{Synchronization Issues}

The data in this research comes from two different sources, namely NASDAQ, and Thomson Reuters (TR), that are not necessarily perfectly synchronized. We use the TR time stamp directly on the NASDAQ data (which we assume is time stamped with the 'true' time). This could lead to some inaccuracy in the exact

\footnotetext{
${ }^{8}$ For 13 macroeconomic news announcements the actual SIRCA arrival time is before the official announcement time. For 3 of the 13 announcement the news arrives in the second before the official announcement time. For 4 of the 13 announcement the actual arrival time is more than one minute before the official announcement time. This holds for the FOMC rate decisions of March 15, 2011 (time difference of -68.71 seconds), March 16, 2010 (time difference of -110.06 seconds), and June 22, 2011 (time difference of -176.67 seconds). The most extreme difference of -1164.12 seconds is found for the consumer confidence data on June 28, 2011 (official announcement time 10:00 a.m.). 3 of the 13 announcements that occur before the official announcement time coincide with another news arrival at the same official announcement time.
} 
time news is observed in the market. For example, when we apply a TR clock that runs 2 milliseconds (ms) late (early) with respect to the data with a NASDAQ clock, we will observe the news 2 ms before (after) it is actually available $?^{9}$

For the analysis of algorithmic trading and market quality around news announcements the synchronization problem is unlikely to distort the results. The intervals that we consider around the news event are large compared to a potential millisecond distortion due to mis-synchronization. The importance of speed analysis, however, may be affected by mis-synchronization. Both an early and late TR clock lead to an understimation of the importance of speed because either news is not yet available (late clock) or news has already arrived (early clock).

We do not have access to data that would prevent mis-synchronization. Therefore, we assess the degree of mis-synchronization not only by considering official announcement times and the news arrival times from SIRCA, but also by including refined news announcement times (empirical announcement times). That is, we search for early or late reactions to news around the SIRCA arrival time. Refined news arrival times are constructed by means of raw message activity $50 \mathrm{~ms}$ before and after the SIRCA event time. The refined news arrival time is the moment that corresponds to the peak in message activity in the interval around the SIRCA event time. In case structural mis-synchronization is present we would expect to observe a systematic relation between the refined announcement times and SIRCA announcement times ${ }^{10}$ Furthermore, in case of mis-synchronization the importance of speed analysis would lead to different results when we use empirical arrival times instead of SIRCA arrival times.

Figure 2 presents an overview of the difference between the SIRCA news arrival time and refined news arrival time (y-axis) against the inverse tangent

\footnotetext{
${ }^{9}$ To clarify this confusing issue a bit more. In case the TR clock is $2 \mathrm{~ms}$ late w.r.t. the NASDAQ clock it is 10:00:00.500 a.m. on TR, whereas it is 10:00:00.502 on NASDAQ. Now, when we use the TR time stamped news on NASDAQ we observe news at 10:00:00.500 that should not have been available until 10:00:00.502.

${ }^{10}$ This does not completely rule out mis-synchronization. It is also possible that the degree of mis-synchronization is time varying due to differences in the accuracy of time stamps during periods with a lot of news (TR) or high message activity (NASDAQ).
} 
transformed difference of the official announcement time and SIRCA news arrival time (x-axis). The vertical dashed lines separate events for which the difference between the official announcement time and SIRCA time is more than $500 \mathrm{~ms}$. We observe no clustering of announcements at a certain difference between the SIRCA announcement time and refined announcement times. In addition, the results for the analysis of the importance of speed (provided in Section 4.3) are virtually identical when we use refined news arrival times instead of the SIRCA news arrival times. Hence, there is no evidence of structural mis-synchronization 11

\section{Methodology}

\subsection{Market Activity and Automated Trading Activity}

Unlike in Brogaard (2012) or Chaboud, Chiquoine, Hjalmarsson and Vega (2009) we do not observe whether specific transactions involve high frequency traders. Therefore, we use several proxies of automated trading activity. The first proxy for algorithmic trading is total message activity. Total message activity (NMSGS) is the sum of all messages (orders) send to NASDAQ during a specific time period. This proxy is not the cleanest measure of algorithmic activity because it can simply reflect high market-wide activity of a large number of human traders. The second proxy of algorithmic activity is the percentage of fleeting orders. The concept of a fleeting order is introduced by Hasbrouck and Saar (2009) and is defined as an order added and removed from the orderbook within a short period of time ( $s$ milliseconds). The time periods that we consider are $50 \mathrm{~ms}$ and $100 \mathrm{~ms}$ and this proxy is denoted as NFLTs ${ }^{12}$ We expect that NFLTs is a reliable proxy for algorithmic activity because it is unlikely that human market participants can (consistently) submit and cancel orders within 50 or $100 \mathrm{~ms}$.

\footnotetext{
${ }^{11}$ We also find no evidence for mis-synchronization when we use empirical announcement times obtained by searching for the peak in activity in the 25 or $100 \mathrm{~ms}$ around the SIRCA arrival time.

${ }^{12}$ O'Hara (2010) describes how fleeting orders (but also, for example, flash orders or 'match only' orders) lead to a situation where it is no longer clear what can be considered a quote.
} 
The remaining proxies for algorithmic trading are all related to the concept of fleeting orders. The first variant is the number of fleeting executions $\left(N F L T s_{\text {exe }}\right)$. This is the number of orders added to the orderbook that are executed within 50 or $100 \mathrm{~ms}$. However, as with the NMSGS proxy, the number of fleeting executions can simply be the result of an increase in market-wide (human) market order submissions. In addition, we include the number of fleeting orders that improve upon the best bid or ask quote $\left(N F L T s_{b a}\right)$ and the number of fleeting orders that improve upon the best bid or ask quote that leave a worse orderbook when removed $\left(N F L T s_{m o}\right)$. Scholtus and van Dijk (2012) refer to this measure as missed opportunities. Both the NFLT $s_{b a}$ and the NFLT $s_{m o}$ are measures of algorithmic trading activity for which it is impossible that these are systematically affected by human activity.

When discussing the results we will focus on those algorithmic trading proxies that are not distorted by human activity (NFLTs, NFLT $s_{b a}$, and NFLT $s_{m o}$ ). Of these proxies, the $N F L T s_{b a}$, and $N F L T s_{m o}$ focus mainly on the top of the orderbook, whereas the NFLTs measure targets the whole orderbook. It is likely that algorithmic activity that affects the top of the orderbook has a different effect on market quality than algorithmic activity in the full orderbook for two reasons. First, because some market quality measures are simply more related to the top of the orderbook (e.g. quoted half-spread) or full orderbook (e.g. depth). Second, because algorithms that target the top of the orderbook may be used by different market participants than algorithms that target the whole orderbook.

\subsection{Market Quality}

Market quality during macroeconomic news announcements is investigated by measuring liquidity and volatility. The liquidity measures can be divided into depth, volume, and spread variables. The orderbook depth measures include the quoted number of shares at the best bid and ask price $(N B B A)$ and the quoted number of shares on the bid and ask side up to five cents away from the best bid or ask quote $(D P)$. The depth measures are comparable to those used by 
Erenburg and Lasser (2009) and Hasbrouck and Saar (2011). The trading volume measure we use is the dollar volume traded $(\$ V)$.

For the spread measures, we use the quoted half-spread and the 5 and 60 seconds realized spreads. All spread measures use the midpoint at time $t$, denoted $m_{t}$, which is the the average of the bid $\left(p_{b, t}\right)$ and ask $\left(p_{a, t}\right)$ price at time $t$ and are in basis points (bps) relative to the midpoint. The quoted half-spread at time $t$ and $x$ second realized spread at the time of trade $i\left(t_{t r_{i}}\right)$ are defined as $Q H S_{t}=\left(p_{a, t}-p_{b, t}\right) / 2 m_{t}$ and $R S x_{t_{t r_{i}}}=\left(q_{i}\left(p_{t_{t r_{i}}}-m_{t_{t r_{i}}+x s e c}\right)\right) / m_{t_{t r_{i}}}$, respectively, where $p_{t t_{i}}$ is the transaction price of trade $i$ and $q_{i}$ is $1(-1)$ if trade $i$ is buyer (seller) initiated. The realized spread gives an estimate of the revenue of liquidity providers and assumes that the liquidity provider can close open positions in $x$ seconds. The losses of liquidity providers, or the profit of liquidity demanders, is captured by the $x$ second adverse selection costs $(A D V x)$, or price impact, calculated as $A D V x_{t_{t r_{i}}}=\left(q_{i}\left(m_{t_{t r_{i}}+x s e c}-m_{t_{t r_{i}}}\right)\right) / m_{t_{t r_{i}}}{ }^{13}$

The volatility measures we consider are the realized variance, $R V x=\sum_{j=1}^{(x / v)} m r_{j}^{2}$, and realized bi-power variation, $B P x=\frac{\pi}{2} \sum_{j=2}^{x / v}\left|m r_{j-1}\right|\left|m r_{j}\right|$. Both measures are calculated over intervals of $1(x=60)$ and $5(x=300)$ minutes. Each 1 (5) minute interval is divided in subintervals of $v=1(v=5)$ seconds. The subintervals are indexed by the subscript $j(j=1 \ldots(x / v))$. At the end of each subinterval $j$ we calculate the midpoint return, $m r_{j}=\ln \left(m_{j} / m_{j-1}\right)$. Note that $m_{j}$ is the midpoint at the change of each $v$ seconds. When $j=1, m_{j-1}$ is the midpoint present at the change of an $x$ second interval ${ }^{14}$ By using midpoint returns we reduce noise in the volatility measures due to the bid-ask bounce. However, some measurement error remains as a result of midpoint discreteness. For a continuous price process with martingale properties $R V$ and $B P$ converge to the same limit (Barndorff-Nielsen and Shephard, 2004).

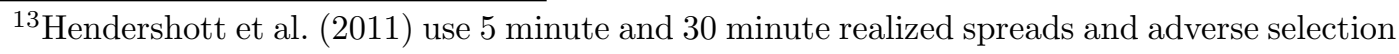
costs under the assumption that this is the time market makers, on average, take to neutralize positions. We assume that fully automated market makers balance their books more frequently.

${ }^{14}$ In case of the first $x$ minute trading interval of the day and $j=1, m_{j-1}$ is the first midpoint observed on the trading day.
} 
We also assess the effect of algorithmic activity $(A A)$ on market quality $(M Q)$ during news. This is done by means of the regression model in Equation (1) where, for announcement $k, M Q$ is either $N B B A$ (number of shares at the best bid and ask quote), DP (depth of the orderbook up to 5 cents away from the best bid or ask), QHS (quoted half-spread), $R S x$ ( $x$ second realized spread), $A D V x$ ( $x$ second adverse selection costs), $R V x$ ( $x$ second realized variance), or $B P x$ ( $x$ second realized bi-power). The algorithmic activity measures $A A$ include total message activity ( $N M S G S)$, the number of fleeting orders (NFLTs), the number of fleeting executions $\left(N F L T s_{\text {exe }}\right)$, the number of fleeting orders that improve the best bid or ask quote $\left(N F L T s_{b a}\right)$, and the number of missed opportunities $\left(N F L T s_{m o}\right)$. All fleeting order variants are considered at the $s=50$ and $s=100 \mathrm{~ms}$ level 15 The regression model is given by

$$
\begin{aligned}
M Q_{k} & =\alpha+\beta A A_{k}+\gamma D_{N}+\delta\left(D_{N} A A_{k}\right)+\zeta D_{F} \\
& +\sum_{l=1}^{5} \xi_{l} I D_{l, k}+\sum_{l=1}^{35} \nu_{l} T T_{l, k}+\sum_{i=1}^{2} \mu_{l} M Q_{k, t-i} \\
& +\sum_{i=1}^{2} \theta_{l} R V 300_{k, t-i} I\left(M Q_{k}\right)+\epsilon .
\end{aligned}
$$

Equation (1) also includes a dummy variable that identifies days with macroeconomic news $\left(D_{N}\right)$ and the interaction variable $D_{N} A A$, which captures the effect of algorithmic activity during a macroeconomic news announcement. In addition, we include a dummy for the period with flash orders $\left(D_{F}\right)$ and correct for autocorrelation (by means of lagged market quality variables), intraday patterns (the $I D$ dummy variables), and month-by-month variation in market quality (the $T T$ dummy variables) ${ }^{16}$ In case the market quality variables are not related to

\footnotetext{
${ }^{15}$ In the remainder of this paper we present and discuss only the results for the $50 \mathrm{~ms}$ fleeting order types. The results of the $100 \mathrm{~ms}$ fleeting order proxies, which are very similar to the results of the 50 ms proxies, can be found in the internet appendix.

${ }^{16}$ There are 6 moments during the day with macroeconomic news (see Table 1 ) and our sample consists of 36 months. Hence, we include 5 dummies to correct for intraday patterns and 35 dummies to correct for month-by-month variation in market quality.
} 
volatility we also include two lags of 5 minute realized volatility 17 All variables, except for the dummy variables, are standardized, and market quality is signed such that a positive $\delta$ always indicates an improvement in market quality 18

The regression is performed for windows of $[-5,5],[0,5],[-60,60]$, and $[0,60]$ seconds around the event time 0 with lagged market quality over intervals matching the interval size around the event. In case of the $[-5,5]$ and $[-60,60]$ second windows the dependent realized volatility measure is the average of the 1 (5) minute realized volatility over the 1 (5) minutes before and after the event. For the $[0,5]$ and $[0,60]$ second windows around the event the dependent realized volatility is simply the 1 or 5 minute realized volatility over the interval starting at the official announcement time. The lagged volatility values always relate to the two 5 minute intervals preceding the event window. Because of the wide windows around the event the regression is estimated only for official announcement times.

Both Chaboud et al. (2009) and Hendershott et al. (2011) point out that the regression in Equation (1) has a potential endogeneity problem caused by traders that base their choice of manual or automatic trading on current market conditions as liquidity and volatility. This is indeed the case on a daily level. However, we focus on the short time periods during the day when news arrives. We assume that the choice of manual or automated trading is made before the macroeconomic announcement and that traders stick with this decision for at least a few minutes.

\subsection{Trading Procedures and The Importance of Speed}

The trading rules considered in this paper are event-based. This means that all trade signals are based on macroeconomic news that arrives in the market.

\footnotetext{
${ }^{17}$ Note that $I\left(M Q_{k}\right)=1$ if $M Q_{k} \in\{N B B A, D P, Q H S, R S x, A D V x\}$ for all $x$, and $I\left(M Q_{k}\right)=0$ otherwise.

${ }^{18}$ Improvements in market quality are increases in $N B B A, D P$, and $\$ V$ and decreases in all other market quality variables. Decreases in realized spreads around events indicate a reduction of market power of market makers during news announcements. Decreases in adverse selection costs (price impact) are also considered favorable and suggest that market makers manage to reduce losses to liquidity demanders by, for example, fast quote updates.
} 
The only information we use is the exact millisecond arrival time of the news. Trade signals are not constructed by means of interpreting the news announcement, but by the value of the S\&P500 ETF 1 minute after the announcement. Buy (sell) signals are provided for announcements which are followed by a price increase (decrease) in the first minute after the news. No price change leads to no signal (neutral position). Of course, in reality investors do not have perfect foresight and have to determine the trade direction by means of the released macroeconomic data. Therefore, we re-sample the perfect foresight signals 10,000 times to create success ratios (or hit ratios) for determining trade direction ranging from $50 \%$ to $100 \%$. Each success ratio can be considered as a separate trading strategy.

Returns are based on an investment of $\$ 1$ in a strategy that buys or sells (has a capacity level of) 1 ETFs during each announcement 19 The returns of buy $\left(r_{b u y, c, t_{1}, t_{2}}\right)$ and sell $\left(r_{\text {sell }, c, t_{1}, t_{2}}\right)$ signals of a trade starting at time $t_{1}$ (the moment you take a position) to time $t_{2}$ (the moment a position is unwinded) for capacity level $c$ are calculated as $r_{b u y, c, t_{1}, t_{2}}=\frac{p_{b i d, c, t_{2}-p_{a s k, c, t_{1}}}}{p_{a s k, c, t_{1}}}$ and $r_{s e l l, c, t_{1}, t_{2}}=$ $-1 \times \frac{p_{a s k, c, t_{2}}-p_{b i d, c, t_{1}}}{p_{b i d, c, t_{1}}}$, respectively. The holding period considered in this paper is 1 minute. Most of the returns during macroeconomic news announcements are realized in the first seconds. Therefore, the results are robust to (large) changes in the holding period.

The importance of speed during macroeconomic news announcements is calculated as the difference between the return of a trading strategy (with a certain success ratio) when signals are executed with small delays (ranging from $10 \mathrm{~ms}$ up to 1 second) and the return of the same trading strategy when signals are executed instantaneously. We assume that the delay captures all potential sources of speed differences between market participants. These include, for example, the time it takes from the moment an order is sent to the exchange until it is

\footnotetext{
${ }^{19}$ The importance of speed is initially investigated for a buy/sell order involving $1 \mathrm{ETF}$, whereas robustness checks are performed for a trade capacity of 100, 200, 500, and 1,000 ETFs. For each capacity level a price-impact price per ETF is calculated as the average price paid for the capacity level number of ETFs.
} 
processed, and the (computational) time it takes to construct a trading signal. We determine the statistical significance of the importance of speed by testing whether the returns in the first part of the holding period are significantly larger than the returns in the rest of the holding period. Assume we have $z$ macroeconomic announcements and a strategy with a holding period from $t_{1}$ to $t_{2}$ and a delay $\delta$. We then have $z \cdot\left(\frac{t_{2}-t_{1}}{\delta}\right)$ midpoint returns of which $z_{1}=z$ returns occur in the first subinterval of the holding period (from $t_{1}$ to $t_{1}+\delta$ ) and $z_{2}=\left(\left(\frac{t_{2}-t_{1}}{\delta}\right)-1\right) \cdot z$ returns occur in the remaining $\left(\frac{t_{2}-t_{1}}{\delta}\right)-1$ subintervals. Speed is of significant importance if the nonzero returns in the set of $z_{1}$ returns that occur in the first subinterval are significantly different from the nonzero returns in the set of $z_{2}$ returns that occur in the subintervals from $t_{1}+\delta$ up to $t_{2}$. This is tested by means of a Wilcoxon rank-sum test.

\section{Results}

\subsection{Market Quality around News Announcements}

Figures 3 to 6 display the market quality measures $N B B A, D P$, and $Q H S$ during the day. Figures of the remaining market quality variables can be found in the internet appendix ${ }^{20}$ All figures consist of two subplots. In subplot (a) the market quality measure is provided over the complete trading day. This figure is constructed by calculating the average market quality measure per minute ${ }^{21}$ The market quality measure per minute is averaged separately for days with news (regardless of the intraday time point of the news) and days without news. By re-sampling the days without macroeconomic news 10,000 times, we construct a $90 \%$ confidence interval around the no-news market quality measure. In subplot (b) we repeat this exercise for days with news at 10:00 a.m. In this plot days

\footnotetext{
${ }^{20}$ Throughout the remainder of this section it holds that all figures and tables of discussed results without explicit reference to a figure or table number can be found in the internet appendix. The internet appendix is included in all electronic versions of this paper.

${ }^{21}$ All spread measures, except for $R S x$ and $A D V x$ are completely time weighted. $R S x$ and $A D V x$ measures are obtained by (1) calculating the average realized spread and adverse selection costs per ETF traded within each second, and (2) averaging the spread measures over the seconds in the minute.
} 
with news at other intraday time points are not considered as news days (but as no news days) and the market quality measure is not averaged every minute but every ten seconds. The realized variance and realized bi-power measure are constructed over 1 minute and 5 minute intervals, and, therefore, both in subplot (a) and (b), provided at these frequencies.

The depth measures $N B B A($ Figure 3) and $D P($ Figure 4$)$ show a large increase in the number of shares in the (top) of the orderbook when the end of the trading day approaches. When we compare days with and without macroeconomic news it is clear that on news days both the $N B B A$ and $D P$ are lower than on days without news. In fact, $D P$ is significantly lower throughout the whole trading day. Apparently market participants reduce their positions in the orderbook on news days to prevent unintentional executions in case of large news surprises. Around 10:00 a.m. we observe a macroeconomic news related decline in both depth measures. The decline (and recovery) is symmetric around the official announcement time and starts (ends) three minutes before (after) the event time. All other intraday moments with macroeconomic news are also characterized by a significant decline in $D P$. Our results for the depth measures are in line with Erenburg and Lasser (2009) who find, for the NASDAQ 100 ETF (QQQQ) traded on the Island ECN over the period January 1, 2002 to September 22, 2002, a significant decrease (with respect to no news days) in depth from 2 minutes before to 4 minutes after 10:00 a.m.

Figure 5 provides the quoted half-spread $(Q H S)$. As all other spread measures, the $Q H S$ is calculated in basis points (bps) with respect to the midpoint. From Figure 5 (a) it appears that the $Q H S$ on news days is, during the complete trading day, slightly higher compared to days without news. This difference is significant for announcements at 10:00 a.m. and 02:15 p.m. In Figure 5 (b) we focus solely on 10:00 a.m. events and observe that the increase in $Q H S$, from 0.50 bps on no news days to 0.65 bps on days with news, is substantial. This increase starts (ends) about 3 minutes before (after) 10:00 a.m. Erenburg and Lasser (2009) also find a significant increase in $Q H S$ at 10:00 a.m. that starts 
1 minute minute before 10:00 a.m. and ends within 3 to 4 minutes after 10:00 a.m. Their results also show a small increase in $Q H S$ around 10:00 a.m. on days without news that is not present in our data. For the $R S 5$ ( $A D V 5)$ the news days exhibit low (high) values compared to days with no news. Around 10:00 a.m. the $R S 5$ ( $A D V 5)$ are significantly lower (higher) than normal ${ }^{22}$

The average trading volume $(\$ V)$ over the day is U-shaped and, on average, higher when the day contains a news arrival. The large spike at 10:00 a.m. and smaller spikes at, for example, 10:30 a.m. and 02:15 p.m. are significantly higher than the normal volumes on no news days. The intraday patterns of 5 minute realized variance $(R V 300)$ and 5 minute realized bi-power (BP300) both exhibit a U-shape over the day with a spike at 10:00 a.m. that coincides with macroeconomic news. An analysis of the 1 minute realized variance $(R V 60)$ and realized bi-power $(B P 60)$ leads to the same conclusion.

For $D P, R S 5, A D V 5$, and $\$ V$ we also observe small increases or decreases around 10:00 a.m. for days without news. In order to analyze this further, we provide for $D P$, in Figure 6 (a), an overview of what happens at 10:00 a.m. in clock time on days without news. Despite the fact that there is no news, there is still a rapid decrease in depth that starts exactly at 10:00 a.m. and ends at about $175 \mathrm{~ms}$ after 10:00 a.m. This move in $D P$ is, most likely, triggered by intervalbased (clock-based) traders that act every hour, minute, or second. Figure 6 (b) provides $D P$ on days with news. Compared to days without news (Figure 6 (a)) $D P$ is much lower. Furthermore, on days with news we see that in clock time $D P$ already decreases before 10:00 a.m. up to about $800 \mathrm{~ms}$ after 10:00 a.m. In event time ( $0 \mathrm{~ms}$ is centered on the exact announcement time from the SIRCA database) this decline reaches its minimum value exactly at the news release. In the second following the event, $D P$ is quite volatile and increases again.

\footnotetext{
${ }^{22}$ The results for the $R S 1$ and $A D V 1$ are comparable to $R S 5$ and $A D V 5$, whereas the $R S 60$ and $A D V 60$ results are more noisy, suggesting that a 60 second window might already be too long to calculate sensible realized spreads and price impact measures.
} 


\subsection{Algorithmic Activity around News Announcements}

Figure 7 displays the NFLT50 algorithmic trading proxy over the day and around 10:00 a.m. All algorithmic trading proxies are at a higher level on news days compared to no news days. In addition, all proxies exhibit a U-shape over the trading day with a spike at 10:00 a.m., which corresponds to the pattern found for most of the market quality measures. Algorithmic trading proxies that are restricted to the top of the orderbook $\left(N F L T 50_{b a}\right.$ and $\left.N F L T 50_{m o}\right)$ are less U-shaped, but show more (and higher) peaks due to macroeconomic news. The NFLT50 and NMSGS proxies show a reaction before the event with a decrease that starts about 5 minutes before 10:00 a.m. The decrease is most pronounced (and significant) for the NMSGS measure.

The results suggest that during macroeconomic news announcements peaks in algorithmic activity coincide with lower market quality. The effect of increases (or decreases) in algorithmic trading activity on market quality is formally investigated by estimating the regression model provided in Equation (1). The regression is estimated for four windows and five different algorithmic trading proxies. Table 2 provides the results for the NFLT50 proxy and a 60 seconds window around the event. The table shows least squares estimates of the coefficients $\gamma$ and $\delta$ from Equation (1) for all intraday moments with news arrivals, and for news arrivals at 09:55 a.m., 10:00 a.m., 02:00 p.m., and 02:15 p.m.

The estimated $\gamma$ coefficients in Table 2 for depth $(N B B A$ and $D P)$ and the quoted half-spread $(Q H S)$ confirm that, over all announcements and all individual times, a news arrival is characterized by a significantly lower market quality. With a few exceptions this also holds for volatility ( $R V x$ and $B P x)$ and $A D V 5$. $\$ V$ always increases significantly during a macroeconomic news announcement. Evidence for $R S 5$ is mixed with a significant positive impact over all announcements, macroeconomic news at 09:55 a.m., and announcements at 02:00 p.m., whereas we find a significant increase in $R S 5$ (a significant negative impact on market quality) for 02:15 p.m. announcements. The $R S 60$ and ADV60 measures are in most cases not significant. 
The estimates for the $\delta$ coefficient from Equation (1) (the effect of algorithmic trading during announcement days on market quality) indicate that more algorithmic trading leads to a significant improvement in $N B B A, D P, \$ V$, and $A D V 5$ over all announcements and, to a lesser extent, over the four different individual announcement times. An increase in algorithmic trading leads to a significant decrease in market quality based on the $Q H S$ and $R S 5$. Also here the observed effect is strongest over all announcements. For the volatility measures we find that an increase in algorithmic trading leads to an increase in volatility (decrease in market quality) when one pools all macroeconomic news announcements. For the 10:00 a.m. announcements, however, more algorithmic trading has a mixed effect on volatility. The regressions with $R S 60$ and $A D V 60$ as dependent market quality variables only result in significant coefficients (for which the signs match the estimates of $R S 5$ and $A D V 5$, respectively) at 10:00 a.m.

To assess whether the results in Table 2 hold in general, we summarize the regression results for the four windows and five algorithmic trading proxies over the whole day and for announcements at 10:00 a.m. and 02:15 p.m. in Tables 3 to 6. Positive (negative) $\delta$ coefficients significant at the $10 \%$ or $5 \%$ level are marked with a $+(-)$, whereas coefficients significant at the $1 \%$ level are marked with a $\oplus(\ominus)$, respectively. Insignificant coefficients are represented by a dot.

Table 3 provides an overview of the effect of algorithmic trading during announcement days on market quality for a 60 second window around the event. The findings for the NFLT50 proxy, as provided in Table 2, hold to a lesser extent for the NMSGS proxy. Differences between NMSGS and NFLT50 occur at 10:00 a.m. for $R S 60, A D V 60$, and volatility. Whereas the $N M S G S$ proxy suggests a negative impact of an increase in algorithmic activity on volatility, the NFLT50 measure indicates a mixed effect. When we compare the NFLT50 proxy with the alternative algorithmic trading proxies $\left(N F L T 50_{\text {exe }}, N F L T 50_{\text {mo }}\right.$, and NFLT50 $0_{b a}$ ) it becomes clear that their effects on the market quality variables $N B B A, D P, R S 5$, and $A D V 5$ are similar. Furthermore, for the NFLT50 proxy we find that increases in algorithmic trading lead to a deterioration in 
market quality in terms of the $Q H S$, an improvement in market quality in terms of $\$ V$, and a mixed effect on volatility. When we compare this to the effect of an increase in algorithmic activity targeted at the top of the orderbook $\left(N F L T_{b a}\right.$ and $\left.N F L T_{m o}\right)$ the effect on $Q H S$ and volatility now is positive, whereas the effect on $\$ V$ becomes negative. Hence, the effect of algorithmic activity on market quality depends on which algorithms are active. Algorithms that are active on top of the orderbook have a positive impact on market quality, whereas the effect of algorithms that target the whole orderbook is more mixed.

By comparing the results of different windows around the event it is possible to assess when algorithmic trading impacts market quality (before or after the news event) and whether the impact is short or long lived. The results for the $[-5,5]$ seconds window around the event can be found in Table 4 . The differences compared to the $[-60,60]$ window are small. The impact of algorithmic trading on the (noisy) $R S 60$ and $A D V 60$ market quality measures decreases. Furthermore, we find a more positive (negative) effect of increases in algorithmic trading on $D P(\$ V$ and $A D V 5)$ for the $[-5,5]$ window compared to the $[-60,60]$ window.

When we move to the $[0,60]$ seconds event window, provided in Table 5 , the most noteworthy difference is the large decrease in the number of significant $\delta$ coefficients for the depth variables. For the $[0,5]$ window around the event (Table 6) the effect of an increase in algorithmic trading on the $N B B A$ market quality measure completely disappears. At the same time, the number of positive relations between algorithmic activity and $D P$ remains unchanged compared to the $[-60,60]$ window. Our findings suggest that the impact of an increase in algorithmic activity on $N B B A$ and $D P$ is more important before the event than after the event. When the number of algorithmic traders increases, only the fastest traders might still have an opportunity to update quotes at the news arrival. Slow algorithmic traders will have to reconsider every position in the orderbook before the macroeconomic announcement takes place. Shortly after 
macroeconomic news events algorithms do provide liquidity but at a higher price (not at the best bid or ask quote).

In Tables 2 through 6 we find for the 02:15 p.m. announcements, which only include the FOMC rate decisions, less significant relations between market quality and algorithmic trading. One explanation is that with a small number of announcements statistical relations are harder to detect. Another explanation is that the FOMC decisions are not very punctual and, therefore, can fall outside of the event windows around the official announcement time. This can also explain why for the $[-5,5]$ and $[0,5]$ windows the sign of the significant coefficients does not always match the sign of the (significant) coefficients over the whole trading day (as is the case for the $[-60,60]$ and $[0,60]$ windows).

The results of the regression analysis can be summarized as follows. First, the choice of the algorithmic trading proxy matters. For the basic proxy over the full orderbook, NFLT50, we find that an increase in algorithmic activity has a mixed effect on market quality with, a positive effect on $N B B A, D P, \$ V$, and $A D V 5$, a negative effect on $Q H S$ and $R S 5$, and a mixed effect on the volatility variables. For proxies that focus on the top of the orderbook we observe a positive effect on all market quality measures, except for $\$ V$. Second, the results for the depth measures $N B B A$ and $D P$ suggest that algorithmic traders position themselves in the orderbook before the event and provide liquidity during the announcement, but at a higher price. Third, most significant relations between algorithmic trading and market quality are obtained for the regression over all announcements and the announcements at 10:00 a.m.

It is interesting to relate our results to the findings of Hasbrouck and Saar (2011), Hendershott et al. (2011), and Brogaard (2012) to see whether their findings for algorithmic trading and market quality also hold during periods of macroeconomic news. Hendershott et al. (2011) and Hasbrouck and Saar (2011) find that, over the whole trading day, the effect of an increase in algorithmic trading on several spread variables is positive. We show that this effect is the same for increases in algorithmic trading during macroeconomic news announcements 
for an algorithmic trading proxy that focuses on the top of the orderbook. Using an algorithmic trading proxy over the full orderbook, the effect of an increase in algorithmic trading during news on spreads can also be negative.

For depth, Hendershott et al. (2011) (Hasbrouck and Saar (2011)) find that, over the whole trading day, increases in algorithmic trading are associated with lower (higher) depth. Our findings indicate that, just before a macroeconomic news announcement, increases in algorithmic activity lead to more depth which is in line with Hasbrouck and Saar (2011). Shortly after the macroeconomic news arrival, the effect of increases in algorithmic trading on quoted depth up to five cents from the best bid and ask remains positive, whereas the effect on the number of shares quoted at the best bid and ask dissapears. ${ }^{23}$ It appears that algorithms position themselves just before the macroeconomic news, whereas shortly after the news arrival they only contribute to depth away from the best bid or ask quote. This could explain why Brogaard (2012) finds that, in the ten seconds following macroeconomic news, proprietary high frequency traders significantly reduce the liquidity that they supply for large stocks with $2.4 \%$. The negative relationship between algorithmic activity and depth (at the best bid or ask quote), observed by Hendershott et al. (2011), can be explained by the fact that their data, consisting of NYSE stocks from 2001 up to 2005, is considerably different from the more recent NASDAQ data in Hasbrouck and Saar (2011) and this research.

The effect of an increase in high frequency trading activity has a stabilizing effect on intraday volatility according to both Hasbrouck and Saar (2011) and Brogaard (2012). This is also the case around macroeconomic news announcements, except if you proxy algorithmic trading over the full orderbook. In this case the effect of an increase in algorithmic activity on volatility is mixed, with a positive effect for 10:00 a.m. announcements and a negative effect (increase in volatility) over all announcements, and macroeconomic news at 02:15 p.m.

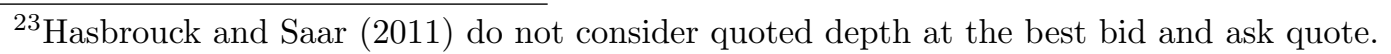


The results of the regressions including all announcements using the algorithmic trading proxies over the full and top of the orderbook differ for $\$ V, Q H S$, and volatility. The differences may be explained as follows. When submitting limit orders investors face the risk of adverse information events that trigger an undesirable execution and the risk of favourable information events that prevent the execution of desireable trades (Handa and Schwartz (1996), Foucault (1999), and Liu (2009) ) ${ }^{24}$ These risks decrease when traders can update quotes faster or when they are better informed. In case of macroeconomic news announcements all market participants have access to the same source of information, but differences exist in the time they need to obtain, process, and act on the news. ${ }^{25}$ As a result, some traders are better informed but only for a very short period of time. Better informed (Menkhoff et al. 2010) and faster (Hendershott and Riordan. 2012) traders are more likely to be active on top of the orderbook, especially during periods of news induced volatility. Hence, mainly these traders are captured by the algorithmic trading proxies that focus on the top of the orderbook.

Cvitanić and Kirilenko (2010), Biais, Foucault and Moinas (2011), Martinez and Roşu (2011), Foucault, Kadan and Kandel (2012), and Jovanovic and Menkveld (2012) analyze theoretical consequences of speed differences that arise due to the introduction of high-frequency traders. It is most natural to classify algorithmic activity on top of the orderbook as middlemen activity (Jovanovic and Menkveld, 2012) or market making activity (Foucault et al., 2012). Jovanovic and Menkveld (2012) show that in case adverse selection is present, the introduction of informed middlemen that update quotes with a speed that prevents being picked-off, can alleviate this problem. The empirical analysis finds a decrease in $Q H S$ and $\$ V$ when middlemen get introduced. This is consistent with the effects that we observe for increases in algorithmic trading on top of the orderbook. In the framework of Foucault et al. (2012) liquidity suppliers and liquidity

\footnotetext{
${ }^{24}$ Empirical work on the choice between limit orders and market orders is provided by Bloomfield, O'Hara and Saar (2005) and Menkhoff, Osler and Schmeling (2010).

${ }^{25}$ The resulting faster access to information appears to be valuable. Hendershott and Riordan (2012), and Brogaard, Hendershott and Riordan (2012) find that high frequency trading activity is more informative than the actions of slower traders.
} 
takers face a tradeoff between costs of monitoring and profits of being the first to seize new opportunities. The model suggests that increases (decreases) in the QHS are expected when investments for liquidity takers (market makers) lead to lower monitoring costs 26 This would mean that our proxies of algorithmic trading over the top of the orderbook mainly capture algorithmic market making activity, whereas the proxies over the full orderbook detect algorithmic liquidity taking. In the model of Biais et al. (2011) an increases in high frequency trading can arise from different types of financial institutions. This broad approach is captured better by the more general algorithmic trading proxy over the full orderbook. The empirical implications of an increase in high frequency activity over a wide array of market participants include an increase in short term volatility and both an increase (due to a higher ability to find trade opportunities) or decrease (due to larger adverse selection costs) in $\$ V{ }^{27}$ The model implications match our findings for increases in algorithmic activity over the full orderbook. Our results for the $Q H S$ and volatility in case of the algorithmic trading proxy over the top of the orderbook are also consistent with the empirical analysis of Menkhoff et al. (2010) who find that more informed traders (in our case algorithmic traders active in the top of the orderbook) help to narrow the spread and dampen increases in volatility by placing more (aggressive) limit orders.

\subsection{The Importance of Speed}

Figures 8 to 12 provide plots that show the importance of speed for the performance of event-based trading strategies around macroeconomic news announcements using SIRCA news arrival times. Figure 8 (a) depicts the average buy and hold profit for the strategy with perfect foresight in basis points (bps) for all macroeconomic news announcements, high impact news, news that occurs

\footnotetext{
${ }^{26}$ Reductions in monitoring costs are the result of investments in technology.

${ }^{27}$ Increases in high frequency trading lead to an increase in $\$ V$ when the fraction of fast traders is either low or high. In this case, the participation rate of high frequency traders of $68.5 \%$ (Brogaard, 2010) can be considered as high.
} 
on low volatility days, and news in the year 2011 28 The average total cumulative return over the first minute following the announcement is 9.99 bps. High impact news leads to a stronger overall reaction (13.05 bps), with most of the difference being realized in the first 5 seconds. News on days with low volatility and news arrivals in 2011 have, with 6.27 bps and 8.39 bps, respectively, lower average cumulative returns.

The importance of speed for the perfect foresight strategy during all macroeconomic announcements can be found in Figure 8 (b). The delays on the x-axis indicate the amount of time (in milliseconds) that execution is delayed with respect to instantaneous execution. In case the delay leads to a significant decline in returns compared to the instantaneous strategy this is indicated by means of a $*, \odot$, and $\bullet$, respectively. It appears that for any delay level returns decrease significantly. The magnitude of this decrease ranges from 0.02 bps per event for a delay of $10 \mathrm{~ms}$ to 0.44 (1.04) bps per event at the $300 \mathrm{~ms}$ (1 second) delay level. This means that, over all 707 macroeconomic events, an investor who is 10 $\mathrm{ms}, 300 \mathrm{~ms}$, or 1 second slower compared to instantaneous execution loses $0.13 \%$, $3.08 \%$, or $7.33 \%$, respectively. In relative terms (with respect to the cumulative returns) the loss at the $300 \mathrm{~ms}$ (1 second) delay level is $4.95 \%(11.76 \%)$. This result shows that trading speed is more important for event-based trading compared to the clock-based technical trading rules in Scholtus and van Dijk (2012) who find a relative importance of speed for a 1 second delay in execution of about $-2.03 \%$.

In Figure 9 (a) we analyze the importance of speed separately for each year in the sample period, whereas Figure 9 (b) depicts the importance of speed for days with high and low volatility 29 Speed appears to be less important for delays of $25 \mathrm{~ms}$ up to $150 \mathrm{~ms}$ in the year 2011. Furthermore, for delays of $500 \mathrm{~ms}$ and up speed is considerably more important in 2009 compared to the other years. A

\footnotetext{
${ }^{28}$ We include cumulative returns for subsamples related to news impact, volatility, announcement year, and intra-day announcement time that are further analyzed in the remainder of this section.

${ }^{29} \mathrm{We}$ sort the days based on the maximum intraday VIX value and analyze the top and bottom half separately.
} 
delay of 1 second in 2009 (2010) leads to a decrease in performance of 1.62 (0.73) bps per event ${ }^{30}$ Aside from these small differences in terms of magnitude and significance, the importance of speed seems relatively stable during our sample period. Whereas for the clock-based strategies in Scholtus and van Dijk (2012) speed is most important on low volatility days, Figure 9 (b) shows that eventbased trading strategies benefit more from high volatility. For all delay levels the decreases in returns on high volatility days are statistically significant. Up to $300 \mathrm{~ms}$ the difference between high and low volatility days is limited. From 400 ms and up speed is much more important on high volatility days. The decrease in returns is 0.92 bps per event for a delay of $400 \mathrm{~ms}$ and 1.61 bps per event for a 1 second delay. The importance of speed on high volatility days can also explain why speed is more important in 2009 for delays of $500 \mathrm{~ms}$ up to 1 second. Of the total number of 352 high volatility days in our sample, 181 occur in 2009.

From the comparison of the importance of speed for news arriving at different hours of the day (see Figure 10 (a)) we observe that speed is especially important for the 10:00 a.m. announcements, with decreases in returns of 0.51 (1.94) bps for a delay in execution of $150 \mathrm{~ms}$ (1 second). For announcements at 09:55 a.m. and 03:00 p.m. we find no significant differences in returns due to delayed execution. The pronounced importance of speed at 10:00 a.m. could be caused by the fact that more high impact news announcements occur at this time compared to the other announcement times (see Table 1). To investigate this in more detail, Figure 10 (b) shows the importance of speed per news impact category. The results indicate that speed is indeed more important for high impact news arrivals. Instead of the 1.04 bps decrease in performance per event, now a 1 second delay leads to a return which is about 2.08 bps lower compared to the same strategy executed instantaneously. Over all 292 announcements with a high

\footnotetext{
${ }^{30}$ In order to investigate whether flash orders can explain the higher importance of speed in 2009 we also analyze the importance of speed in 2009 separately for the 59 (179) announcements within (outside) the period flash orders are active (June 5, 2009 to August 31, 2009). The results, provided in the internet appendix, indicate that flash orders do not influence the results.
} 
impact during the sample period the total loss would accumulate to $6.06 \%$. For low impact announcements we find no significant decreases in returns.

Figure 11 provides the importance of speed for announcements grouped by the time difference between the SIRCA news arrival time and the official announcement time (subplot (a)) as well as the importance of speed for large and small news surprises (subplot (b)) ${ }^{31}$ From the results in Figure 11 (a) can be concluded that speed is more important when the SIRCA arrival time is close to the official announcement time. A 1 second delay when trading announcements with a SIRCA announcement time that is within $250 \mathrm{~ms}$ of the official announcement time leads to a return that is 1.53 bps lower compared to instantaneous execution. The magnitude of the news surprise also influences the importance of speed. For announcements containing large surprises a 1 second delay leads to a significant decrease in returns of 1.15 bps per announcement, whereas this is only 0.67 bps per announcement for small surprise news.

The impact of speed for different trade sizes in Figure 12 (a) indicates that there is little difference in the importance of speed when the strategy with perfect foresight is executed with 100, 200, 500, or with 1,000 ETFs. The only exception occurs when one delays the perfect foresight strategy implemented with a 1,000 ETFs trade size with 1 second. The resulting loss per event is, with 1.75 bps, higher than the losses of approximately $1.04 \mathrm{bps}$ for the other trade sizes.

The importance of speed for different trading strategies is depicted in Figure 12 (b). Different trading strategies are created by means of mixing the perfect foresight strategy with error levels ranging from $10 \%$ (a success ratio of 90\%) to $50 \%$. The results show that, for traders with lower abilities to determine the correct trade direction, speed is less important. Strategies with a success rate of $50 \%$ do not generate positive returns and are not impacted by trading speed, whereas returns significantly decrease for all delay levels for success ratios of $60 \%$

\footnotetext{
${ }^{31}$ Note that in subplot (a) announcements with a SIRCA announcement time before the official announcement time are ignored. News surprises are calculated as the absolute difference between the actual number and the consensus forecast, relative to the consensus. Announcements without an actual or consensus number are ignored. Large (small) surprise news are announcements in the top (bottom) half of news surprises.
} 
and up. The magnitude of the losses for a trader with a success ratio of $100 \%$ is $0.44 \mathrm{bps}(1.04 \mathrm{bps})$ per event in case trades are executed with a delay of 300 $\mathrm{ms}$ ( 1 second). The decrease in returns due to a delay of $300 \mathrm{~ms}$ ( 1 second) for traders with success ratios of $90 \%, 80 \%$, and $70 \%$ is $0.35(0.82), 0.26(0.61)$, and $0.17(0.38)$ bps, respectively. Whether the effect of being slow has any economic significance depends on the investor. For example, an investor who considers a loss of $2 \%$ on an event-based trading strategy as significant (this corresponds to losing 0.28 bps per event over 707 announcements), will find that this threshold is breached for delays of $150 \mathrm{~ms}$ and up for the perfect foresight strategy and for delays of more than $200 \mathrm{~ms}, 300 \mathrm{~ms}$, and $500 \mathrm{~ms}$ in case of a strategy with a success ratio of $90 \%, 80 \%$, and $70 \%$, respectively.

To determine whether the announcement time has an impact on the importance of speed Figures 13 and 14 show the cumulative returns (a) and importance of speed (b) for the perfect foresight strategy using the refined (empirical) SIRCA announcement times and official announcement times, respectively. For the refined announcement times in Figure 13 we find results similar to the normal SIRCA news arrival times (Figure 8). The main difference is that speed is no longer statistically significant for the delays of $10 \mathrm{~ms}$ and $25 \mathrm{~ms}$. For delays above $25 \mathrm{~ms}$ the magnitude of the importance of speed does not change visibly. This indicates that a small change in the news arrival time has a limited impact on results and that there is no evidence of mis-synchronization between the Thomson Reuters and NASDAQ clock.

For the official announcement times in Figure 14 we find higher average cumulative returns that increase faster in the first 5 seconds compared to the cumulative returns based on the SIRCA announcement times. Consequently, the importance of speed for the official announcement times is higher, with a 0.90 bps decrease in returns per event at a delay of $400 \mathrm{~ms}$ up to a 2.40 bps decrease in returns per event at a delay of 1 second. This is remarkable since in most instances the SIRCA announcement time is well beyond the official announcement time (see Figure 1). 
The main difference in the importance of speed using official announcement times compared to the SIRCA announcement times is the inclusion of the period which ranges from the official announcement time up to the SIRCA arrival time (interval 0). We compare interval 0 to the interval with the same length as interval 0 following the SIRCA news arrival time (interval 1). During interval 0 , which is characterized by low depth and large spreads, (clock-based) trades can lead to relatively large returns. High pre-announcement returns in interval 0 compared to the post-announcement returns in interval 1 will explain the high importance of speed using official announcement times instead of SIRCA news arrival times ${ }^{32}$ Unless the pre-announcement period contains any information that can be used for a trading strategy, for example, because some market participants receive the news through a more competitive news feed, the importance of speed using official announcement times is of no practical relevance because trade direction cannot be determined.

The possibility that the high importance of speed using official announcement times is caused by (clock-based) pre-announcement trading activity in a low liquidity environment is investigated by means of Figures 15 and 16 . The $10 \mathrm{~ms}$ midpoint returns on days without news (Figure 15 (a)) show a clear increase at exactly 10:00 a.m. to about 0.09 bps. The increase in midpoint returns lasts about $200 \mathrm{~ms}$ and the most likely explanation is clock-based trading activity. On days with news Figure 15(b)) we observe two interesting differences in clock time compared to days without news. First, returns already start to increase about $150 \mathrm{~ms}$ before 10:00 a.m. Second, at 10:00 a.m. the returns are considerably larger compared to days without news (0.30 bps versus 0.09 bps) and remain high for at least 1 second. Figure 16 (a) provides an overview of clock-based activity on news days separately when the SIRCA announcement time is either within 1 second or after 1 second of the official announcement time. It appears that, in both instances, the results are comparable to Figure 15 (b). When the

\footnotetext{
${ }^{32}$ When we simply compare the magnitude of the returns in interval 0 and interval 1 we find that the absolute size of returns is higher in interval 0 . The internet appendix provides a scatterplot with more details of this analysis.
} 
SIRCA arrival time is more than 1 second after the official announcement time returns remain high due to the sensitive pre-announcement situation, whereas for announcements within 1 second of the official announcement time returns are high due to both activity in the pre-announcement period and the first reactions to the news.

Finally, in Figure 16 (b) we assess to what extent returns in interval 0 have information about the cumulative returns up to 30 intervals (with the same length as interval 0) in the future. ${ }^{33}$ The analysis is performed separately for news that arrives within $250 \mathrm{~ms}$ of the official announcement time or between 250 and $500 \mathrm{~ms}, 500$ and $750 \mathrm{~ms}$, or 750 and $1000 \mathrm{~ms}$ from the official announcement time. The results in Figure 16 (b) indicate that only for announcements that occur within $250 \mathrm{~ms}$ of the official announcement time, the sign of the return in interval 0 has a significant relation with the sign of the cumulative return in interval 5 up to 30 following the SIRCA announcement time. For the other groups of announcements, we do not find evidence that the return in interval 0 contains any information. It is possible that the longer intervals contain the same information but, due to additional activity of other market participants, the information is more difficult to observe ${ }^{34}$ Overall, we find little evidence that market participants can successfully act on information in interval 0 or on information before the official announcement time. This means that the results of the high importance of speed using official announcement times is mainly due to large returns of pre-announcement trading in a period with low depth and

\footnotetext{
${ }^{33}$ This is done by comparing the sign of the return in interval 0 with the sign of the cumulative $\log$ return in each of the future intervals, ignoring announcements for which the return in interval 0 is zero. We test whether the number of times the sign of the return in interval 0 matches the sign of the cumulative return is significantly higher (indicated by means of a $\bullet$ ) or lower (indicated by means of a $\mathbf{-}$ ) compared to a random benchmark. This is done by means of the binomial cdf and a probability of success of $50 \%$.

${ }^{34}$ The internet appendix provides returns of the (in-sample) trading strategy based on the information in interval 0. In addition, it provides figures with hit ratios (HRs) when we use the returns in the $200 \mathrm{~ms}$ to $50 \mathrm{~ms}$ before the SIRCA arrival time or the returns in the $200 \mathrm{~ms}$ to $50 \mathrm{~ms}$ before the official time to construct trade signals used at the official time and SIRCA news arrival time. A surprising result is that HRs based on the $200 \mathrm{~ms}$ before the official announcement time are statistically significant for cumulative returns of the future interval 4 to 30 following the official announcement time. The HRs, however, do not exceed $60 \%$ and are too low for speed to be important.
} 
large spreads. The high importance of speed using official announcement times is not relevant, because it is impossible to successfully determine a trade signal.

From this section we can conclude that during macroeconomic news trading speed is both of statistical and economic significance. We find that, per event, losses due to trading speed for the perfect foresight strategy range from $0.02 \mathrm{bps}$ for a $10 \mathrm{~ms}$ delay up to 0.44 and 1.04 bps for delays of $300 \mathrm{~ms}$ and 1 second, respectively. Over all 707 announcements this accumulates to a loss of $7.33 \%$ at the 1 second delay level. A trader with a success ratio of $90 \%$ loses 0.82 bps per event when he is 1 second slower compared to instantaneous execution, whereas this is 0.61 (0.38) bps per event in case of a success ratio of $80 \%$ (70\%). In addition, we find that speed is more important for high impact news, for large news surprises, in 2009, on high volatility days, in case the SIRCA arrival time is close to the official announcement time, and at 10:00 a.m. Although the importance of speed calculated using the official announcement time is higher than by using the SIRCA announcement times, it has no practical relevance.

\section{Conclusion}

This paper investigates the importance of speed for U.S. macroeconomic news based trading rules as well as the impact of algorithmic trading activity on market quality around macroeconomic news arrivals. This is done by means of analyzing full orderbook activity of the highly liquid S\&P500 ETF traded on NASDAQ over the period January 6, 2009 up to December 12, 2011 (736 trading days). Exact news arrival times are obtained from the SIRCA global news database.

All market quality measures and algorithmic trading proxies, except for the realized spreads and adverse selection costs, show a clear reaction to news announcements at 10:00 a.m. When we regress market quality on the algorithmic trading proxies we find that the effect of algorithmic trading on market quality depends on the choice of the algorithmic trading proxy. For the basic proxy that measures algorithmic activity over the whole orderbook, evidence is mixed. Increases in algorithmic trading during news lead to more depth and trading 
volume, but also larger quoted half-spreads. The effect on volatility is positive if one considers only announcements at 10:00 a.m., but negative if one pools all macroeconomic news announcements. When we use a proxy that focuses on the top of the orderbook, the effect of an increase in algorithmic trading during news now leads to a decrease in trading volume, but the effect on all other market quality variables is positive.

We find that trading speed is of statistical and economic importance for the return of a macroeconomic news based trading strategy. For a success ratio of $80 \%, 90 \%$, and $100 \%$, a $300 \mathrm{~ms}$ (1 second) delay in execution leads to a decrease in return of $0.26,0.35$, and $0.44 \mathrm{bps}(0.61,0.82$, and $1.04 \mathrm{bps})$ per event, respectively. Over all 707 macroeconomic news announcements the losses at the 1 second delay level accumulate to $7.33 \%$ in case of the perfect foresight strategy and $4.31 \%$ in case of a success ratio of $80 \%$. The relative loss (with respect to the total return of the strategy) at a success rate of $100 \%$ (80\%) and a delay of 1 second is $11.76 \%(12.64 \%)$, which is considerably more compared to the relative importance of speed of $2.03 \%$ for clock-based trading strategies in Scholtus and van Dijk (2012). In addition, speed is more important for announcements in 2009, at 10:00 a.m., with a high news impact factor, on days with high volatility, with a SIRCA announcement time that is close to the official announcement time, or for announcements with a large news surprise. Trade size only impacts the importance of speed when the trade size is 1,000 ETFs and the delay in execution is 1 second.

\section{Acknowledgements}

The authors would like to thank NASDAQ and the Securities Industry Research Center of Asia-Pacific (SIRCA) on behalf of Thomson Reuters for providing the necessary data for this research. 


\section{References}

Adams, G., Mcqueen, G., Wood, R., 2004. The Effects of Inflation News on High Frequency Stock Returns. Journal of Business 77, 547-574.

Andersen, T.G., Bollerslev, T., Diebold, F.X., Vega, C., 2007. Real-time price discovery in global stock, bond and foreign exchange markets. Journal of International Economics 73, 251-277.

Barndorff-Nielsen, O.E., Shephard, N., 2004. Power and bipower variation with stochastic volatility and jumps. Journal of Financial Econometrics 2, 1-37.

Biais, B., Foucault, T., Moinas, S., 2011. Equilibrium high frequency trading. Working paper, University of Toulouse 1.

Birz, G., Lott Jr., J.R., 2011. The effect of macroeconomic news on stock returns: New evidence from newspaper coverage. Journal of Banking and Finance 35, 2791-2800.

Bloomfield, R., O'Hara, M., Saar, G., 2005. The "make or take" decision in an electronic market: Evidence on the evolution of liquidity. Journal of Financial Economics 75, 165-199.

Boyd, J.H., Hu, J., Jagannathan, R., 2005. The Stock Market's Reaction to Unemployment News: Why Bad News Is Usually Good for Stocks. Journal of Finance 60, 649-672.

Brogaard, J.A., 2010. High frequency trading and its impact on market quality. Working paper, Northwestern University.

Brogaard, J.A., 2012. High frequency trading and Volatility. Working paper, Northwestern University.

Brogaard, J.A., Hendershott, T.J., Riordan, R., 2012. High frequency trading and price discovery. Working paper, University of Ontario Institute of Technology. 
Chaboud, A., Chiquoine, B., Hjalmarsson, E., Vega, C., 2009. Rise of the machines: Algorithmic trading in the foreign exchange market. FRB International Finance Discussion Paper No. 980.

Cvitanić, J., Kirilenko, A., 2010. High frequency traders and asset prices. Working paper, California Institute of Technology.

Erenburg, G., Lasser, D., 2009. Electronic limit order book and order submission choice around macroeconomic news. Review of Financial Economics 18, 172182.

Evans, K.P., 2011. Intraday jumps and US macroeconomic news announcements. Journal of Banking and Finance 35, 2511-2527.

Foucault, T., 1999. Order flow composition and trading costs in a dynamic limit order market. Journal of Financial Markets 2, 99-134.

Foucault, T., Kadan, O., Kandel, E., 2012. Liquidity cycles and make/take fees in electronic markets. Journal of Finance, Forthcoming.

Gomber, P., Arndt, B., Lutat, M., Uhle, T., 2011. High-frequency trading. Working paper, University of Frankfurt.

Handa, P., Schwartz, R.A., 1996. Limit Order Trading. Journal of Finance 51, $1835-1861$.

Hardouvelis, G.A., 1987. Macroeconomic Information and Stock Prices. Journal of Economics and Business 39, 131-140.

Hasbrouck, J., Saar, G., 2009. Technology and liquidity provision: The blurring of traditional definitions. Journal of Financial Markets 12, 143-172.

Hasbrouck, J., Saar, G., 2011. Low-latency trading. Working paper, Johnson School Research Paper Series No. 35-2010.

Hendershott, T., Jones, C.M., Menkveld, A.J., 2011. Does algorithmic trading improve liquidity? Journal of Finance 66, 1-33. 
Hendershott, T., Riordan, R., 2012. Algorithmic trading and the market for liquidity. Journal of Financial and Quantitative Analysis, Forthcoming.

Jain, P.C., 1988. Response of Hourly Stock Prices and Trading Volume to Economic News. Journal of Business 61, 219-231.

Jovanovic, B., Menkveld, A.J., 2012. Middlemen in limit-order markets. Working paper, VU University Amsterdam.

Liu, W.M., 2009. Monitoring and limit order submission risks. Journal of Financial Markets 12, 107-141.

Martinez, V.H., Roşu, I., 2011. High frequency traders, news and volatility. Working paper, Baruch College.

McQueen, G., Roley, V.V., 1993. Stock Prices, News, and Business Conditions. Review of Financial Studies 6, 683-707.

Menkhoff, L., Osler, C.L., Schmeling, M., 2010. Limit-order submission strategies under asymmetric information. Journal of Banking and Finance 34, 2665-2677.

O'Hara, M., 2010. What is a quote? The Journal of Trading 5, 10-16.

Pearce, D.K., Roley, V.V., 1985. Stock Prices and Economic News. Journal of Business 58, 49-67.

Scholtus, M.L., van Dijk, D., 2012. High-Frequency Technical Trading: The Importance of Speed. Working paper, Erasmus University Rotterdam. 


\section{Figures and Tables}

Table 1: An overview of the number of macroeconomic announcements.

\begin{tabular}{|c|c|c|c|c|c|}
\hline & & all days & 2009 & 2010 & 2011 \\
\hline \multicolumn{2}{|c|}{ trading days } & 736 & 248 & 250 & 238 \\
\hline \multicolumn{2}{|c|}{ days with news } & 520 & 178 & 169 & 173 \\
\hline \multicolumn{2}{|c|}{ news announcements } & 800 & 268 & 273 & 259 \\
\hline \multicolumn{2}{|c|}{ unique ann. times } & 707 & 238 & 239 & 230 \\
\hline \multicolumn{2}{|c|}{ high impact news ann. } & 292 & 95 & 103 & 94 \\
\hline \multicolumn{2}{|c|}{ medium impact news ann. } & 334 & 115 & 110 & 109 \\
\hline \multicolumn{2}{|c|}{ low impact news ann. } & 81 & 28 & 26 & 27 \\
\hline 09:45 a.m. & Chicago PMI (med) & 35 & 12 & 12 & 11 \\
\hline \multirow[t]{2}{*}{ 09:55 a.m. } & Mich Sentiment-Prel (high) & 36 & 12 & 12 & 12 \\
\hline & Mich Sentiment-Rev (med) & 35 & 12 & 12 & 11 \\
\hline \multirow[t]{12}{*}{ 10:00 a.m. } & Construction Spending (low) & 35 & 11 & 12 & 12 \\
\hline & Factory Orders (med) & 36 & 12 & 12 & 12 \\
\hline & Business Inventories (med) & 35 & 12 & 12 & 11 \\
\hline & Leading Indicators (low) & 35 & 12 & 12 & 11 \\
\hline & New Home Sales (high) & 35 & 12 & 12 & 11 \\
\hline & Consumer Confidence (high) & 35 & 12 & 12 & 11 \\
\hline & ISM Index (high) & 35 & 11 & 12 & 12 \\
\hline & ISM Services (high) & 36 & 12 & 12 & 12 \\
\hline & Pending Home Sales (high) & 35 & 12 & 12 & 11 \\
\hline & Wholesale Inventories (low) & 36 & 12 & 12 & 12 \\
\hline & Philadelphia Fed (high) & 35 & 12 & 12 & 11 \\
\hline & Existing Home Sales (high) & 35 & 12 & 12 & 11 \\
\hline 10:30 a.m. & Crude Inventories (med) & 133 & 46 & 44 & 43 \\
\hline 11:00 a.m. & Crude Inventories (med) & 20 & 6 & 8 & 6 \\
\hline \multirow[t]{2}{*}{ 12:30 p.m. } & FOMC Rate Decision (med) & 3 & 0 & 0 & 3 \\
\hline & Pending Home Sales (high) & 1 & 0 & 1 & 0 \\
\hline \multirow[t]{2}{*}{ 02:00 p.m. } & Treasury Budget (med) & 34 & 10 & 12 & 12 \\
\hline & FOMC Minutes (high) & 23 & 7 & 8 & 8 \\
\hline 02:15 p.m. & FOMC Rate Decision (med) & 20 & 8 & 8 & 4 \\
\hline 02:30 p.m. & Treasury Budget (med) & 1 & 1 & 0 & 0 \\
\hline 03:00 p.m. & Consumer Credit (low) & 36 & 12 & 12 & 12 \\
\hline
\end{tabular}

This table provides the number of trading days and news announcements over the whole sample period (January 6, 2009 up to December 12, 2011). In addition, the number of news messages are split up per impact category, intraday moment, and exact macroeconomic announcement. For each macroeconomic announcement is also indicated whether this is a high, low, or medium (med) impact announcement. 
Table 2: Regression coefficients of the algorithmic trading proxy NFLT50 on market quality measures using the $[-60,60]$ window around all intraday moments that potentially have a macroeconomic announcement.

\begin{tabular}{|c|c|c|c|c|c|c|c|c|c|c|}
\hline & \multicolumn{2}{|c|}{ all day, $N=7,360$} & \multicolumn{2}{|c|}{$09: 55 \mathrm{AM}, N=736$} & \multicolumn{2}{|c|}{ 10:00AM, $N=736$} & \multicolumn{2}{|c|}{ 02:00PM, $N=736$} & \multicolumn{2}{|c|}{$02: 15 \mathrm{PM}, N=736$} \\
\hline & $\gamma$ & $\delta$ & $\gamma$ & $\delta$ & $\gamma$ & $\delta$ & $\gamma$ & $\delta$ & $\gamma$ & $\delta$ \\
\hline$N B B A$ & $-0.690 \ddagger$ & $0.034 \dagger$ & $-0.842 \ddagger$ & 0.085 & $-0.821 \ddagger$ & 0.051 & $-0.647 \ddagger$ & $0.279 *$ & $-0.406 \ddagger$ & -0.024 \\
\hline$D P$ & $-0.962 \ddagger$ & $0.035 \ddagger$ & $-1.099 \ddagger$ & $0.116 \ddagger$ & $-0.976 \ddagger$ & $0.106 \ddagger$ & $-0.696 \ddagger$ & 0.084 & $-0.178 \ddagger$ & -0.011 \\
\hline$\$ V$ & $1.458 \ddagger$ & $0.055 \ddagger$ & $1.574 \ddagger$ & 0.037 & $0.871 \ddagger$ & -0.080 & $0.751 \ddagger$ & 0.168 & $0.432 \ddagger$ & $0.187 \ddagger$ \\
\hline$Q H S$ & $-0.359 \ddagger$ & $-0.058 \ddagger$ & $-0.171 \ddagger$ & $-0.248 \ddagger$ & $-0.410 \ddagger$ & $-0.109 \ddagger$ & $-0.326 \ddagger$ & -0.041 & $-0.750 \ddagger$ & -0.019 \\
\hline$R S 5$ & $0.490 \ddagger$ & $-0.164 \ddagger$ & $0.884 \ddagger$ & $-0.429 \ddagger$ & 0.150 & $-0.280 \ddagger$ & $0.774 \ddagger$ & 0.250 & $-0.325 \ddagger$ & -0.072 \\
\hline$A D V 5$ & $-0.603 \ddagger$ & $0.141 \ddagger$ & $-0.905 \ddagger$ & $0.347 \ddagger$ & $-0.288 \ddagger$ & $0.234 \ddagger$ & $-0.799 \ddagger$ & -0.271 & 0.152 & 0.043 \\
\hline$R S 60$ & -0.015 & -0.022 & $0.738 \ddagger$ & $-0.540 \ddagger$ & $-0.181 \dagger$ & 0.056 & -0.276 & 0.156 & -0.118 & -0.135 \\
\hline$A D V 60$ & -0.026 & 0.018 & $-0.757 \ddagger$ & $0.527 \ddagger$ & 0.143 & -0.057 & 0.255 & -0.168 & 0.072 & 0.128 \\
\hline$R V 300$ & $-0.316 \ddagger$ & $-0.046 \ddagger$ & $-0.422 \ddagger$ & 0.083 & $-0.168 \ddagger$ & $0.179 \ddagger$ & $-0.568 \ddagger$ & -0.173 & $-1.426 \ddagger$ & 0.017 \\
\hline$R V 60$ & $-1.115 \ddagger$ & $-0.282 \ddagger$ & $-1.086 \ddagger$ & $-0.208 \ddagger$ & $-0.737 \ddagger$ & $-0.139 \dagger$ & $-0.457 \ddagger$ & $-0.230 \dagger$ & $-0.361 \ddagger$ & $-0.600 \ddagger$ \\
\hline BP300 & $-0.214 \ddagger$ & 0.001 & $-0.354 \ddagger$ & 0.089 & -0.050 & $0.218 \ddagger$ & $-0.643 \ddagger$ & $-0.345 \ddagger$ & $-1.507 \ddagger$ & 0.058 \\
\hline$B P 60$ & $-0.737 \ddagger$ & $-0.214 \ddagger$ & $-0.599 \ddagger$ & $-0.318 \ddagger$ & $-0.450 \ddagger$ & 0.071 & $-0.445 \ddagger$ & $-0.334 \ddagger$ & $-0.371 \ddagger$ & $-0.637 \ddagger$ \\
\hline
\end{tabular}

This table provides the coefficients $\gamma$ (news dummy) and $\delta$ (interaction term which captures the effect of algorithmic activity during news announcements) from the regression provided in Equation (1), $M Q_{k}=$ $\alpha+\beta A A_{k}+\gamma D_{N}+\delta\left(D_{N} A A_{k}\right)+\zeta D_{F}+\ldots+\epsilon$, using the variables in the first column as the dependent, $M Q$ variable and NFLT50 as algorithmic trading proxy. The $M Q$ variables and NFLT50 variable are constructed by means of the 60 seconds before and after the intraday event times (hence, for 10:00 a.m. we use the data from 09:59 a.m. up to 10:01 a.m.). The regression over the whole day (column all day) uses the 6 intraday moments that potentially include news on all 736 trading days in the sample, leading to 4,416 observations. The other regressions are performed per intraday moment and include, therefore, 736 observations per regression. All regression variables (except the dummy variables) are standardized. Market quality is signed such that a positive $\delta$ always indicates an improvement in market quality. Coefficients significantly different from zero at the $10 \%, 5 \%$, and $1 \%$ level (tested by means of a two-sided t-test) are marked with a $*, \dagger$, and $\ddagger$, respectively. 


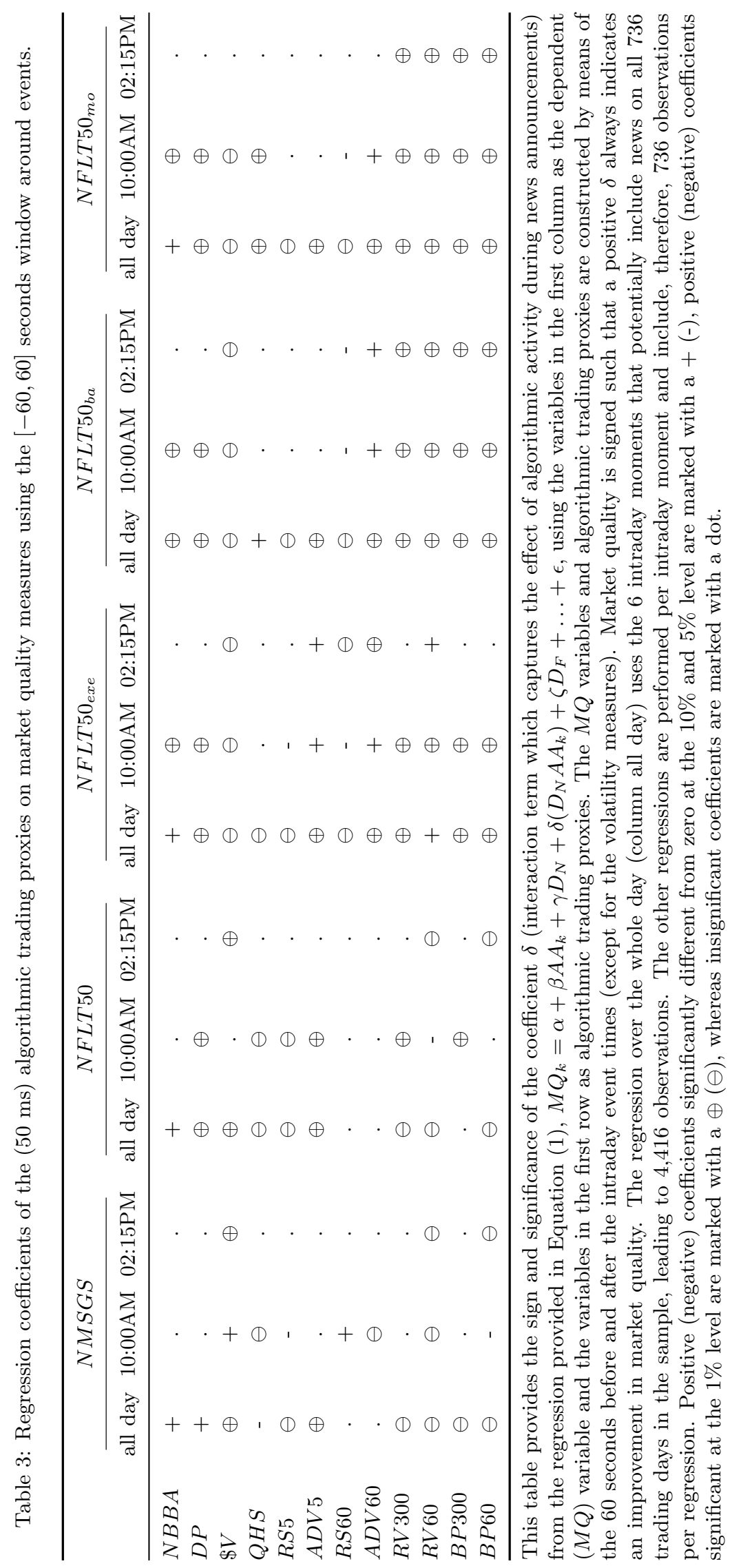




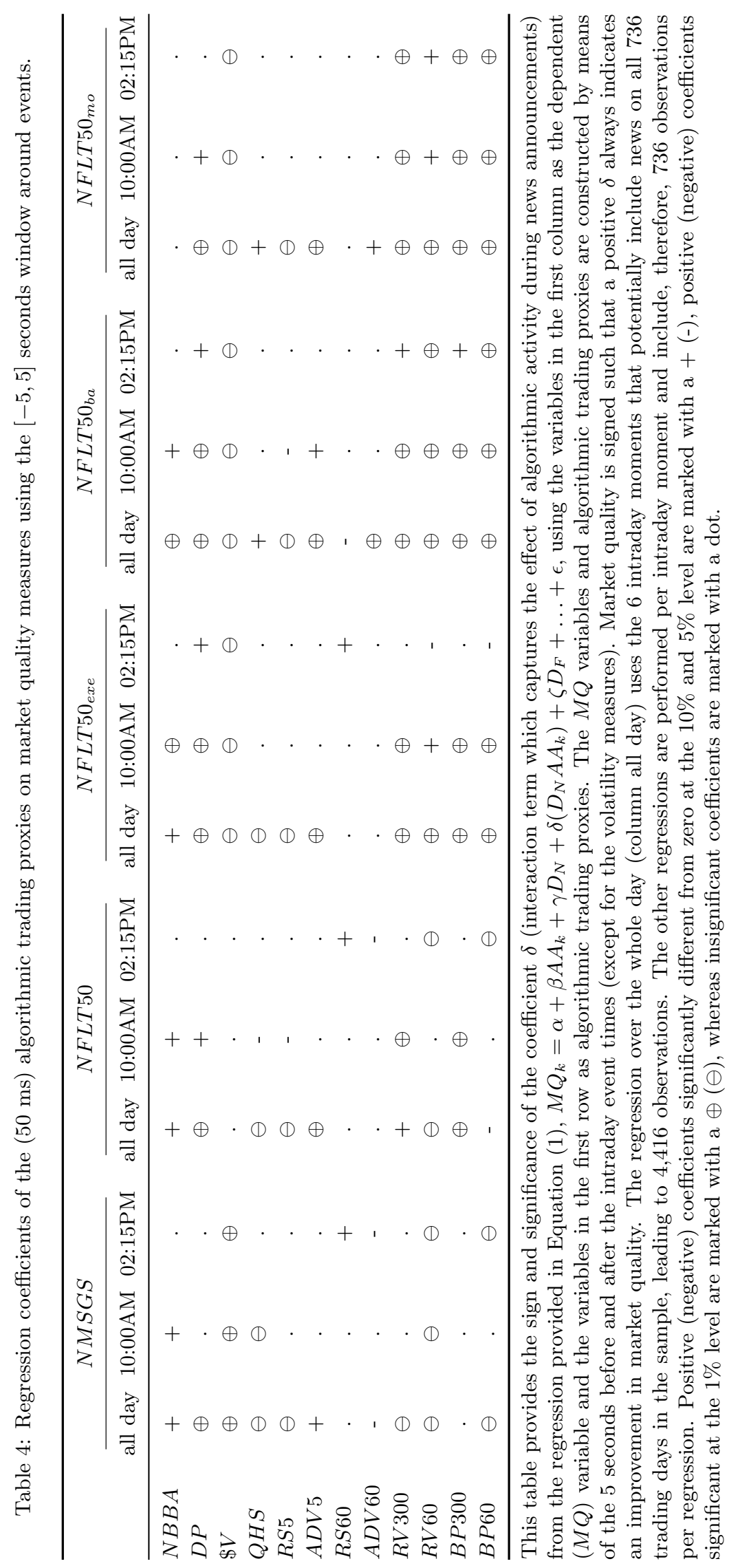




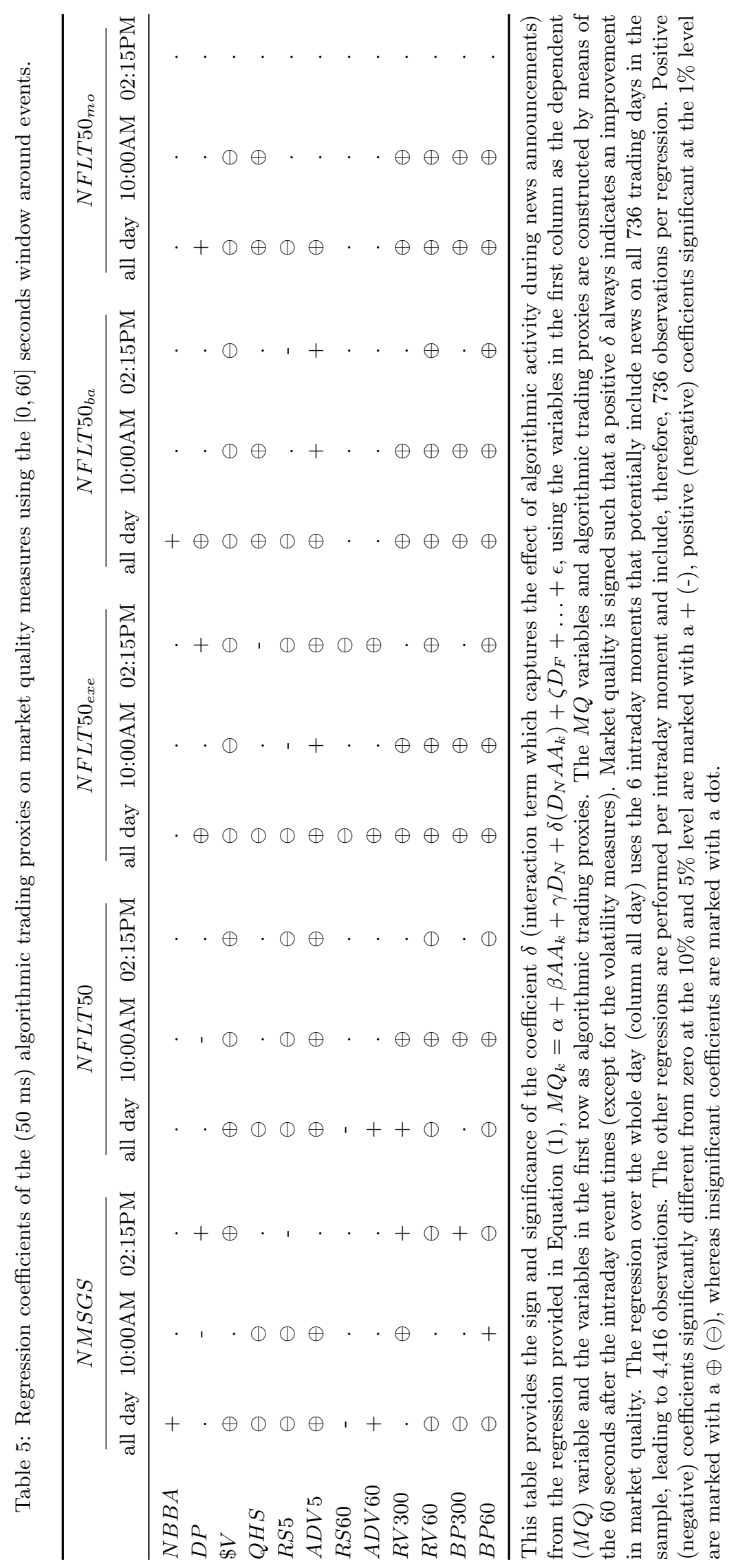




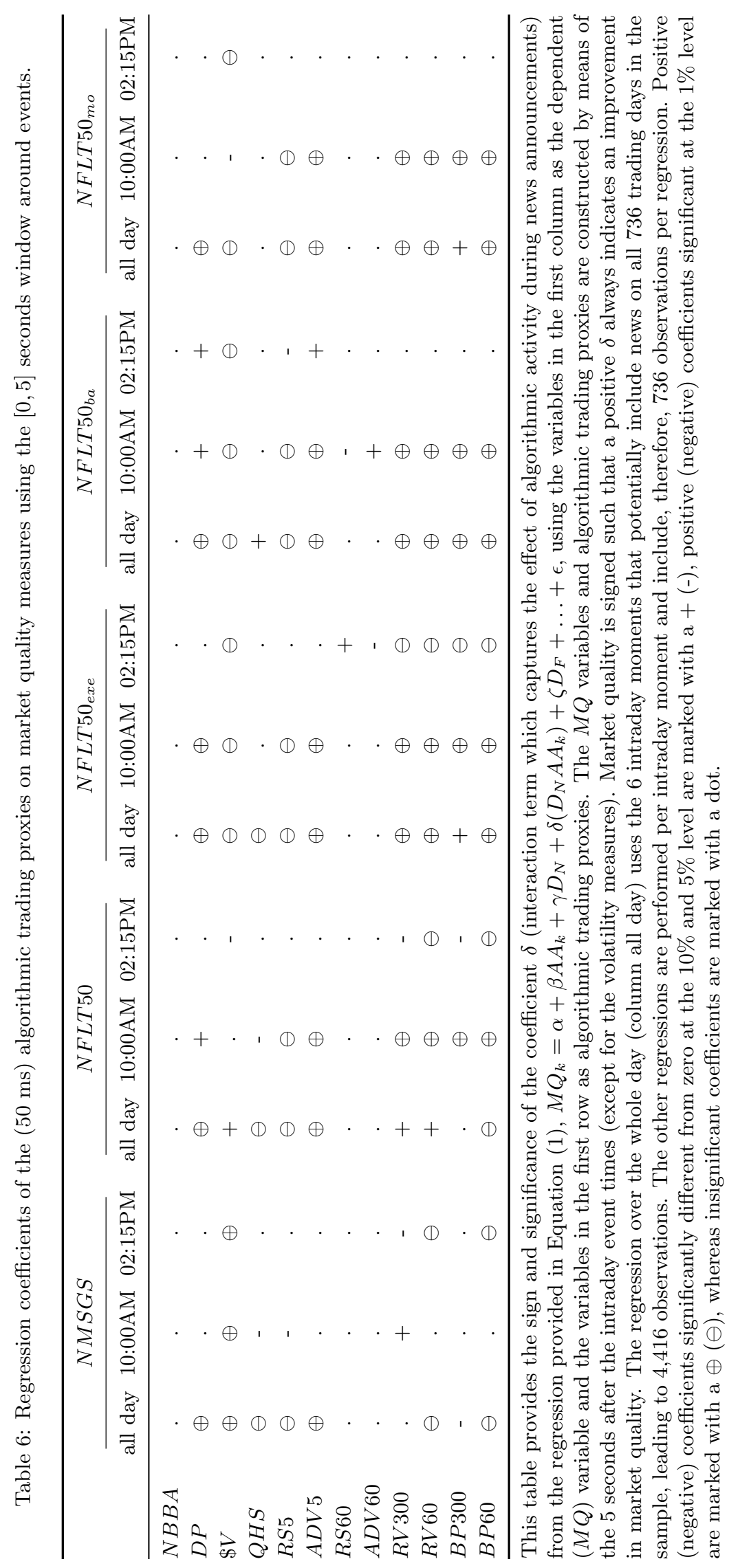


Figure 1: Differences between official announcement time and actual SIRCA arrival time of the news release in seconds (positive values indicate news arrivals after the official announcement time). Time differences are transformed by means of an inverse tangent transformation. For each announcement time the box provides the median and $25^{t h}$ and $75^{\text {th }}$ percentile, the whiskers provide the minimum and maximum time difference. The $\mathrm{x}$-labels correspond to the following announcements: (1) Chicage PMI, (2) Mich. Sent. Prel., (3) Mich. Sent. Rev., (4) Constr. Spending, (5) Fact. Orders, (6) Bus. Inv., (7) Leading Ind., (8) New Home Sales, (9) Cons. Conf. (10) ISM Index, (11) ISM Services, (12) Pending Home Sales, (13) Wholesale Inv., (14) Philly Fed, (15) Existing Home Sales, (16) Crude Inv., (17) FOMC Rate Dec., (18) Tr. Budget, (19) FOMC Min., (20) Cons. Credit. Announcements without SIRCA time are ignored in the construction of this plot.

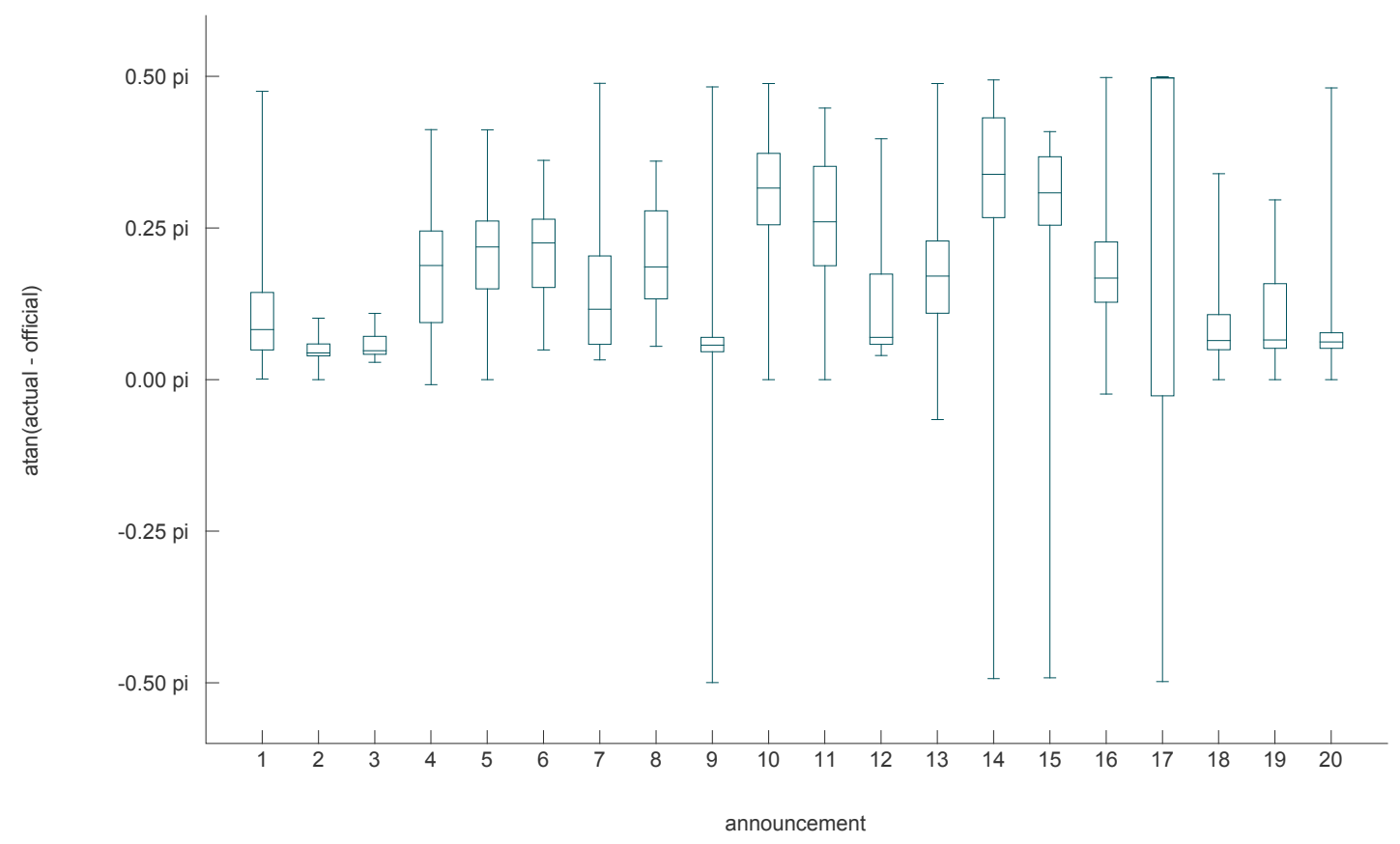

Figure 2: The difference between refined announcement times and SIRCA news arrival times (y-axis) versus an inverse tangent transformation of the difference between official announcement time and SIRCA times (x-axis). Refined announcement times are obtained by searching for the maximum message activity 50 ms before and after the SIRCA announcement time. Announcements without SIRCA announcement time are ignored in the construction of this plot. The vertical dashed lines separate events for which the difference between the official announcement time and SIRCA time is more than $500 \mathrm{~ms}$.

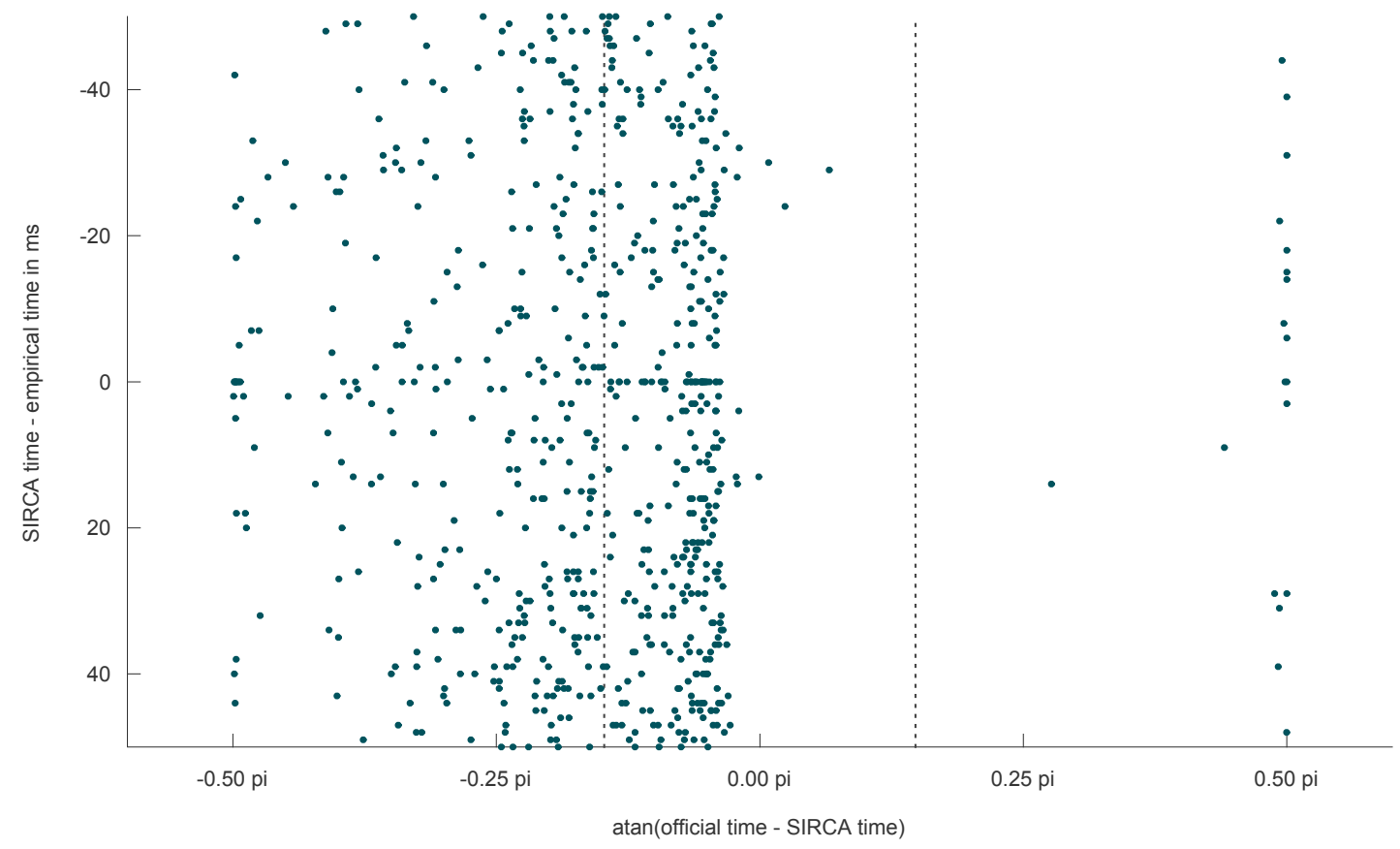


Figure 3: The average (time weighted) number of quoted shares at the best bid and ask price $(N B B A)$ per minute over the whole trading day (a) and per 10 seconds around 10:00 a.m. (b). The solid dark line is the $N B B A$ on days with news, whereas the dashed line is the $N B B A$ on days without news. The light gray lines provide the $90 \%$ confidence level of $N B B A$ on no news days. Note that the figure in (a) is constructed without differentiating between news arrival times (a day with news on, for example, 02:00 p.m. is a news day), whereas in (b) we only consider a day as a news day if there is news at 10:00 a.m.

(a) whole day

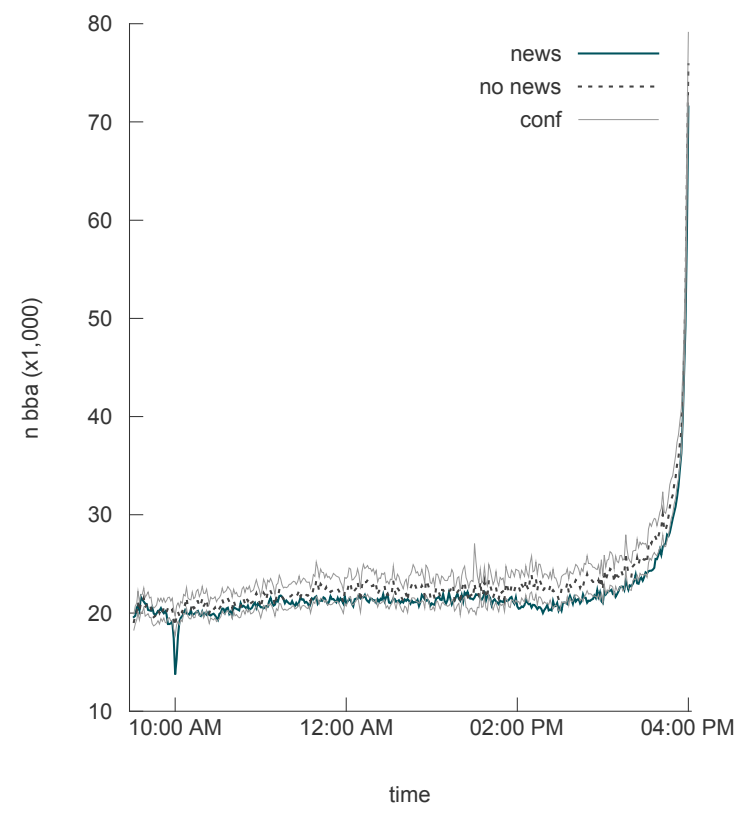

(b) 10:00 AM

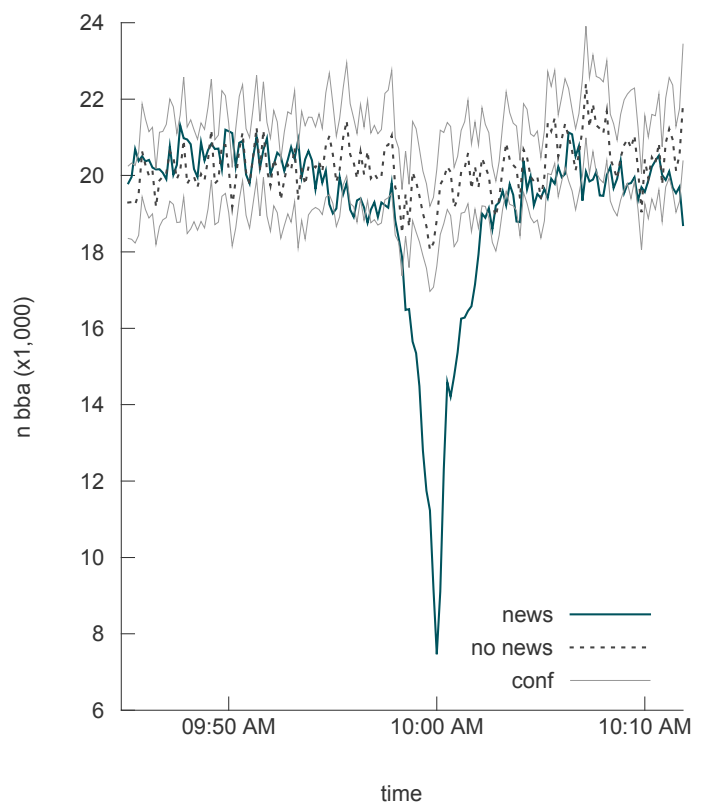

Figure 4: The average (time weighted) number of quoted shares up to 5 cents away from the best bid and ask price $(D P)$ per minute over the whole trading day (a) and per 10 seconds around 10:00 a.m. (b). The solid dark line is the $D P$ on days with news, whereas the dashed line is the $D P$ on days without news. The light gray lines provide the $90 \%$ confidence level of $D P$ on no news days. Note that the figure in (a) is constructed without differentiating between news arrival times (a day with news on, for example, 02:00 p.m. is a news day), whereas in (b) we only consider a day as a news day if there is news at 10:00 a.m.

(a) whole day

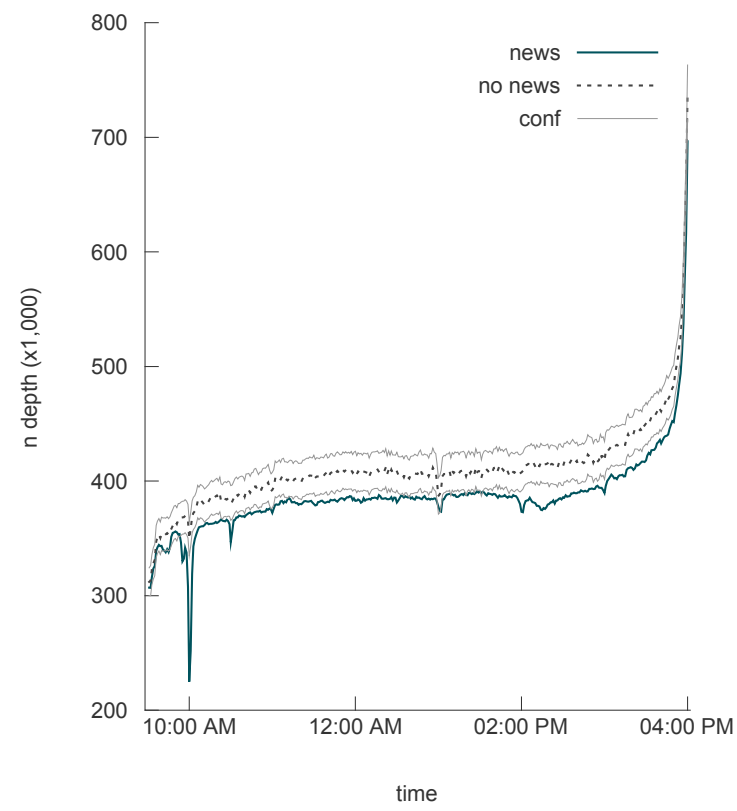

(b) 10:00 AM

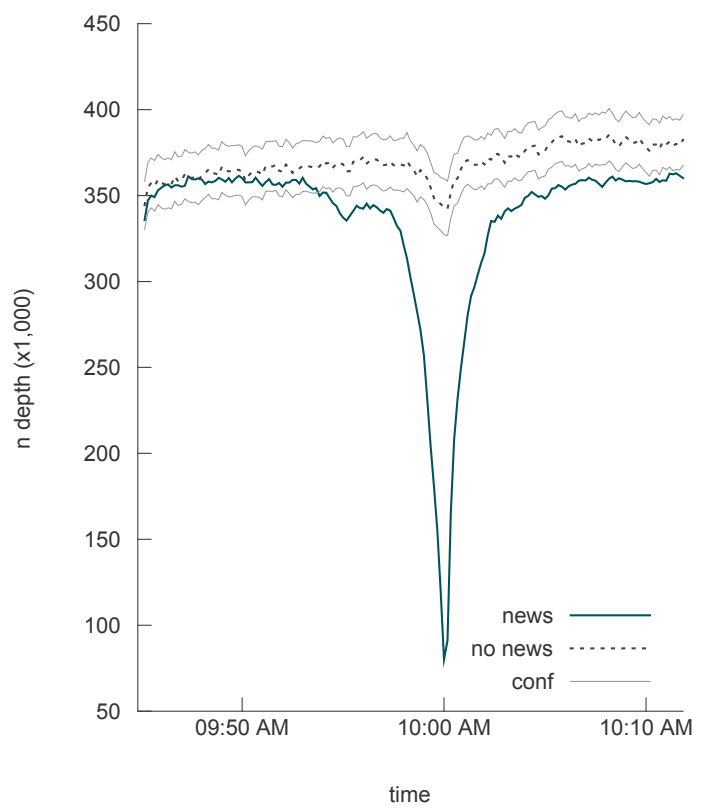


Figure 5: The average (time weighted) quoted half-spread $(Q H S)$ per minute over the whole trading day (a) and per 10 seconds around 10:00 a.m. (b). The solid dark line is the $Q H S$ on days with news, whereas the dashed line is the $Q H S$ on days without news. The light gray lines provide the $90 \%$ confidence level of $Q H S$ on no news days. Note that the figure in (a) is constructed without differentiating between news arrival times (a day with news on, for example, 02:00 p.m. is a news day), whereas in (b) we only consider a day as a news day if there is news on 10:00 a.m.

(a) whole day

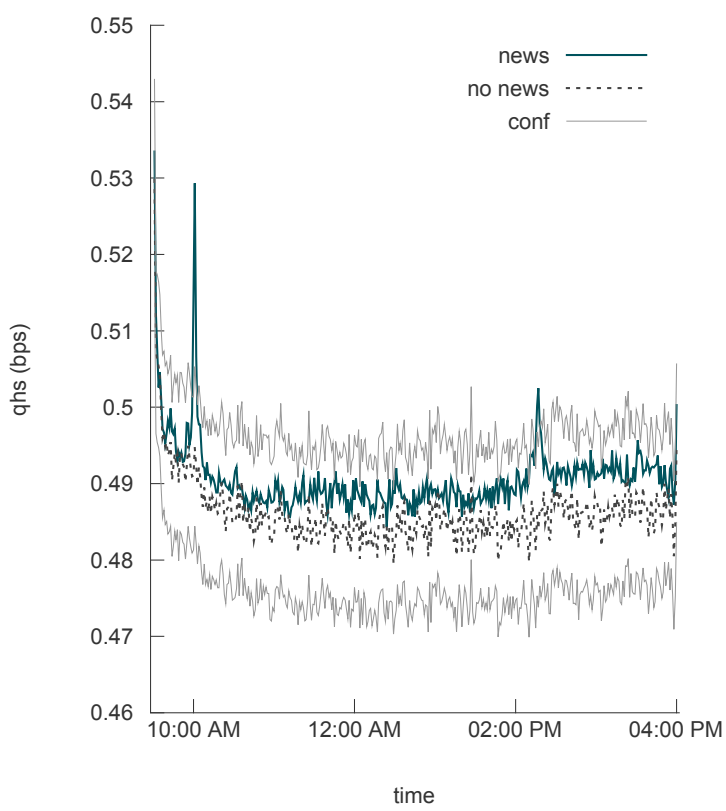

(b) 10:00 AM

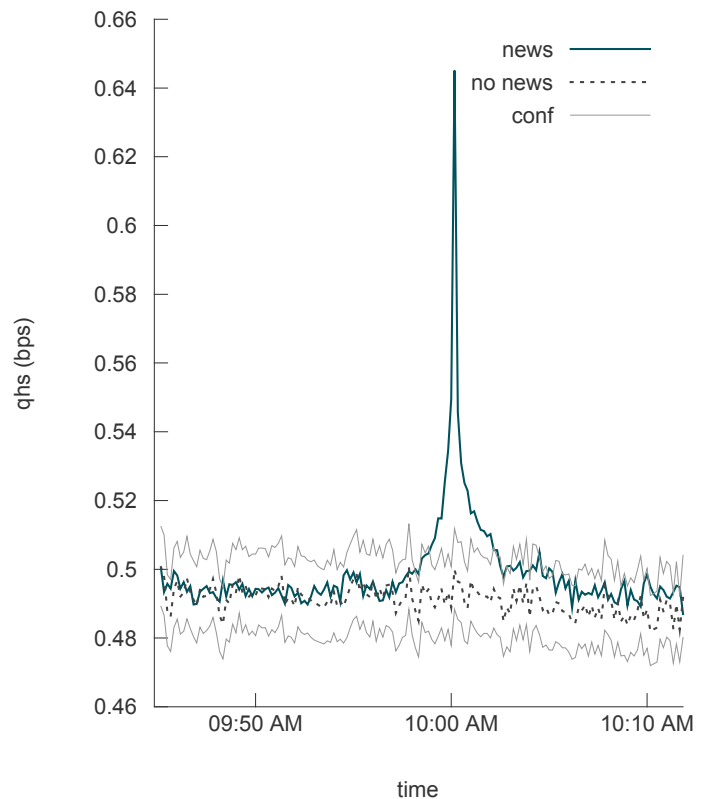

Figure 6: The average number of quoted shares up to 5 cents away from the best bid and ask price $(D P)$ per millisecond for $1000 \mathrm{~ms}$ around 10:00 a.m. in clock time (and event time) on days without (with) news in subplot (a) (subplot (b)). The starred observations is the minimum depth within $200 \mathrm{~ms}$ of 10:00 a.m. or event time.

(a) 1000 ms around 10:00 AM (in clock time) without news

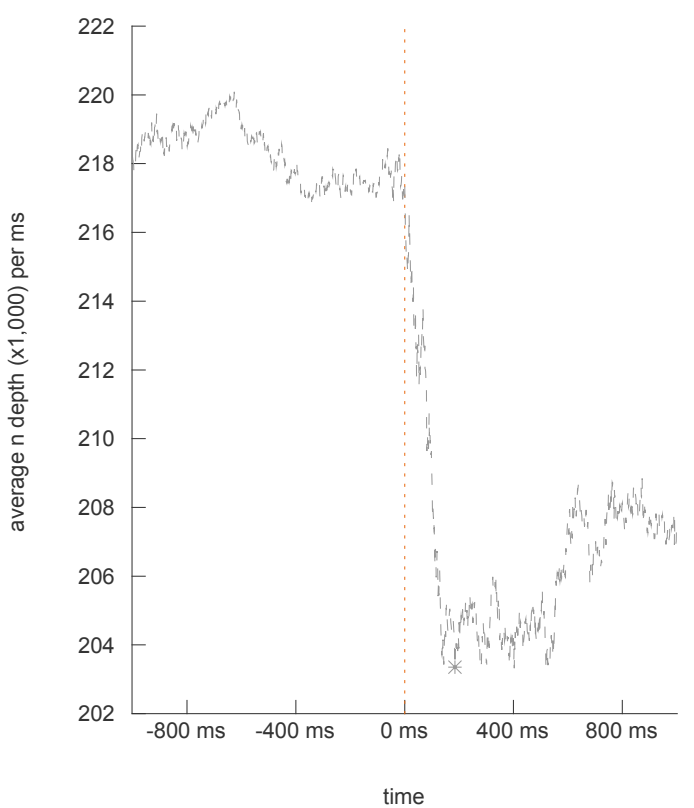

(b) $1000 \mathrm{~ms}$ around 10:00 AM with news

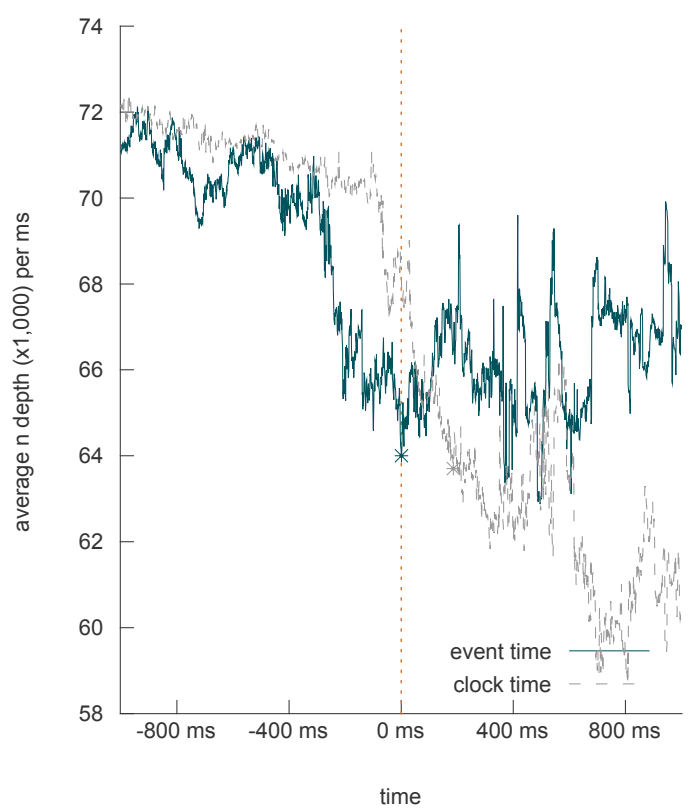


Figure 7: The average aggregate number of fleeting orders at the $50 \mathrm{~ms}$ level (NFLT50) per minute over the whole trading day (a) and per 10 seconds around 10:00 a.m. (b). The solid dark line is the NFLT50 on days with news, whereas the dashed line is the NFLT50 on days without news. The light gray lines provide the $90 \%$ confidence level of NFLT50 on no news days. Note that the figure in (a) is constructed without differentiating between news arrival times (a day with news on, for example, 02:00 p.m. is a news day), whereas in (b) we only consider a day as a news day if there is news at 10:00 a.m.

(a) whole day

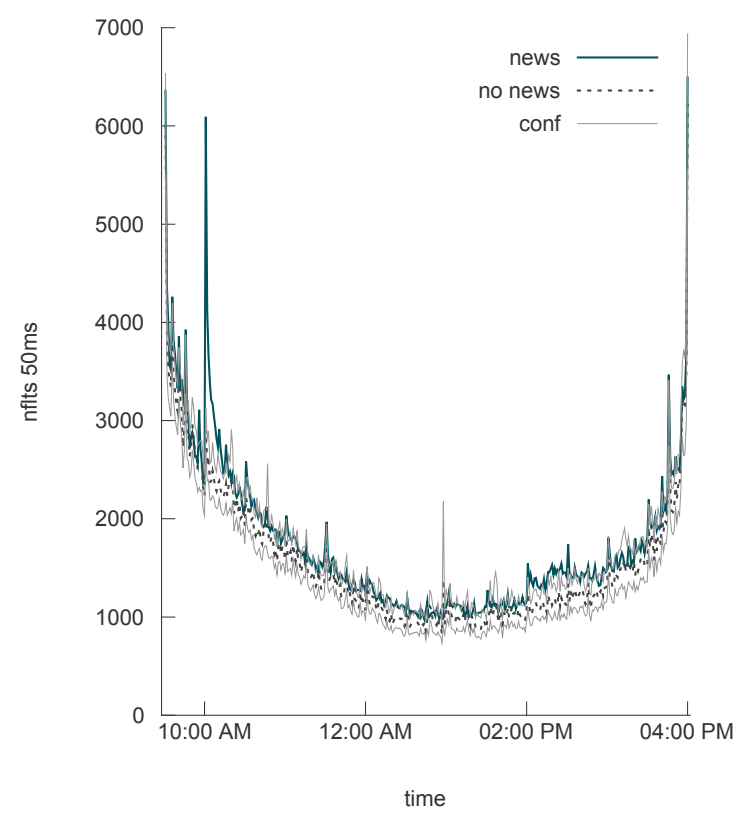

(b) 10:00 AM

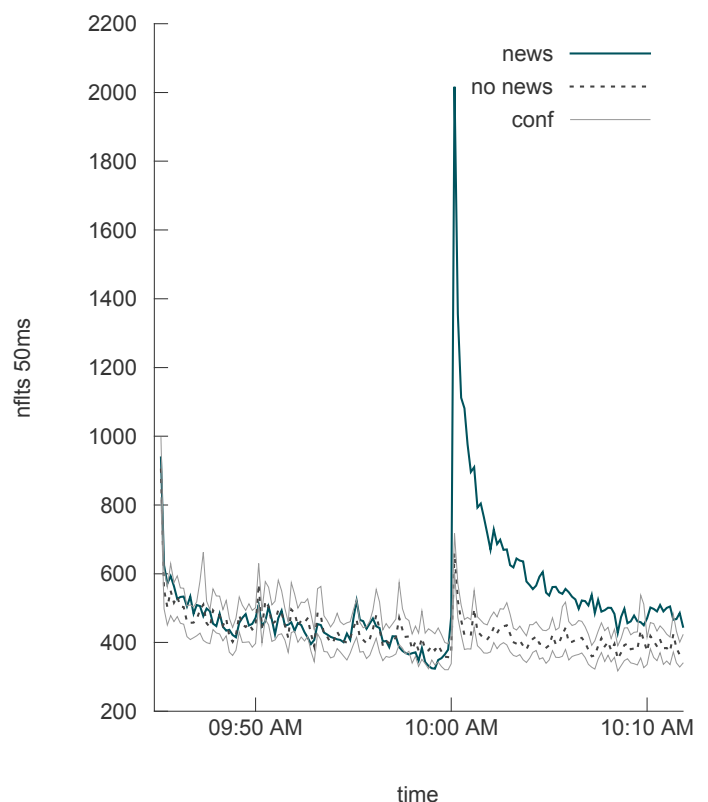

Figure 8: Cumulative return perfect foresight signals (a) and importance of speed during macroeconomic news (b) over all news announcements. Perfect foresight signals are constructed by looking ahead 1 minute. The importance of speed is calculated by comparing the average return of executing the perfect foresight strategy instantaneously with the average returns of executing the perfect foresight strategy with the delay levels provided on the $\mathrm{x}$-axis. In case the importance of speed is significant at the $10 \%, 5 \%$, or $1 \%$ level this is indicated by means of a $*, \odot$, and $\bullet$, respectively.

(a) cumulative returns

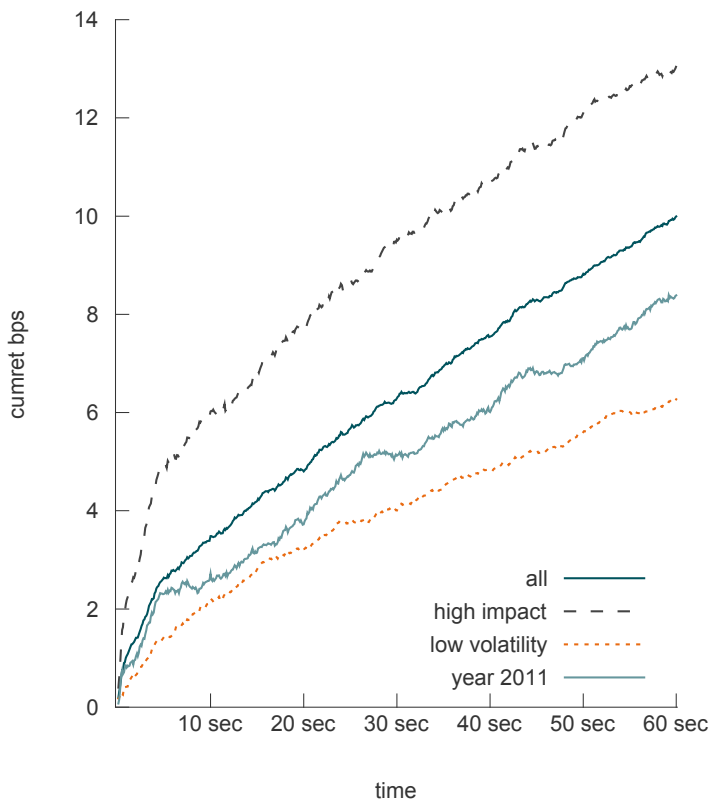

(b) importance of speed, $n=707$

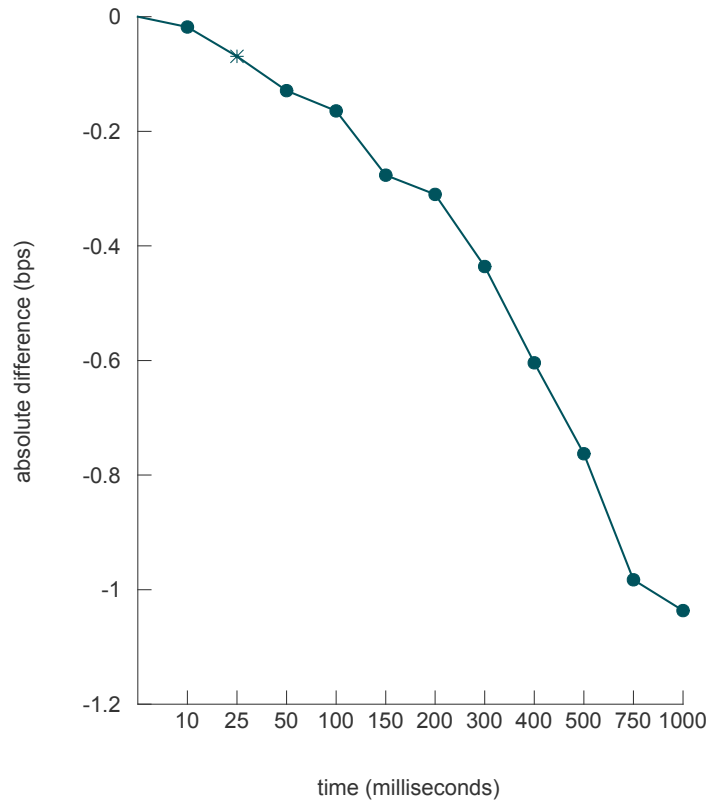


Figure 9: The importance of speed during macroeconomic news announcements for the different years in the sample period (a) and for days with high and low volatility (b). The importance of speed is calculated by comparing the average return of executing the perfect foresight strategy instantaneously with the average returns of executing the perfect foresight strategy with the delay levels provided on the x-axis. In case the importance of speed is significant at the $10 \%, 5 \%$, or $1 \%$ level this is indicated by means of a $*, \odot$, and $\bullet$, respectively.

(a) imp. of speed per year

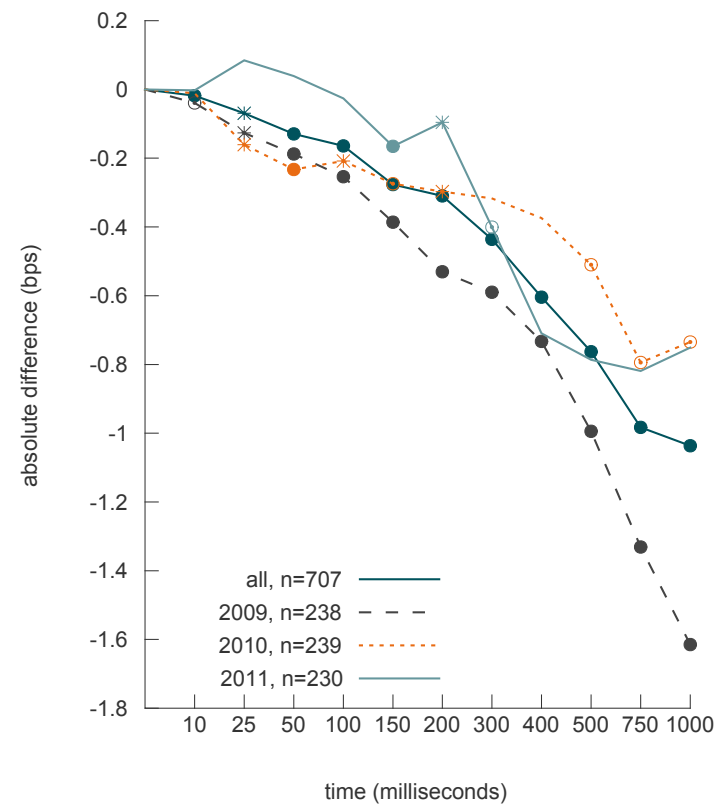

(b) imp. of speed and volatility

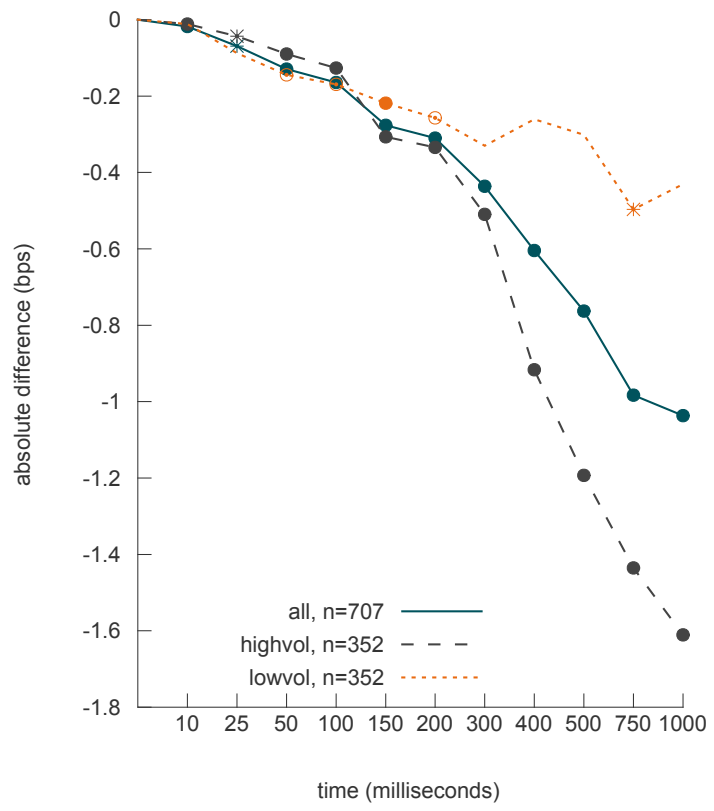

Figure 10: The importance of speed during macroeconomic news announcements for different intraday moments (a) and for different impact levels of the news (b). The importance of speed is calculated by comparing the average return of executing the perfect foresight strategy instantaneously with the average returns of executing the perfect foresight strategy with the delay levels provided on the x-axis. In case the importance of speed is significant at the $10 \%, 5 \%$, or $1 \%$ level this is indicated by means of a $*, \odot$, and $\bullet$, respectively.

(b) imp. of speed per intraday moment

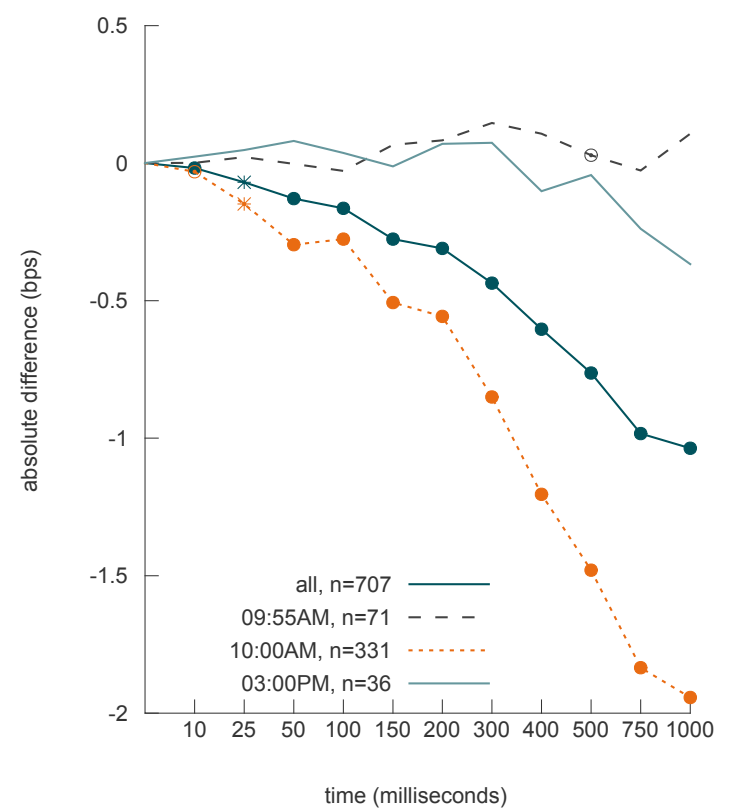

(a) imp. of speed and news impact

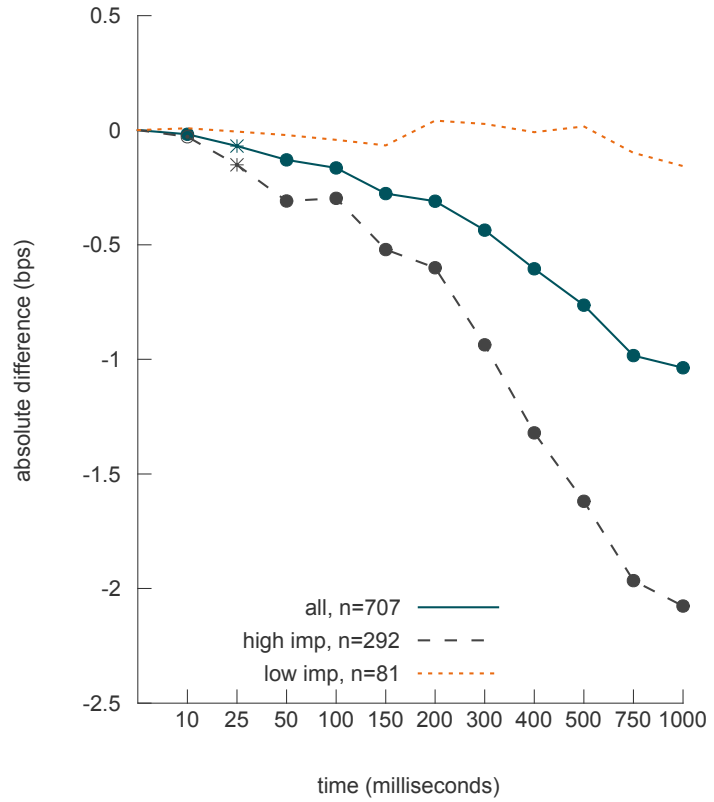


Figure 11: The importance of speed during macroeconomic news announcements for different time differences between the official announcement time (ignoring announcements for which the SIRCA announcement time is before the official announcement time) and SIRCA announcement time (a) and for announcements with large and small surprises (absolute difference actual number and consensus forecast relative to the consensus forecast, ignoring announcements with no actual or consensus number) (b). The importance of speed is calculated by comparing the average return of executing the perfect foresight strategy instantaneously with the average returns of executing the perfect foresight strategy with the delay levels provided on the x-axis. In case the importance of speed is significant at the $10 \%, 5 \%$, or $1 \%$ level this is indicated by means of a $*, \odot$, and $\bullet$, respectively.

(a) imp. of speed and time diff

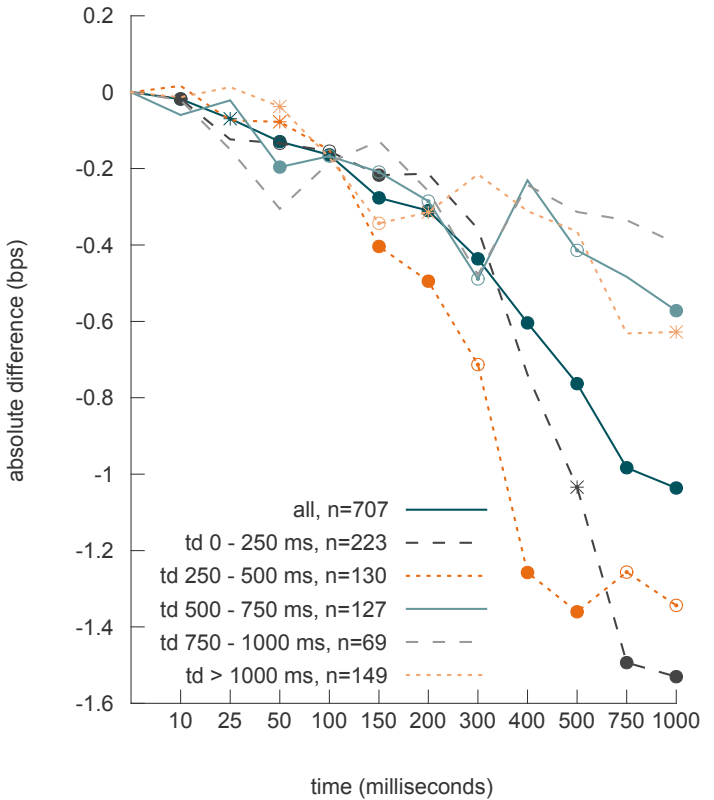

(b) imp. of speed and surprise

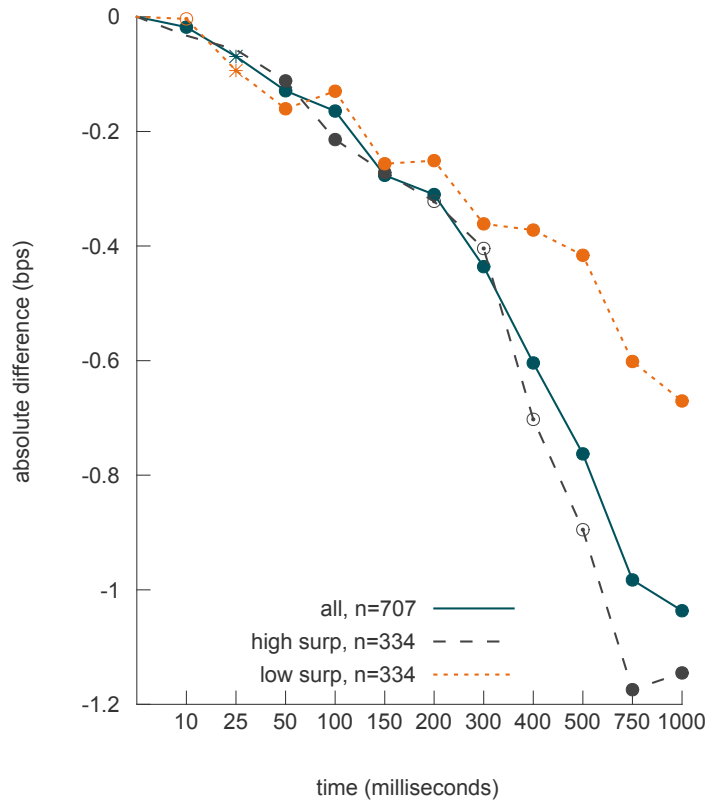

Figure 12: The importance of speed during macroeconomic news announcements for different trade capacity levels (a) and for different trading strategies (b). The importance of speed is calculated by comparing the average return of executing the perfect foresight strategy instantaneously with the average returns of executing the perfect foresight strategy with the delay levels provided on the x-axis. In case the importance of speed is significant at the $10 \%, 5 \%$, or $1 \%$ level this is indicated by means of $\mathrm{a} *, \odot$, and $\bullet$, respectively. The trading strategies in (b) differ with respect to their success ratio and are constructed by randomizing the perfect foresight strategy.

(a) imp. of speed and price impact, $n=707$

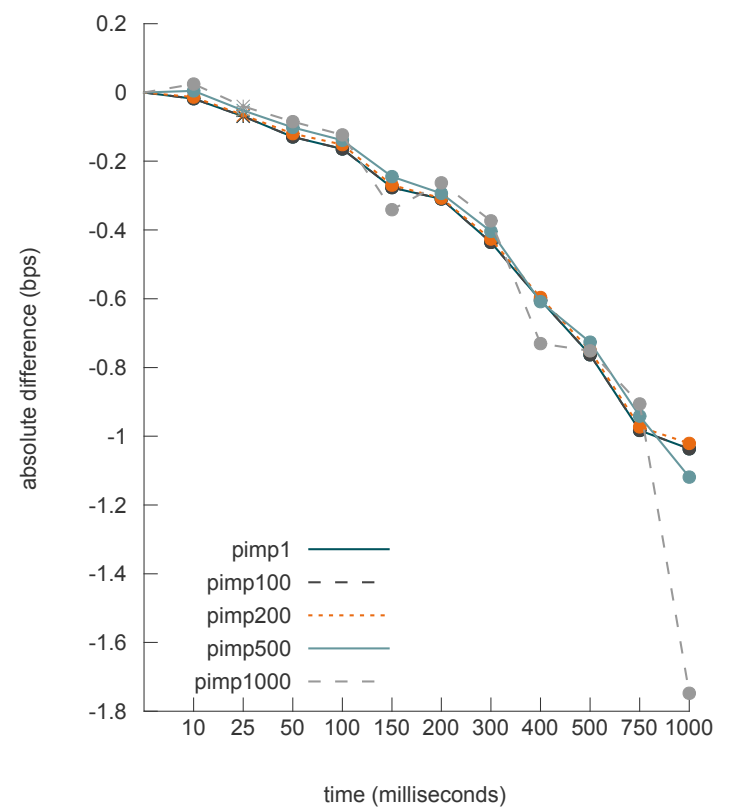

(b) imp. of speed and news reading success ratio

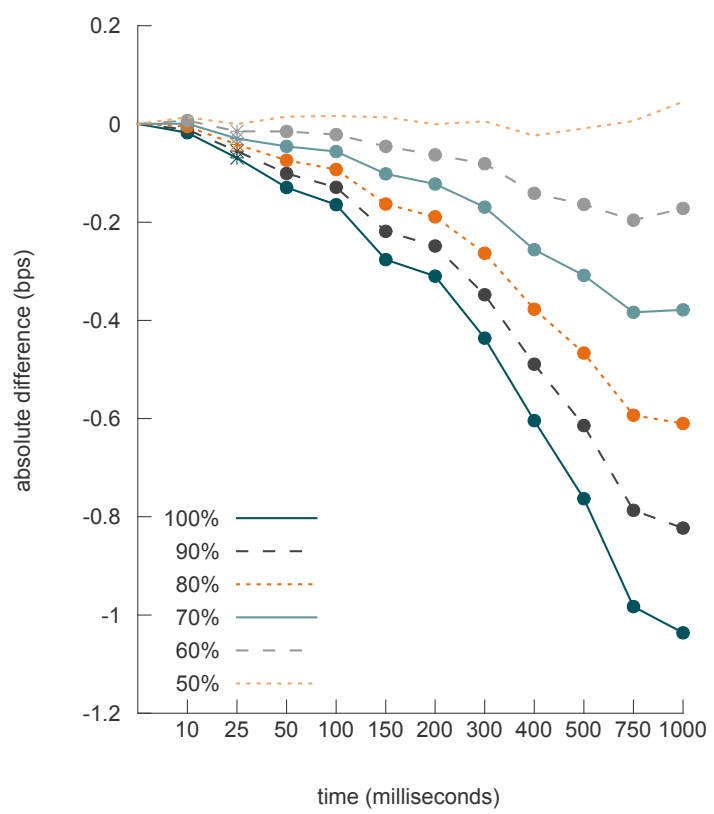


Figure 13: Cumulative return perfect foresight signals (a) and importance of speed during macroeconomic news arrivals (b) over all news announcements using the refined SIRCA news arrival time. Perfect foresight signals are constructed by looking ahead 1 minute. The importance of speed is calculated by comparing the average return of executing the perfect foresight strategy instantaneously with the average returns of executing the perfect foresight strategy with the delay levels provided on the x-axis. In case the importance of speed is significant at the $10 \%, 5 \%$, or $1 \%$ level this is indicated by means of a $*$, $\odot$, and $\bullet$, respectively.

(a) cumulative returns

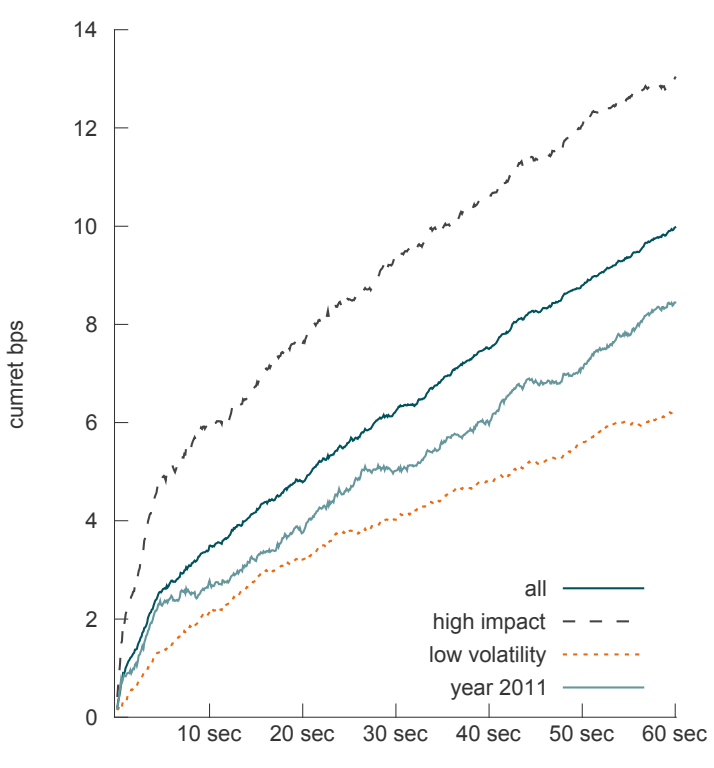

time (b) importance of speed, $n=707$

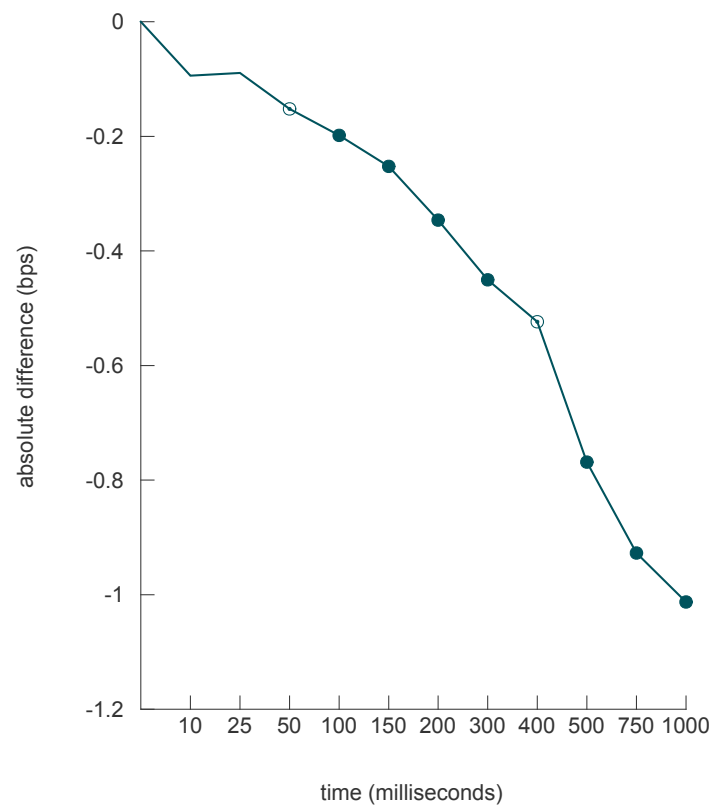

Figure 14: Cumulative return perfect foresight signals (a) and importance of speed during macroeconomic news arrivals (b) over all news announcements using the official announcement time of the news. Perfect foresight signals are constructed by looking ahead 1 minute. The importance of speed is calculated by comparing the average return of executing the perfect foresight strategy instantaneously with the average returns of executing the perfect foresight strategy with the delay levels provided on the x-axis. In case the importance of speed is significant at the $10 \%, 5 \%$, or $1 \%$ level this is indicated by means of a $*, \odot$, and $\bullet$, respectively.

(a) cumulative returns

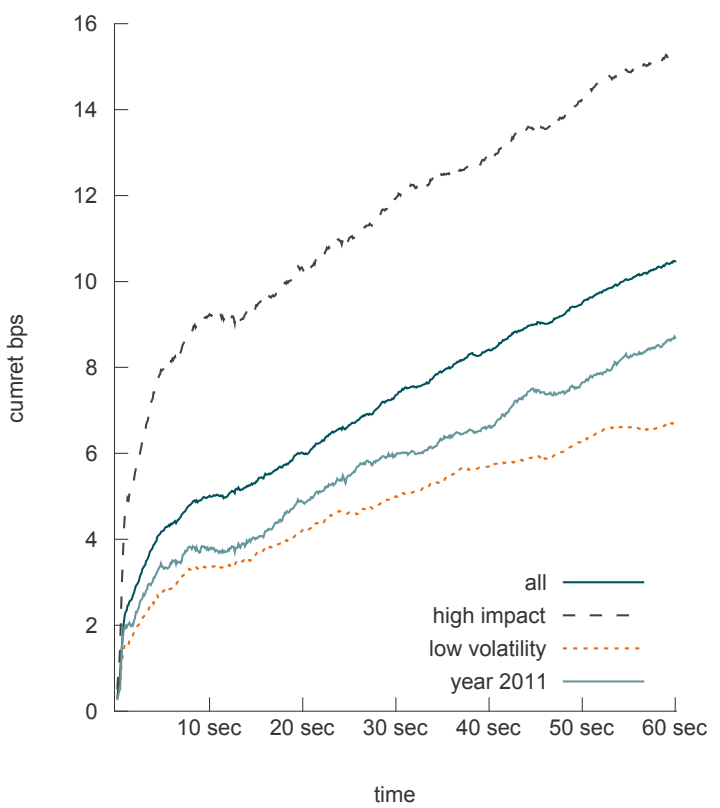

(b) importance of speed, $n=707$

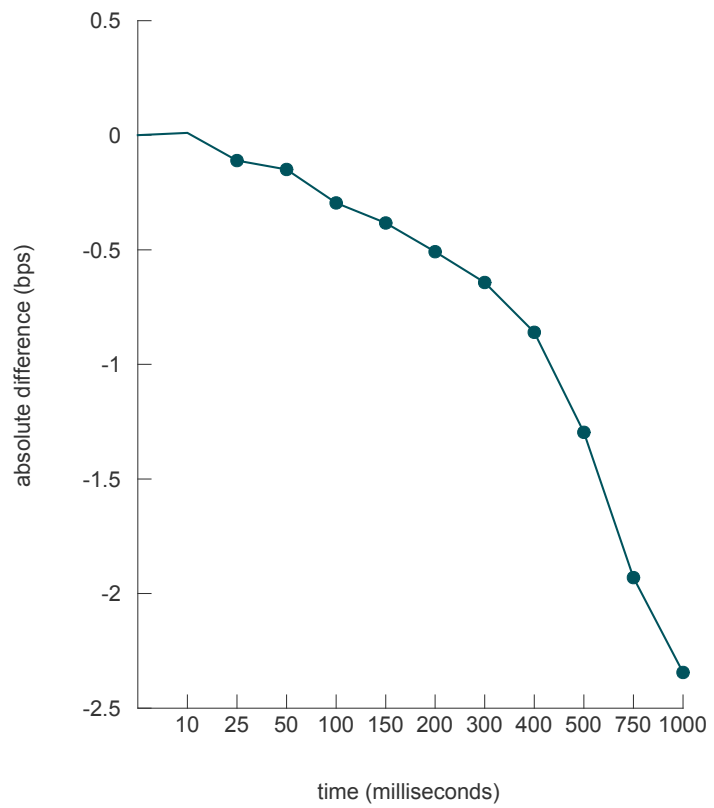


Figure 15: Absolute midpoint returns over $10 \mathrm{~ms}$ intervals around 10:00 a.m. in clock time (and event time) on days without (with) news in subplot (a) (subplot (b)).

(a) $1000 \mathrm{~ms}$ around 10:00 AM (in clock time) without news

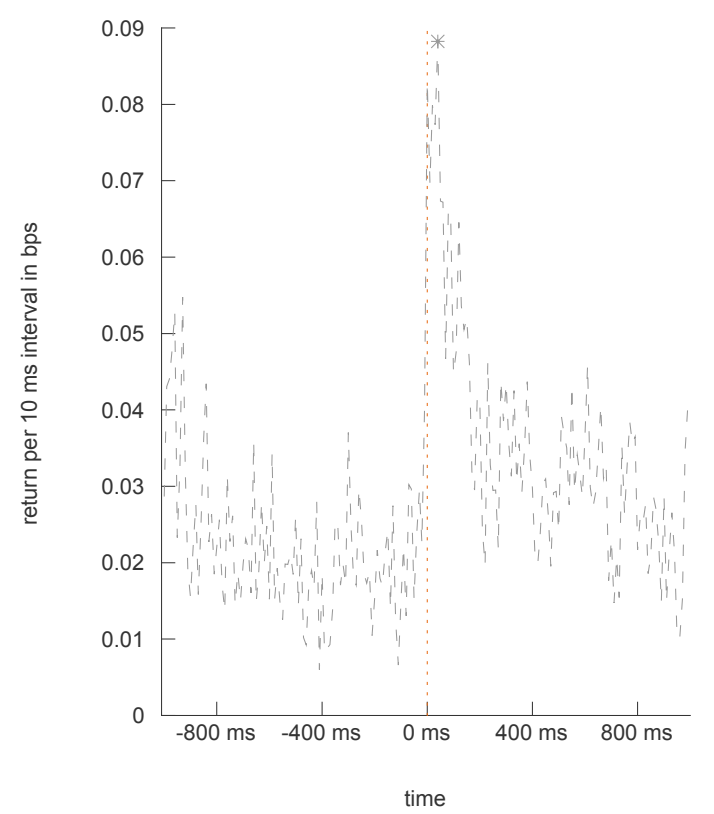

(b) 1000 ms around 10:00 AM with news

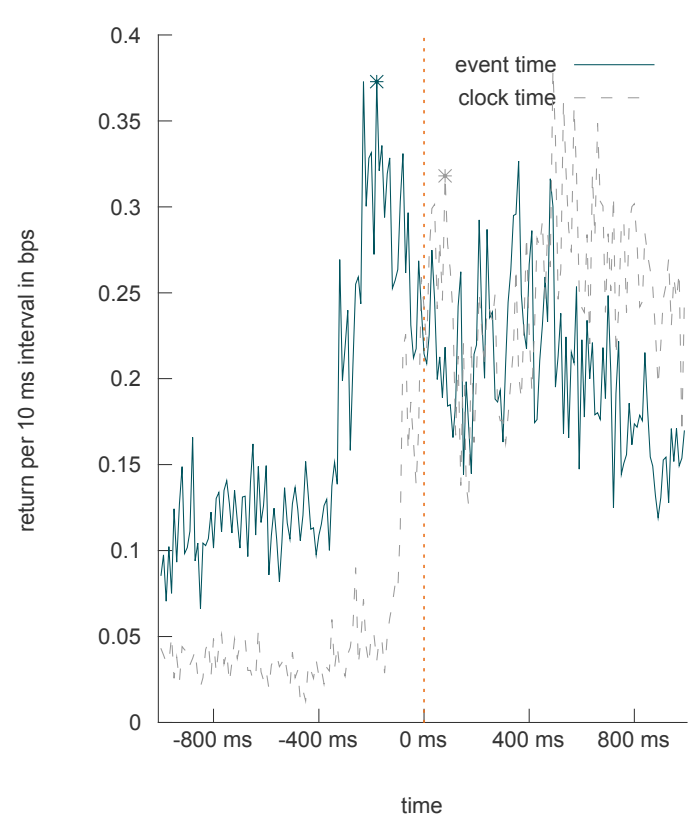

Figure 16: Subplot (a) depicts (absolute) midpoint returns (in clock time) over $10 \mathrm{~ms}$ intervals around 10:00 a.m. on days with news for announcements where the SIRCA arrival time is within 1 second or after 1 second of the official announcement time. Announcements with a SIRCA arrival time before the official announcement time are not included. In subplot (b) we plot the percentage of announcements for which the sign of the return over the interval from the official announcement time to the SIRCA announcement time (interval 0) matches the sign of subsequent intervals of the same length (\# future periods). We do this separately for announcements with a SIRCA time that falls within $0-250,250-500,500-750$, and $750-1000 \mathrm{~ms}$ of the official announcement time. If the number of announcements for which the sign of the return in future periods matches the sign of the return in interval 0 is significantly higher (lower) than one would expect based on randomness, this is indicated by means of a $\bullet$ and ( $\mathbf{\square})$. Announcements with a zero return in interval 0 are ignored. The number of times this occurs is provided in the legend as n0.

(a) $1000 \mathrm{~ms}$ around 10:00 AM (in clock time) with news

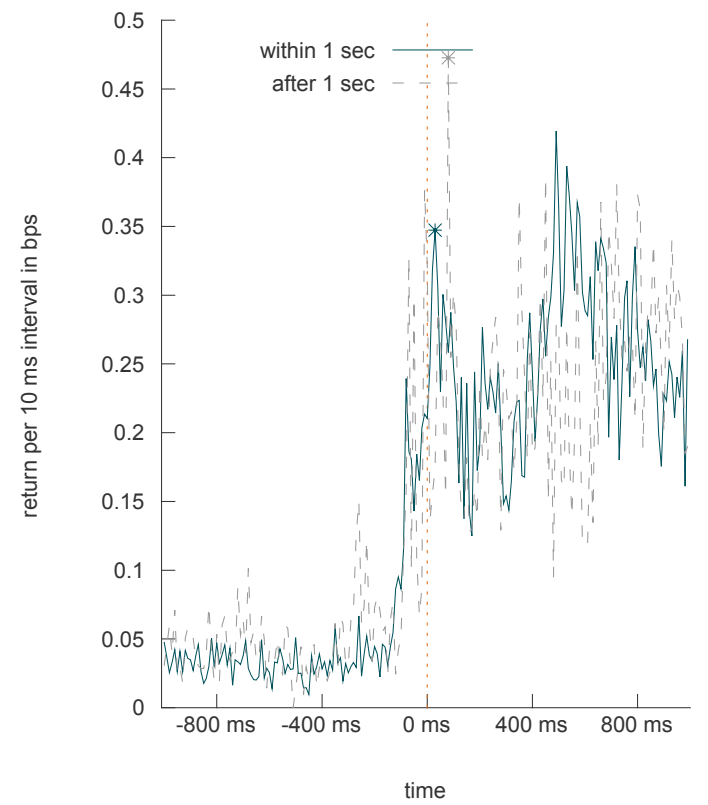

(b) hit ratios using information before SIRCA time excl. zeros

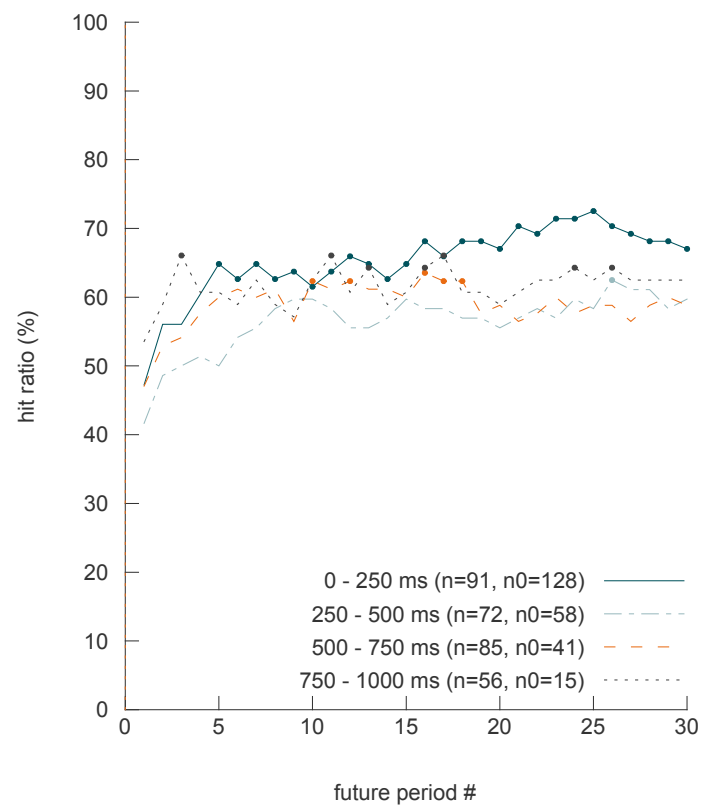




\section{Appendix A. Internet Appendix}

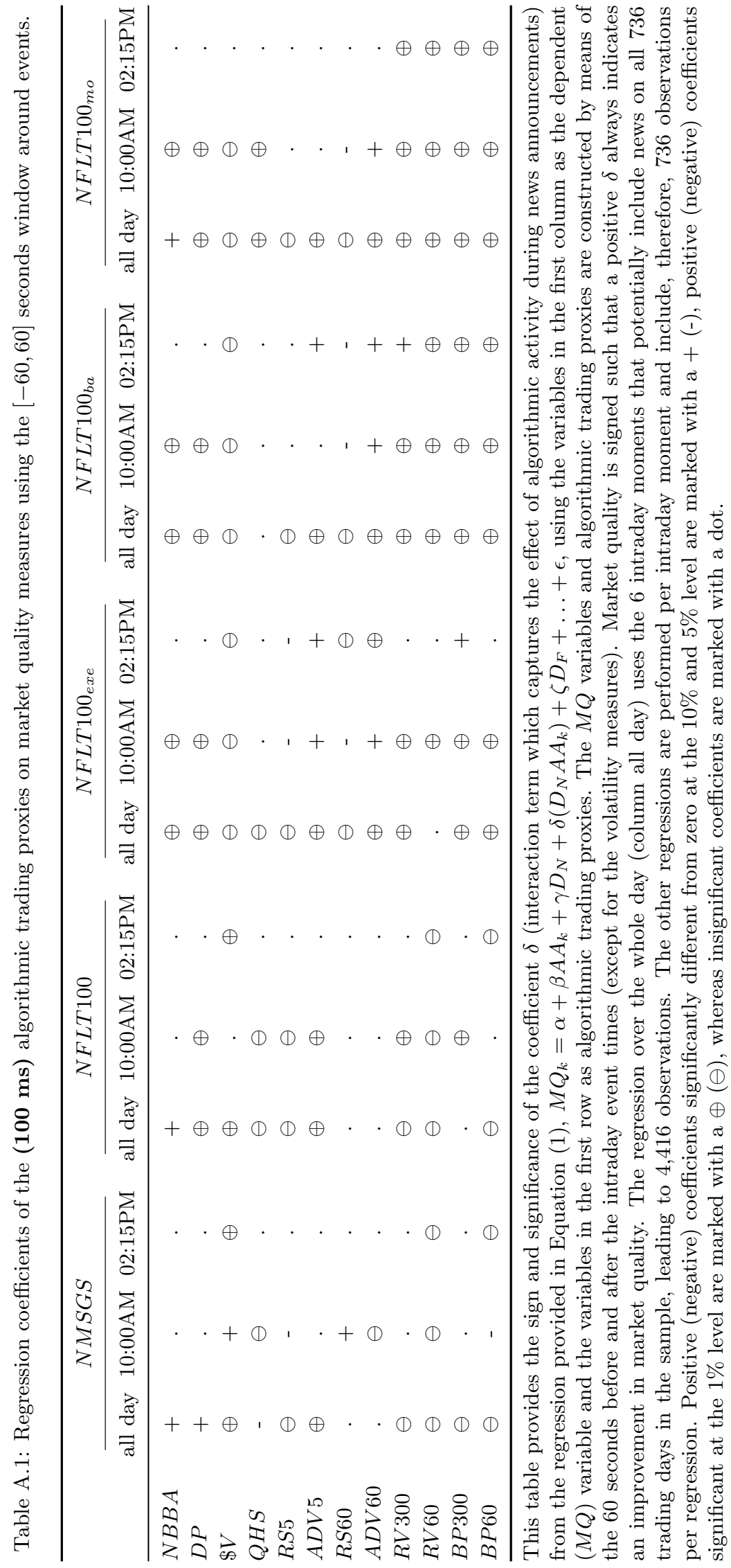




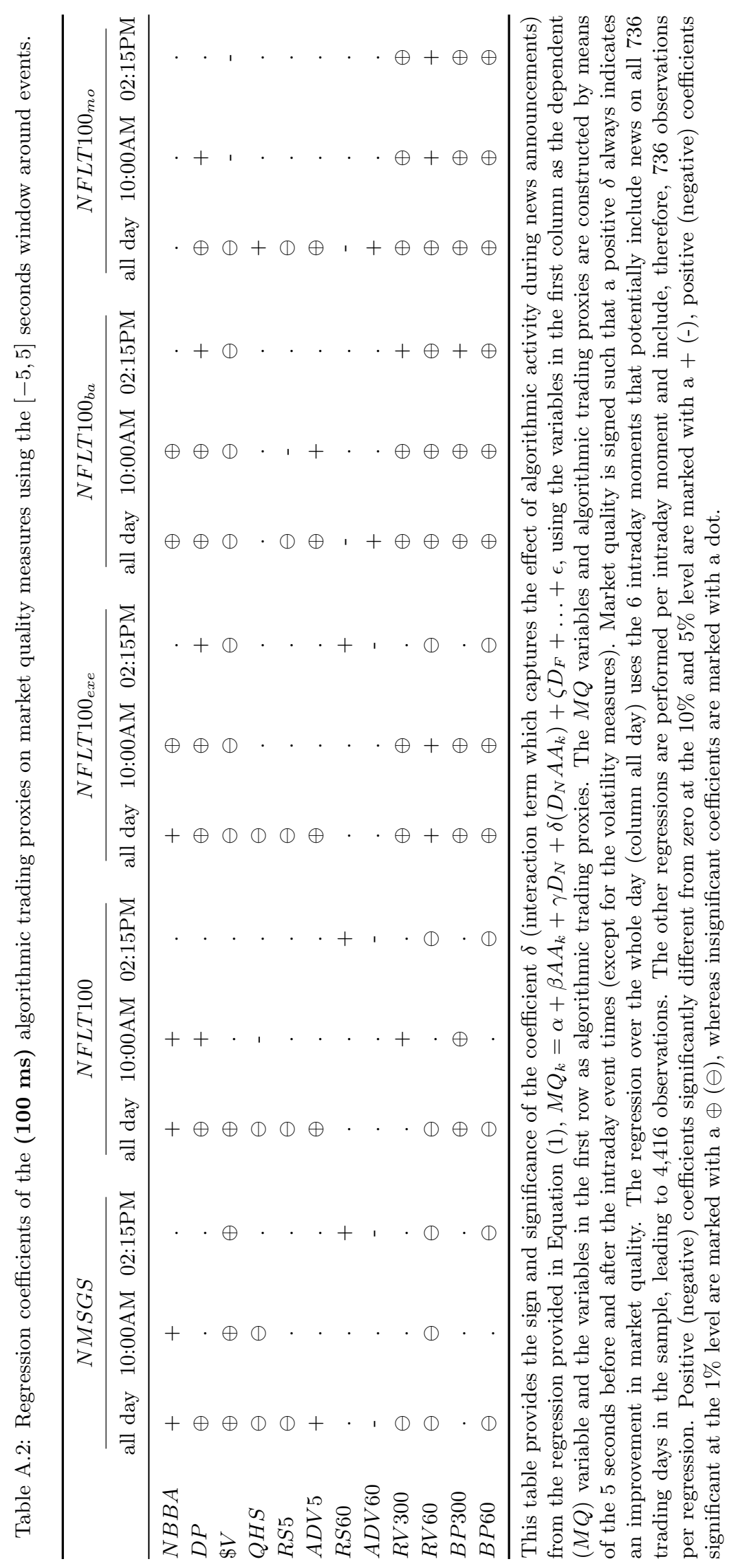




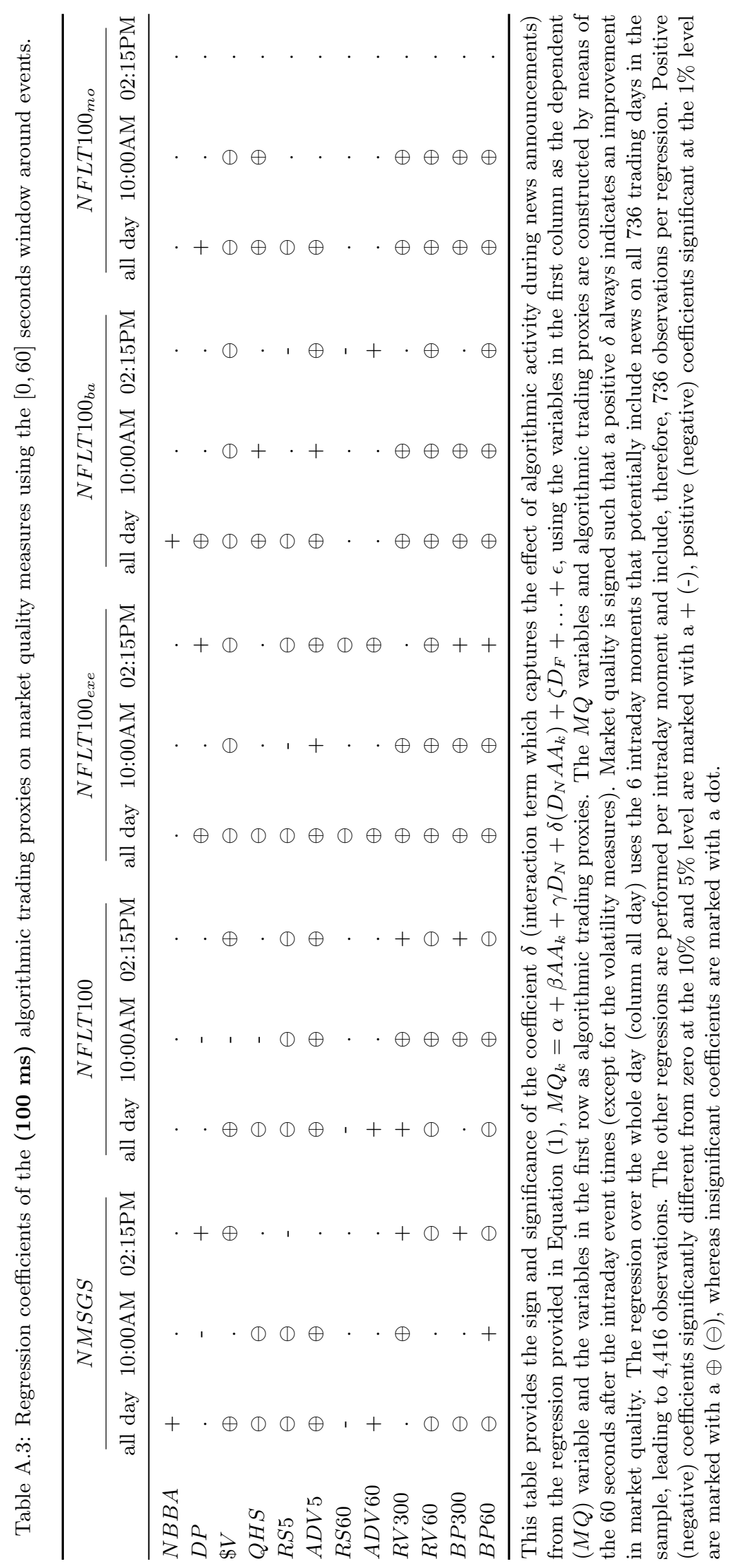




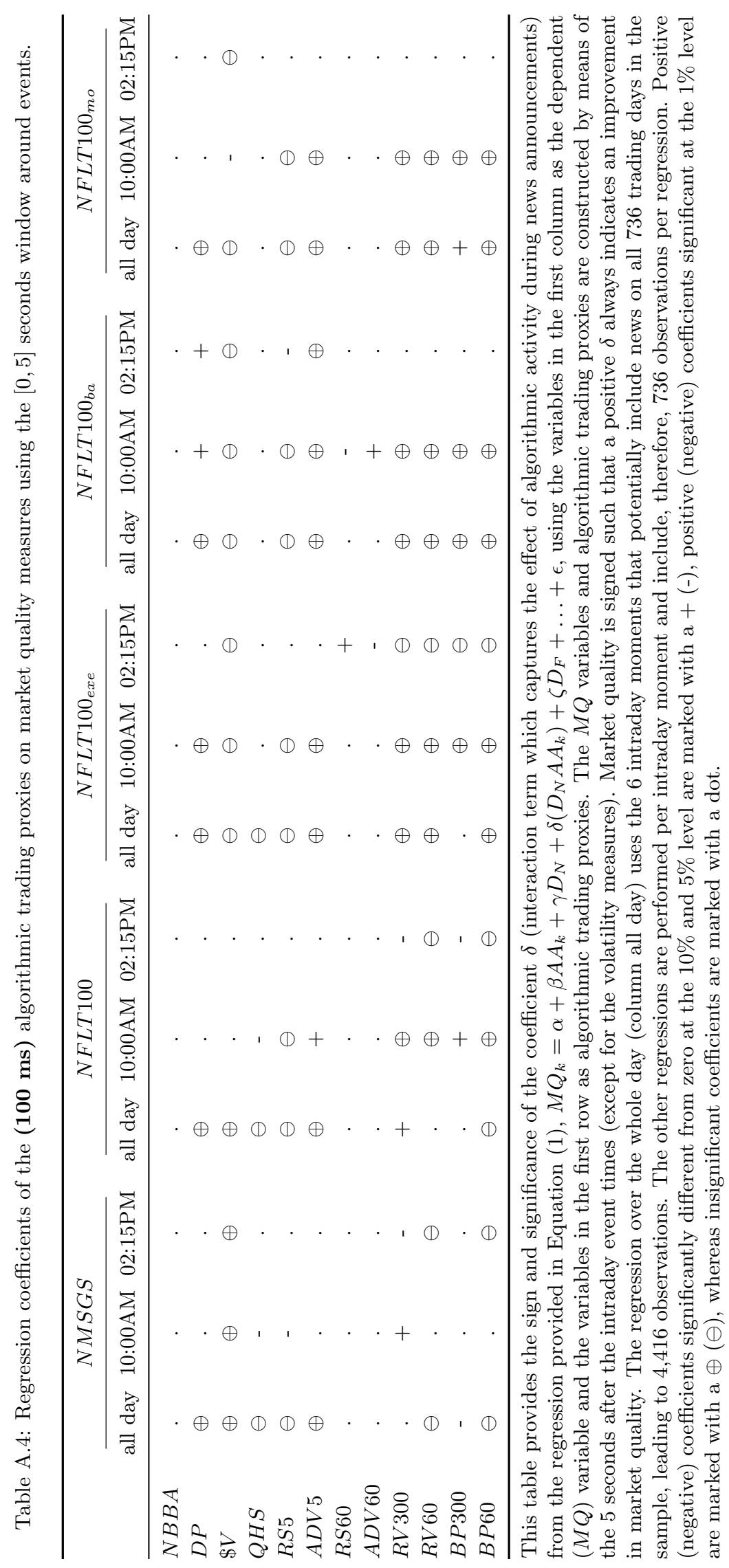


Figure A.1: The average aggregate trading volume $(\$ V)$ per minute over the whole trading day (a) and per 10 seconds around 10:00 a.m. (b). The solid dark line is the $\$ V$ on days with news, whereas the dashed line is the $\$ V$ on days without news. The light gray lines provide the $90 \%$ confidence level of $\$ V$ on no news days. Note that the figure in (a) is constructed without differentiating between news arrival times (a day with news on, for example, 02:00 p.m. is a news day), whereas in (b) we only consider a day as a news day if there is news at 10:00 a.m.

(a) whole day

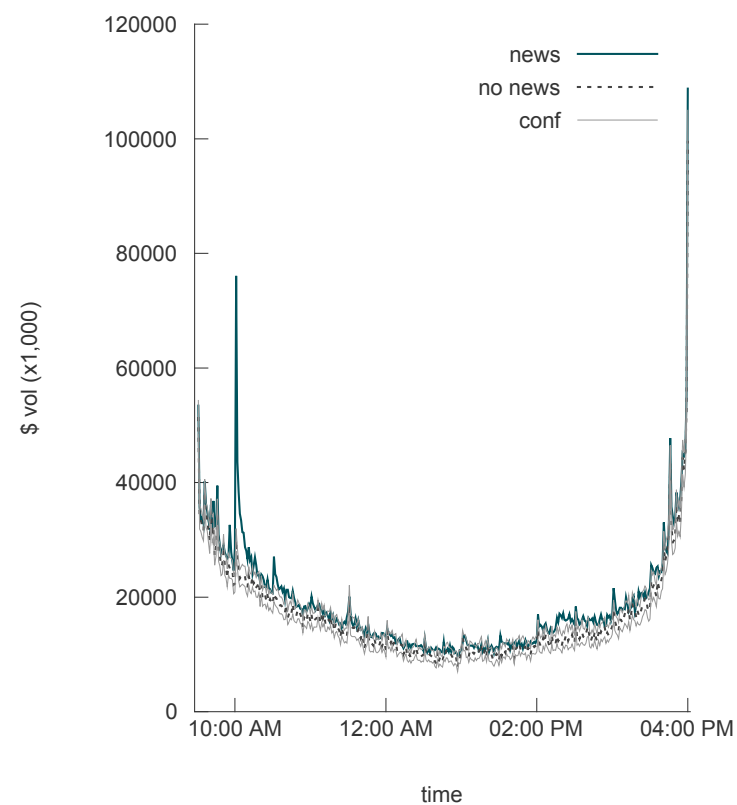

(b) 10:00 AM

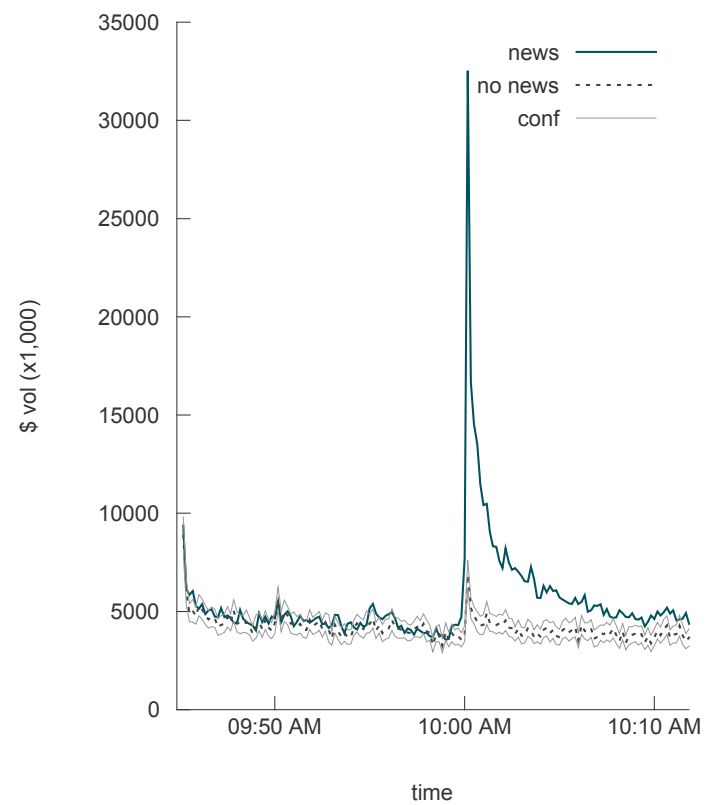

Figure A.2: The average (trade volume weighted) 5 second realized spread ( $R S 5)$ per minute over the whole trading day (a) and per 10 seconds around 10:00 a.m. (b). The solid dark line is the $R S 5$ on days with news, whereas the dashed line is the RS5 on days without news. The light gray lines provide the $90 \%$ confidence level of $R S 5$ on no news days. Note that the figure in (a) is constructed without differentiating between news arrival times (a day with news on, for example, 02:00 p.m. is a news day), whereas in (b) we only consider a day as a news day if there is news on 10:00 a.m.

(a) whole day

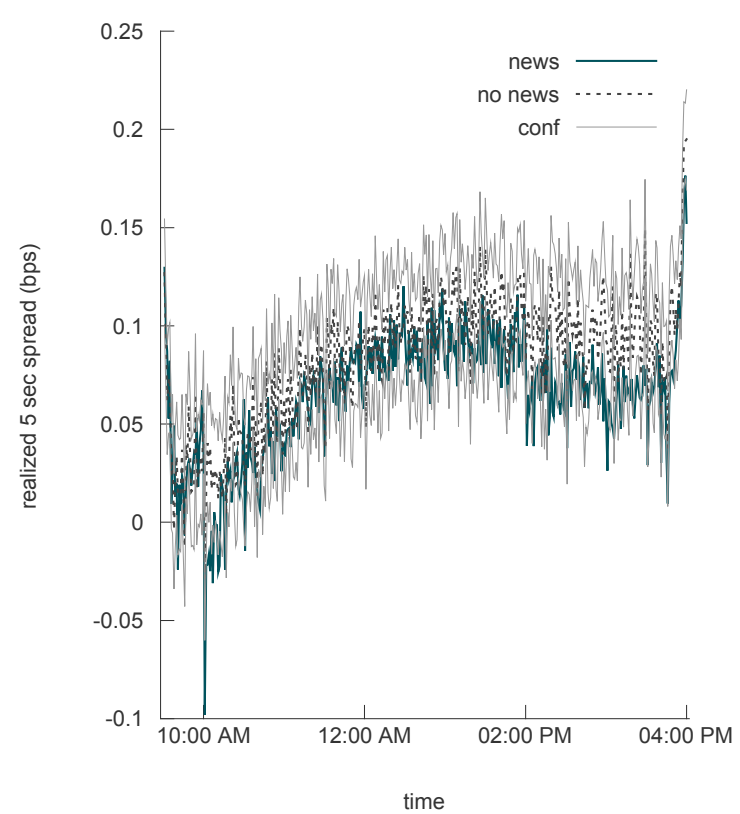

(b) 10:00 AM

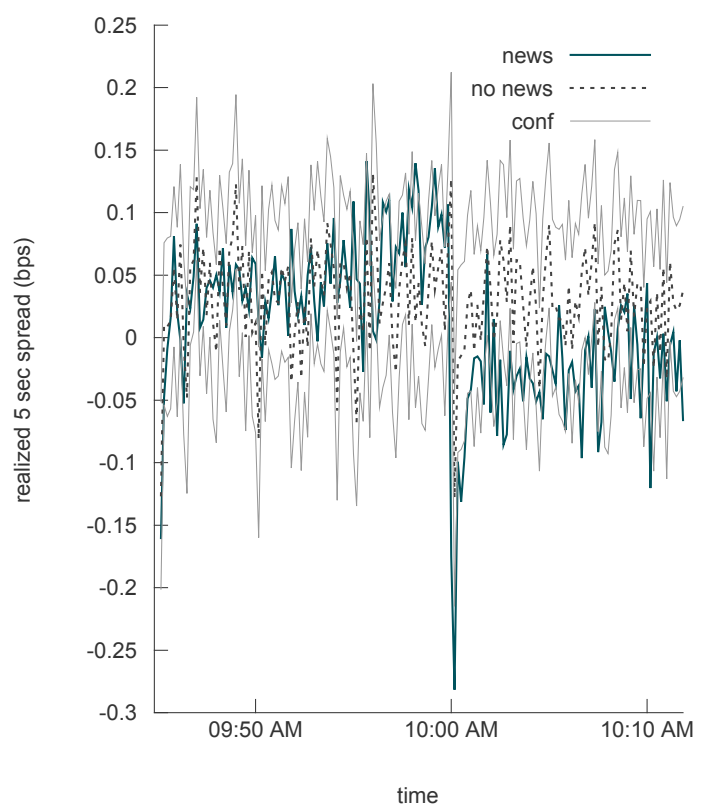


Figure A.3: The average (trade volume weighted) 5 second adverse selection costs (price impact) ( $A D V 5)$ per minute over the whole trading day (a) and per 10 seconds around 10:00 a.m. (b). The solid dark line is the $A D V 5$ on days with news, whereas the dashed line is the $A D V 5$ on days without news. The light gray lines provide the $90 \%$ confidence level of $A D V 5$ on no news days. Note that the figure in (a) is constructed without differentiating between news arrival times (a day with news on, for example, 02:00 p.m. is a news day), whereas in (b) we only consider a day as a news day if there is news at 10:00 a.m.

(a) whole day

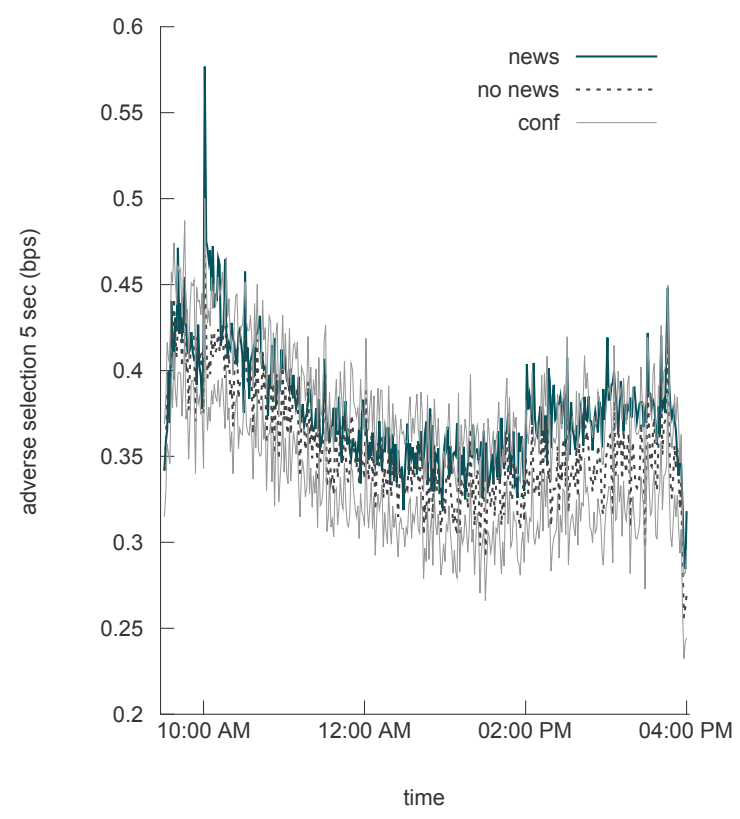

(b) 10:00 AM

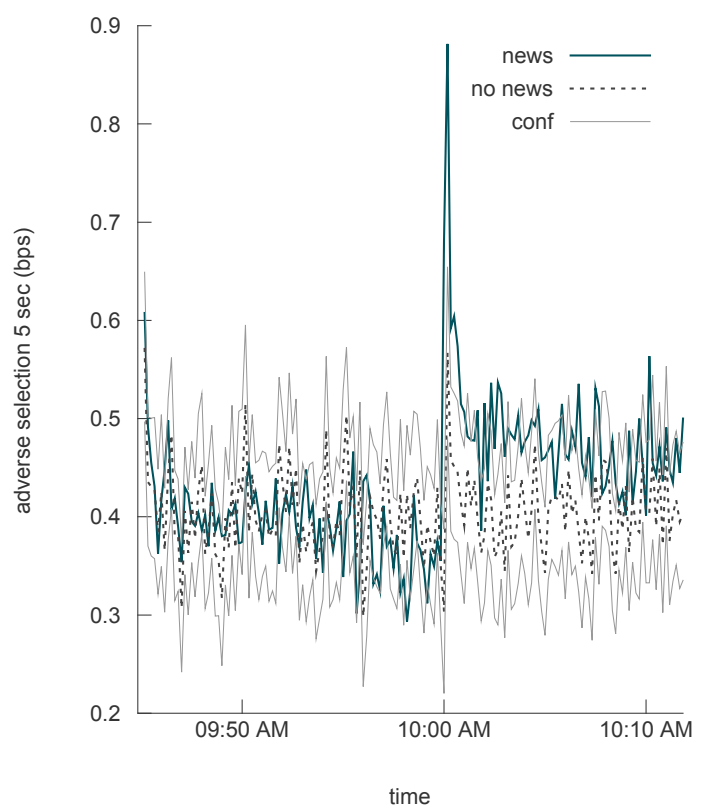

Figure A.4: The average (trade volume weighted) 1 second realized spread ( $R S 1)$ per minute over the whole trading day (a) and per 10 seconds around 10:00 a.m. (b). The solid dark line is the $R S 1$ on days with news, whereas the dashed line is the $R S 1$ on days without news. The light gray lines provide the $90 \%$ confidence level of $R S 1$ on no news days. Note that the figure in (a) is constructed without differentiating between news arrival times (a day with news on, for example, 02:00 p.m. is a news day), whereas in (b) we only consider a day as a news day if there is news at 10:00 a.m.

(a) whole day

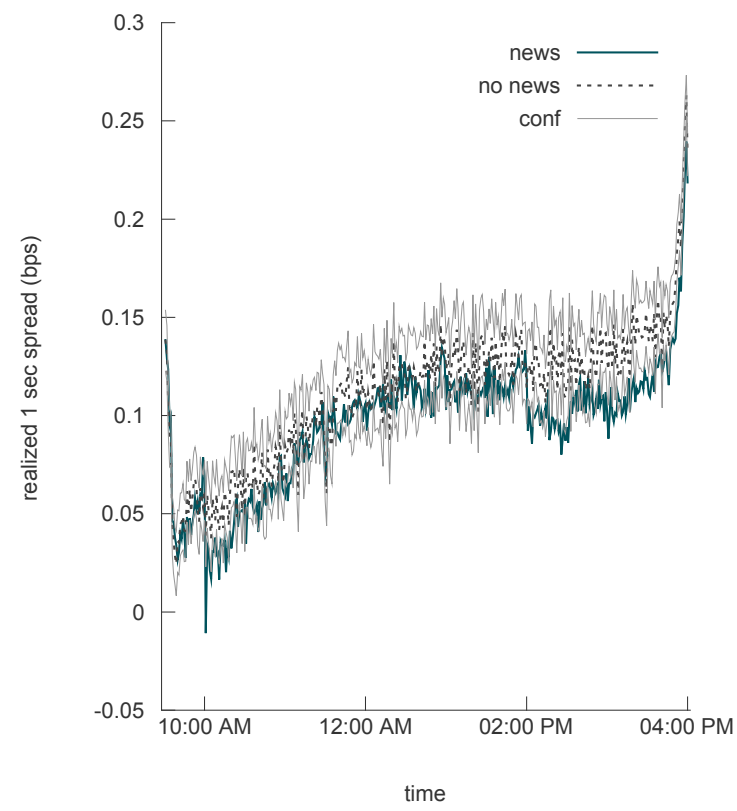

(b) 10:00 AM

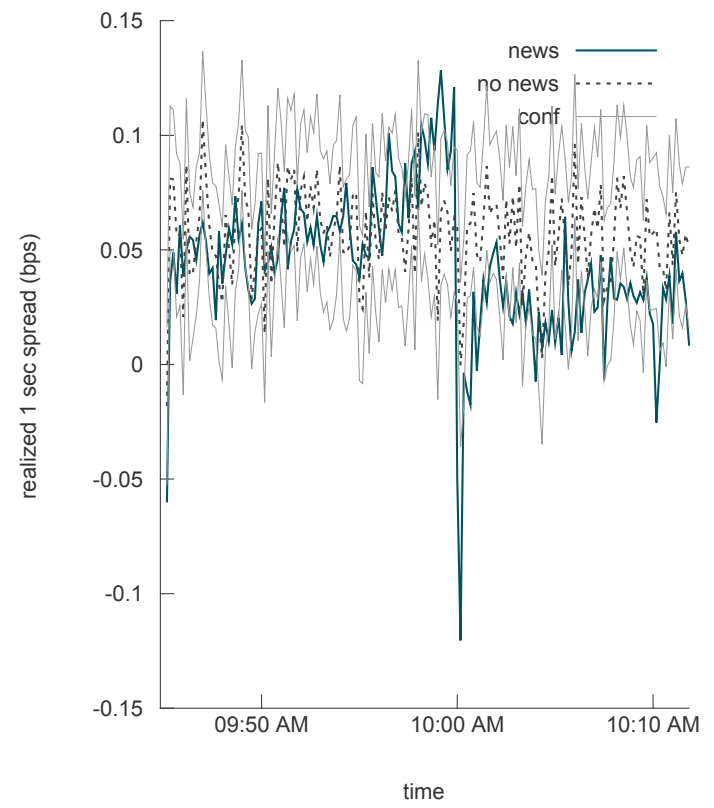


Figure A.5: The average (trade volume weighted) 1 second adverse selection costs (price impact) ( $A D V 1)$ per minute over the whole trading day (a) and per 10 seconds around 10:00 a.m. (b). The solid dark line is the $A D V 1$ on days with news, whereas the dashed line is the $A D V 1$ on days without news. The light gray lines provide the $90 \%$ confidence level of $A D V 1$ on no news days. Note that the figure in (a) is constructed without differentiating between news arrival times (a day with news on, for example, 02:00 p.m. is a news day), whereas in (b) we only consider a day as a news day if there is news on 10:00 a.m.

(a) whole day

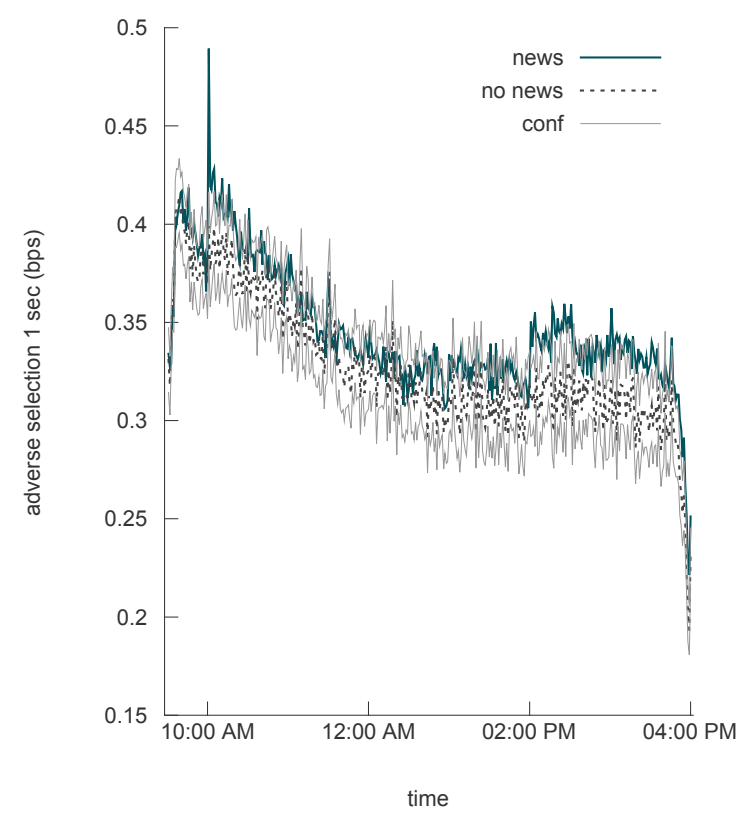

(b) 10:00 AM

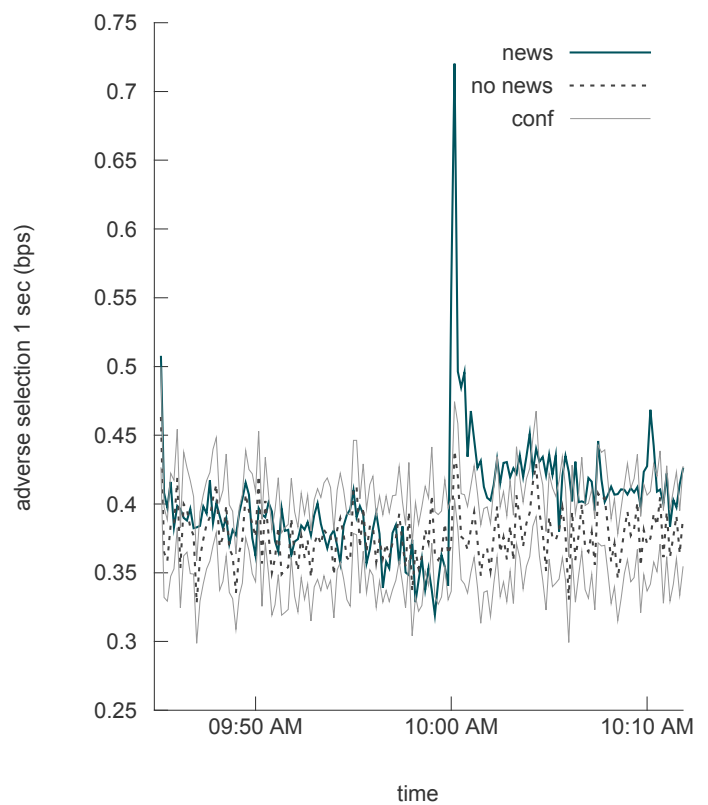

Figure A.6: The average (trade volume weighted) 1 minute realized spread ( $R S 60)$ per minute over the whole trading day (a) and per 10 seconds around 10:00 a.m. (b). The solid dark line is the $R S 1$ on days with news, whereas the dashed line is the $R S 1$ on days without news. The light gray lines provide the $90 \%$ confidence level of $R S 1$ on no news days. Note that the figure in (a) is constructed without differentiating between news arrival times (a day with news on, for example, 02:00 p.m. is a news day), whereas in (b) we only consider a day as a news day if there is news at 10:00 a.m.

(a) whole day

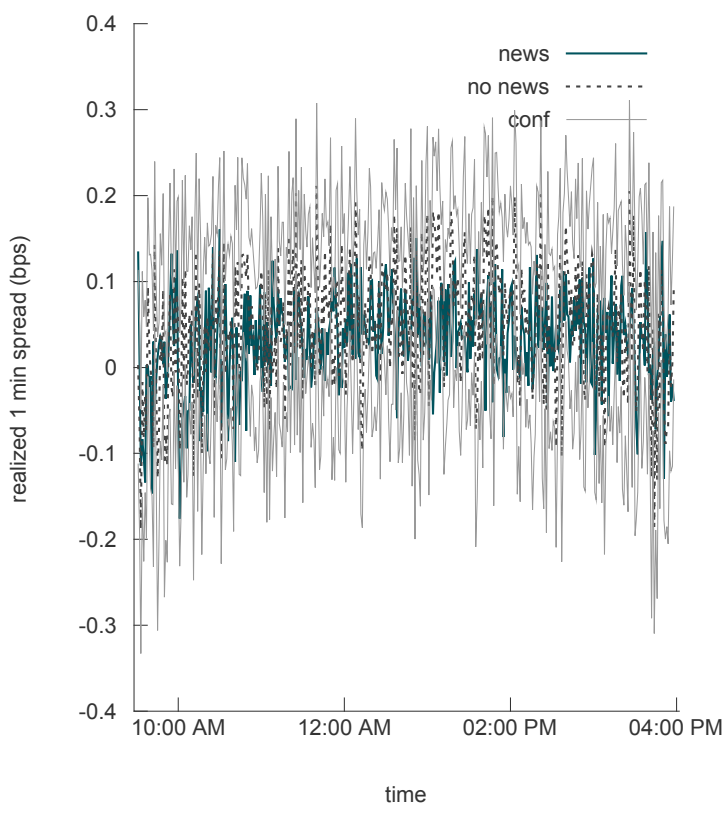

(b) $10: 00 \mathrm{AM}$

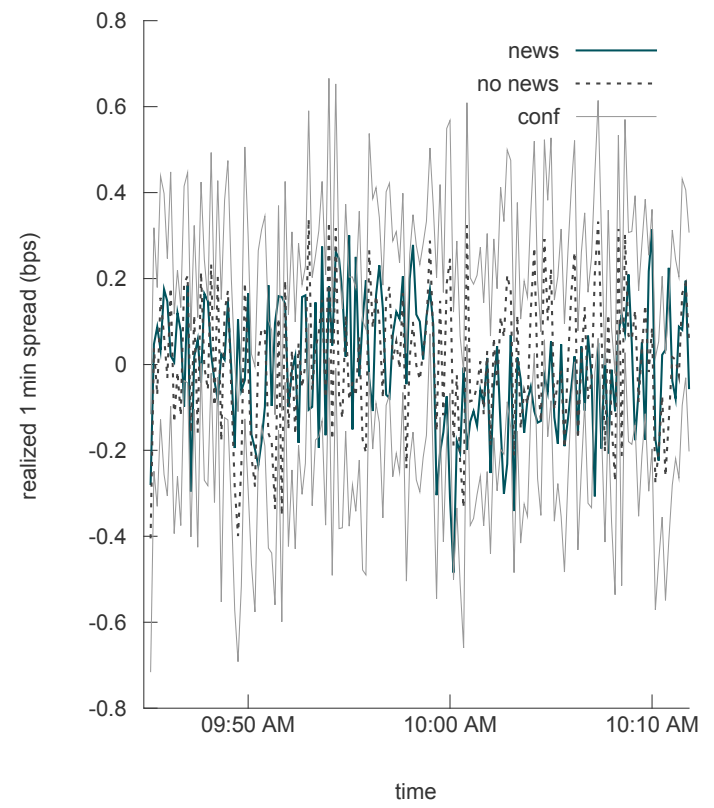


Figure A.7: The average (trade volume weighted) 1 minute adverse selection costs (price impact) (ADV60) per minute over the whole trading day (a) and per 10 seconds around 10:00 a.m. (b). The solid dark line is the $A D V 1$ on days with news, whereas the dashed line is the $A D V 1$ on days without news. The light gray lines provide the $90 \%$ confidence level of $A D V 1$ on no news days. Note that the figure in (a) is constructed without differentiating between news arrival times (a day with news on, for example, 02:00 p.m. is a news day), whereas in (b) we only consider a day as a news day if there is news on 10:00 a.m.

(a) whole day

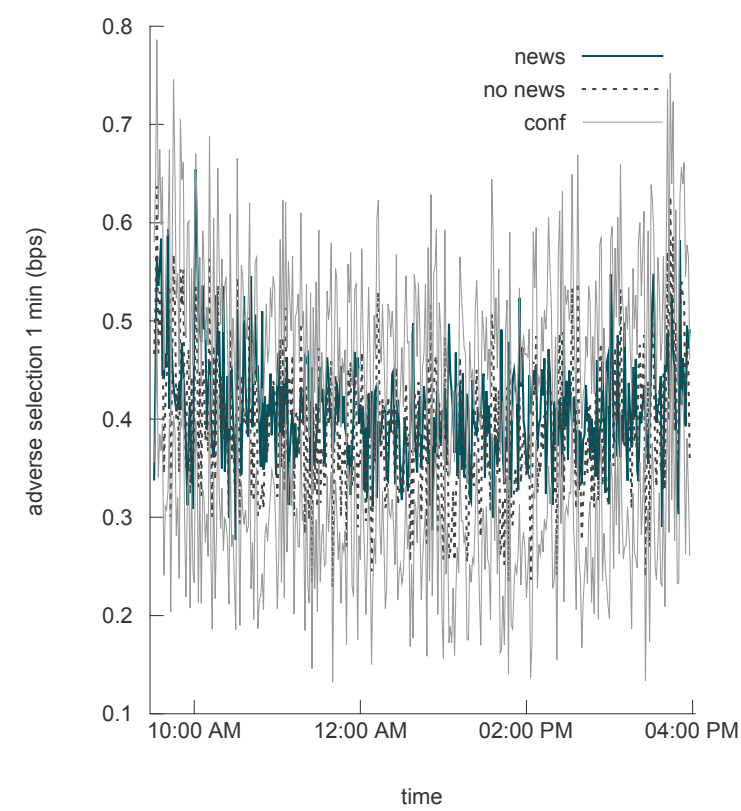

(b) 10:00 AM

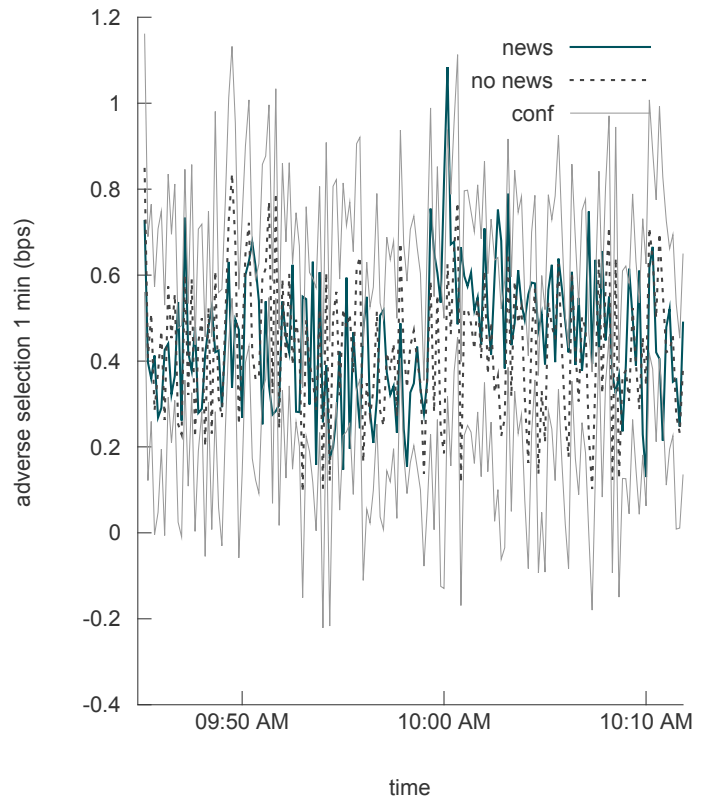

Figure A.8: The average 5 minute realized variance $(R V 300)$ per 5 minutes over the whole trading day (a) and around 10:00 a.m. (b). The solid dark line is the $R V 300$ on days with news, whereas the dashed line is the $R V 300$ on days without news. The light gray lines provide the $90 \%$ confidence level of $R V 300$ on no news days. Note that the figure in (a) is constructed without differentiating between news arrival times (a day with news on, for example, 02:00 p.m. is a news day), whereas in (b) we only consider a day as a news day if there is news at 10:00 a.m.

(a) whole day

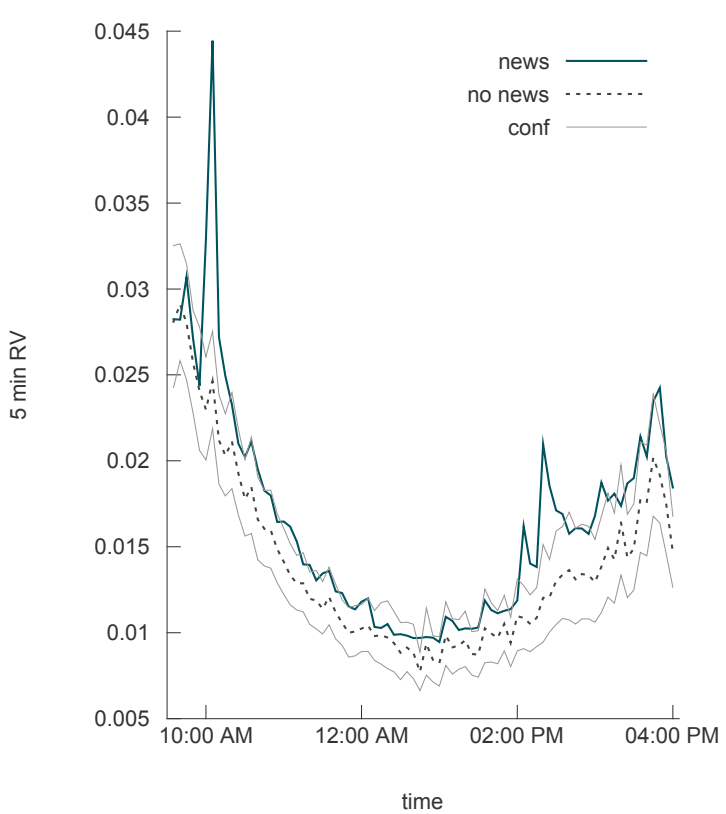

(b) 10:00 AM

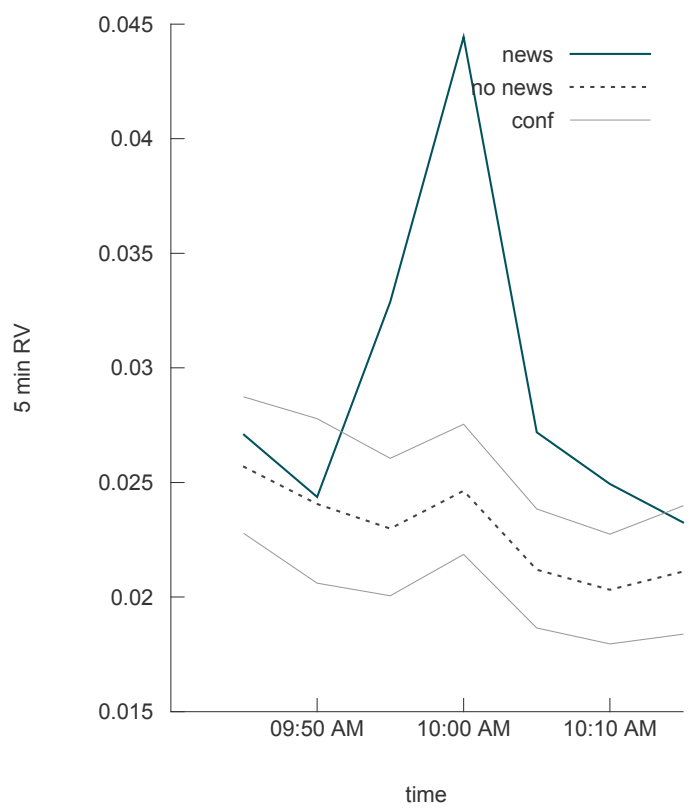


Figure A.9: The average 5 minute realized bi-power (BP300) per 5 minutes over the whole trading day (a) and around 10:00 a.m. (b). The solid dark line is the $B P 300$ on days with news, whereas the dashed line is the $B P 300$ on days without news. The light gray lines provide the $90 \%$ confidence level of BP300 on no news days. Note that the figure in (a) is constructed without differentiating between news arrival times (a day with news on, for example, 02:00 p.m. is a news day), whereas in (b) we only consider a day as a news day if there is news at 10:00 a.m.

(a) whole day

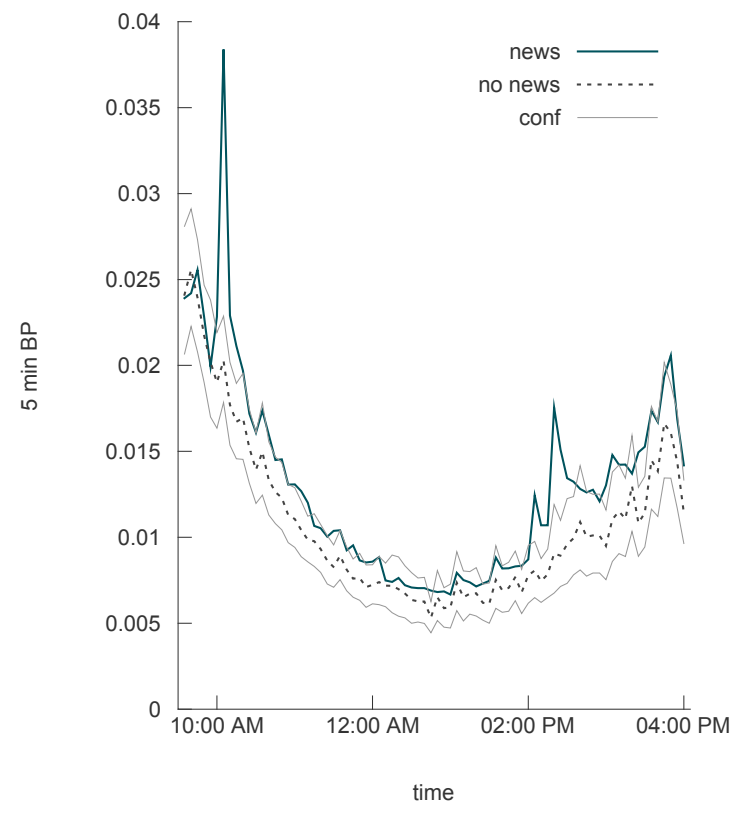

(b) 10:00 AM

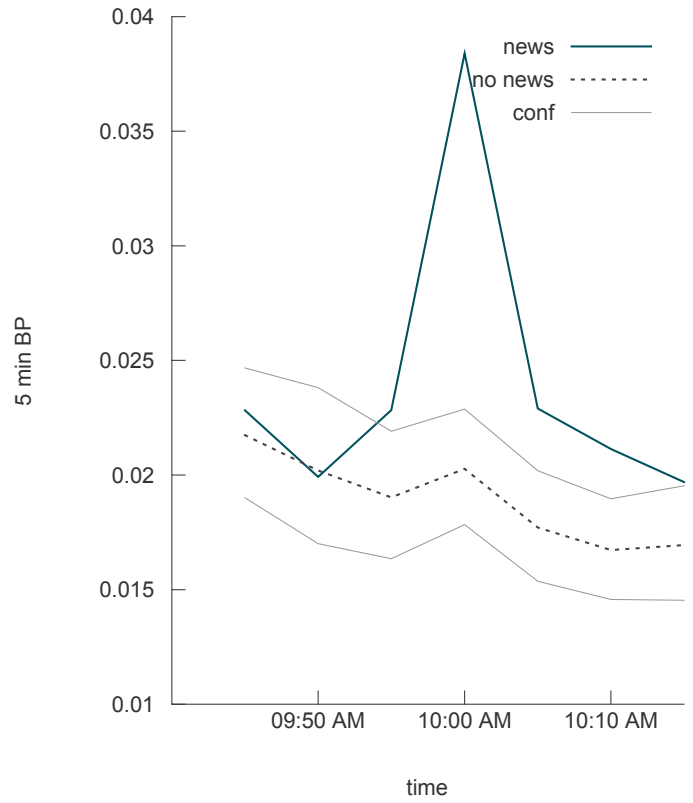

Figure A.10: The average 1 minute realized variance $(R V 60)$ per minute over the whole trading day (a) around 10:00 a.m. (b). The solid dark line is the $R V 60$ on days with news, whereas the dashed line is the $R V 60$ on days without news. The light gray lines provide the $90 \%$ confidence level of $R V 60$ on no news days. Note that the figure in (a) is constructed without differentiating between news arrival times (a day with news on, for example, 02:00 p.m. is a news day), whereas in (b) we only consider a day as a news day if there is news at 10:00 a.m.

(a) whole day

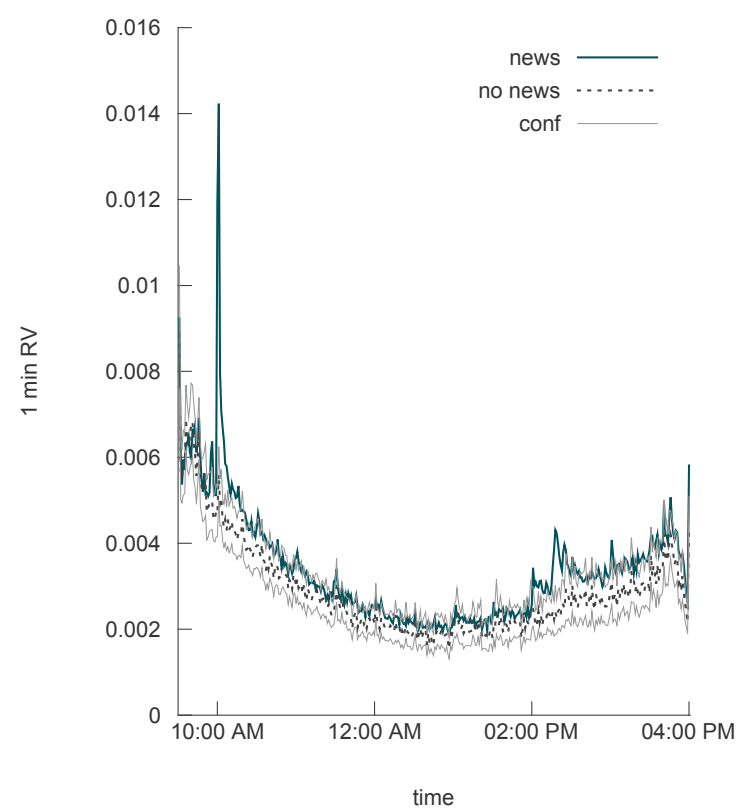

(b) 10:00 AM

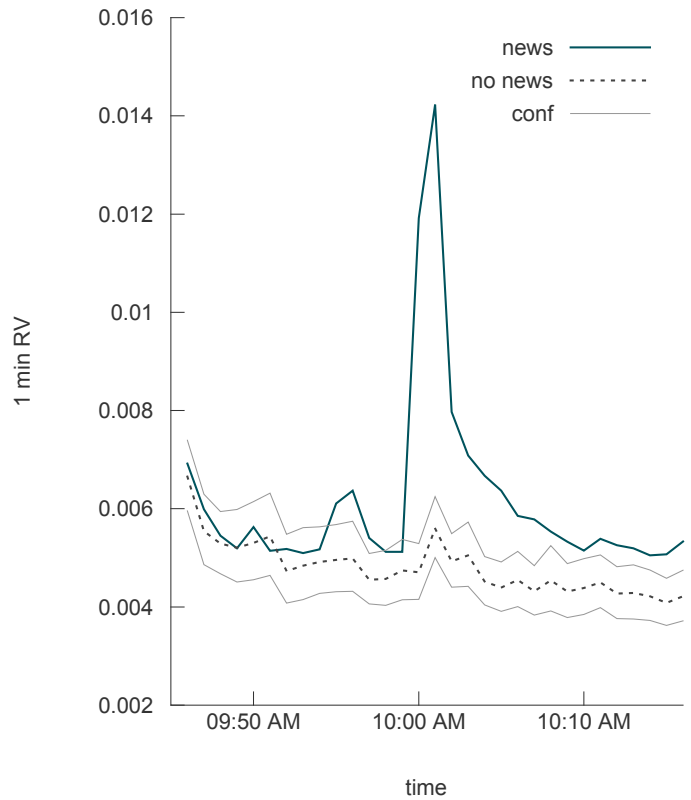


Figure A.11: The average 1 minute realized bi-power $(B P 60)$ per minute over the whole trading day (a) and around 10:00 a.m. (b). The solid dark line is the BP60 on days with news, whereas the dashed line is the $B P 60$ on days without news. The light gray lines provide the $90 \%$ confidence level of $B P 60$ on no news days. Note that the figure in (a) is constructed without differentiating between news arrival times (a day with news on, for example, 02:00 p.m. is a news day), whereas in (b) we only consider a day as a news day if there is news at 10:00 a.m.

(a) whole day

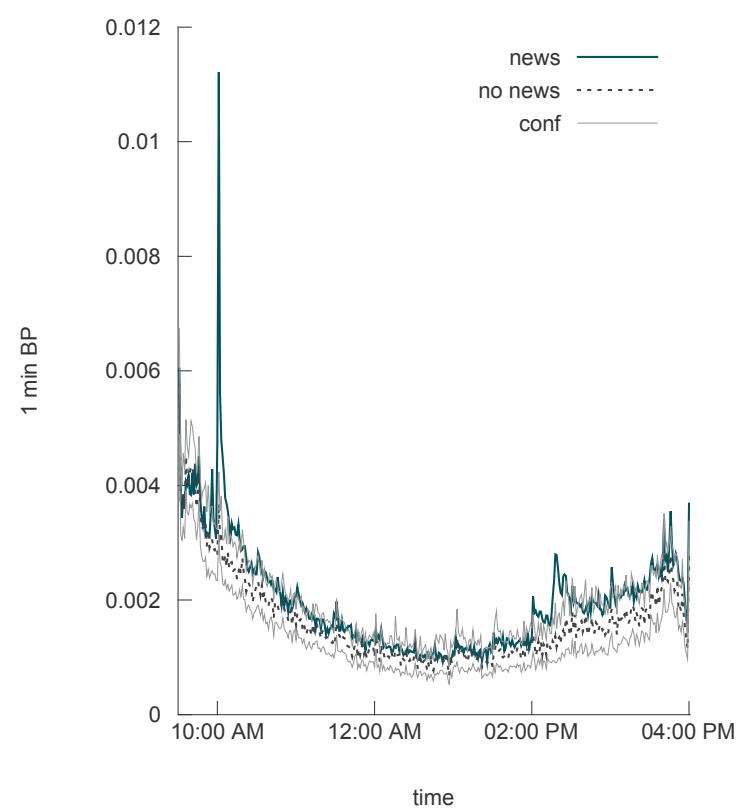

(b) 10:00 AM

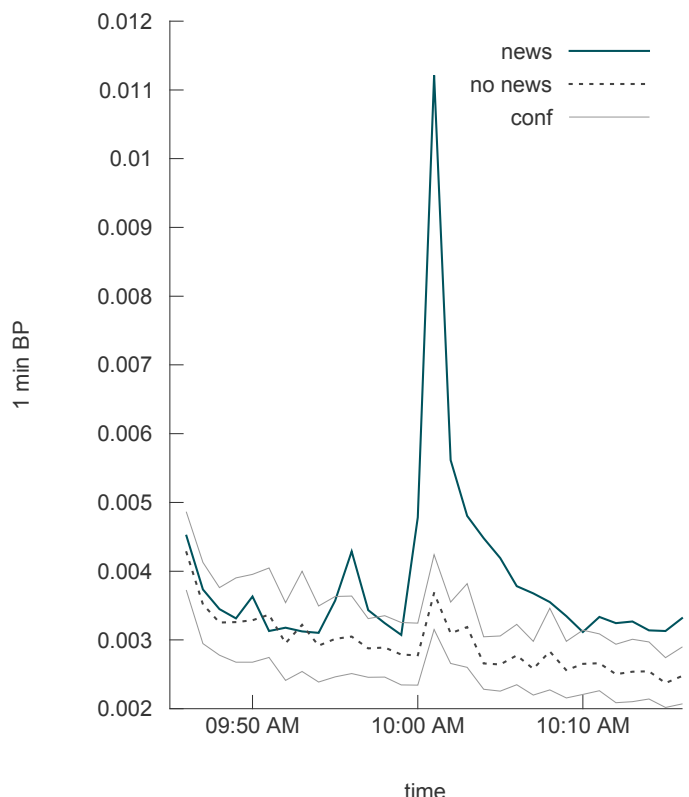

Figure A.12: The average aggregate number of messages (NMSGS) per minute over the whole trading day (a) and per 10 seconds around 10:00 a.m. (b). The solid dark line is the NMSGS on days with news, whereas the dashed line is the NMSGS on days without news. The light gray lines provide the $90 \%$ confidence level of $N M S G S$ on no news days. Note that the figure in (a) is constructed without differentiating between news arrival times (a day with news on, for example, 02:00 p.m. is a news day), whereas in (b) we only consider a day as a news day if there is news at 10:00 a.m.

(a) whole day

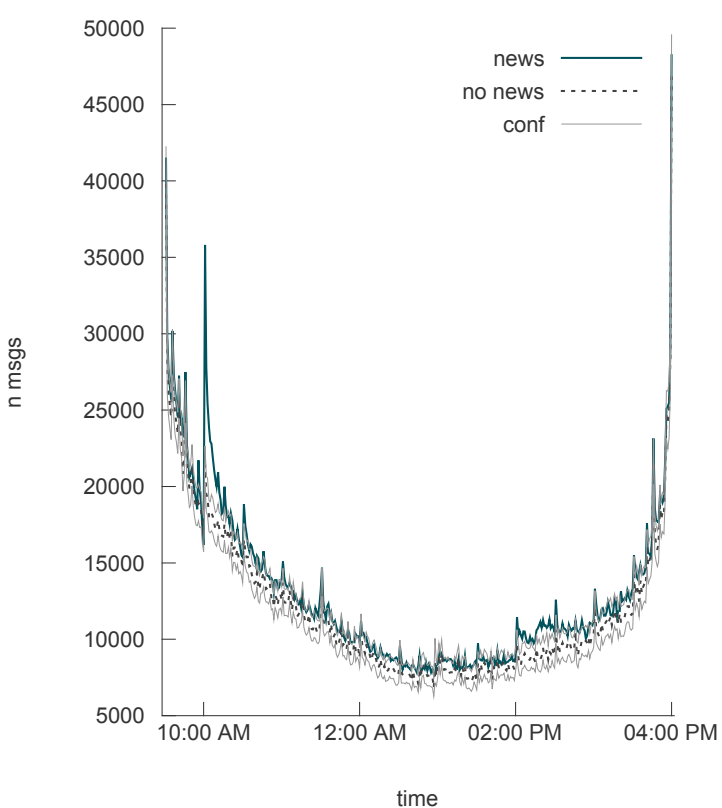

(b) 10:00 AM

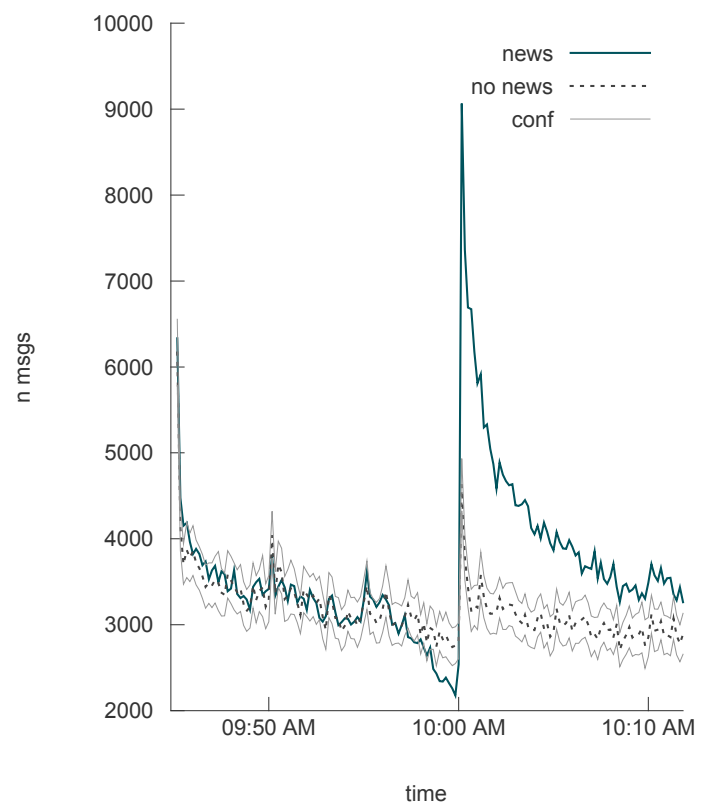


Figure A.13: The average aggregate number of fleeting executions at the $50 \mathrm{~ms}$ level $\left(N F L T 50_{\text {exe }}\right)$ per minute over the whole trading day (a) and per 10 seconds around 10:00 a.m. (b). The solid dark line is the NFLT50exe on days with news, whereas the dashed line is the NFLT50 exe on days without news. The light gray lines provide the $90 \%$ confidence level of NFLT50 exe on no news days. Note that the figure in (a) is constructed without differentiating between news arrival times (a day with news on, for example, 02:00 p.m. is a news day), whereas in (b) we only consider a day as a news day if there is news at 10:00 a.m.

(a) whole day

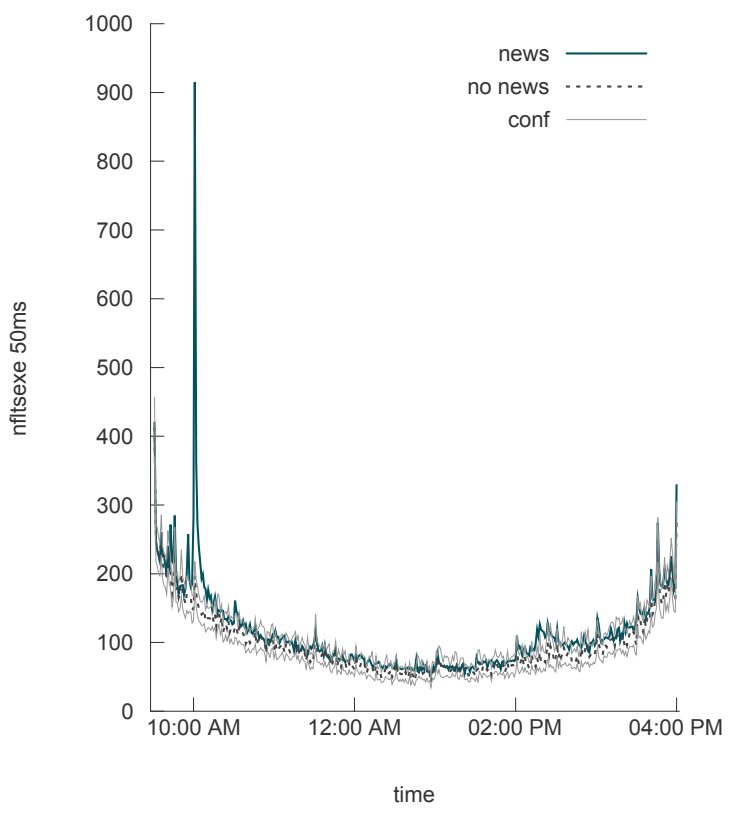

(b) 10:00 AM

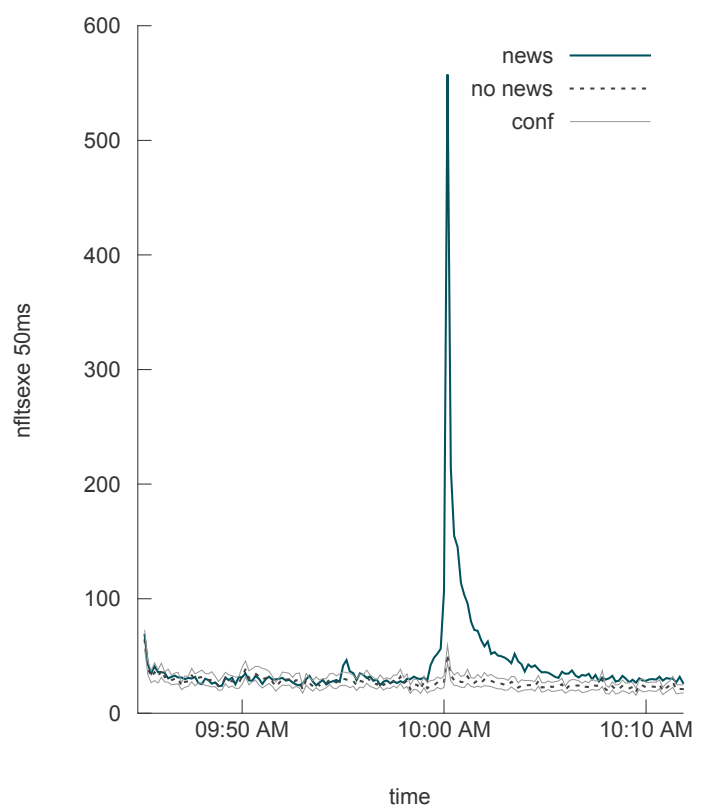

Figure A.14: The average aggregate number of fleeting orders that improve upon the best bid or ask quote at the $50 \mathrm{~ms}$ level $\left(N F L T 50_{b a}\right.$ ) per minute over the whole trading day (a) and per 10 seconds around 10:00 a.m. (b). The solid dark line is the NFLT50ba on days with news, whereas the dashed line is the NFLT50ba on days without news. The light gray lines provide the $90 \%$ confidence level of $N F L T 50_{b a}$ on no news days. Note that the figure in (a) is constructed without differentiating between news arrival times (a day with news on, for example, 02:00 p.m. is a news day), whereas in (b) we only consider a day as a news day if there is news at 10:00 a.m.

(a) whole day

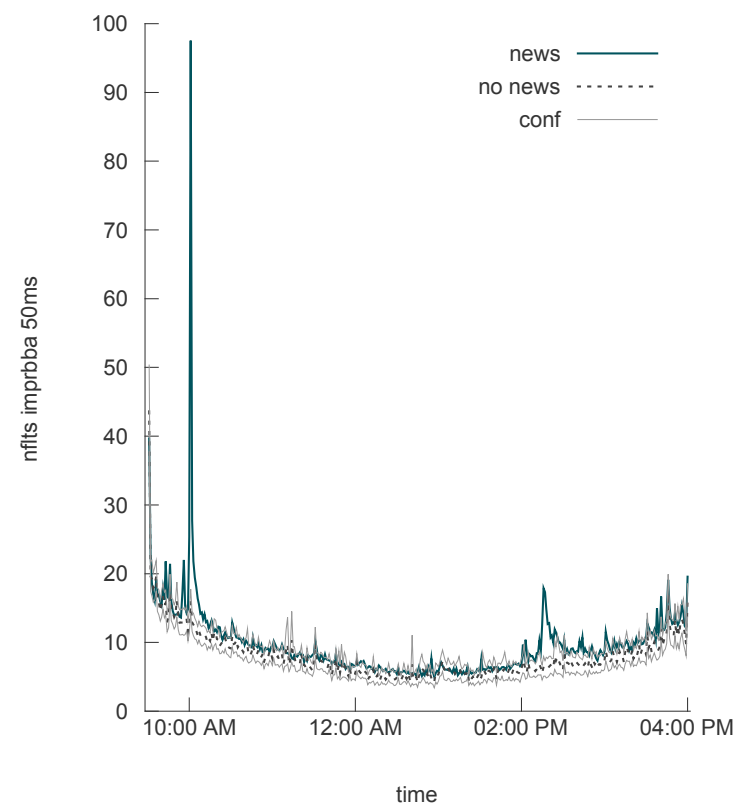

(b) 10:00 AM

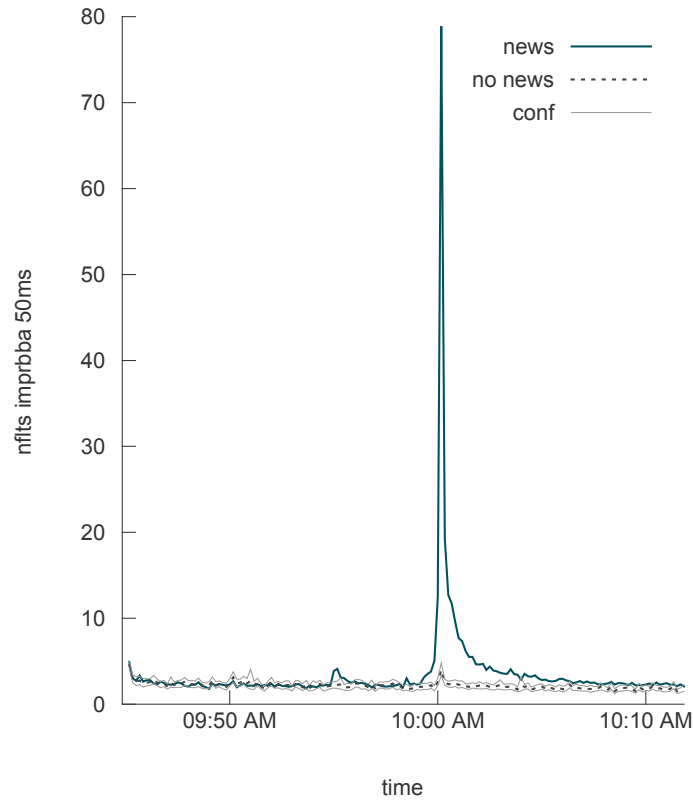


Figure A.15: The average aggregate number of missed opportunities at the $50 \mathrm{~ms}$ level $\left(N F L T 50_{m o}\right)$ per minute over the whole trading day (a) and per 10 seconds around 10:00 a.m. (b). The solid dark line is the NFLT50 mo on days with news, whereas the dashed line is the NFLT50 mo on days without news. The light gray lines provide the $90 \%$ confidence level of NFLT50 mo on no news days. Note that the figure in (a) is constructed without differentiating between news arrival times (a day with news on, for example, 02:00 p.m. is a news day), whereas in (b) we only consider a day as a news day if there is news at 10:00 a.m.

(a) whole day

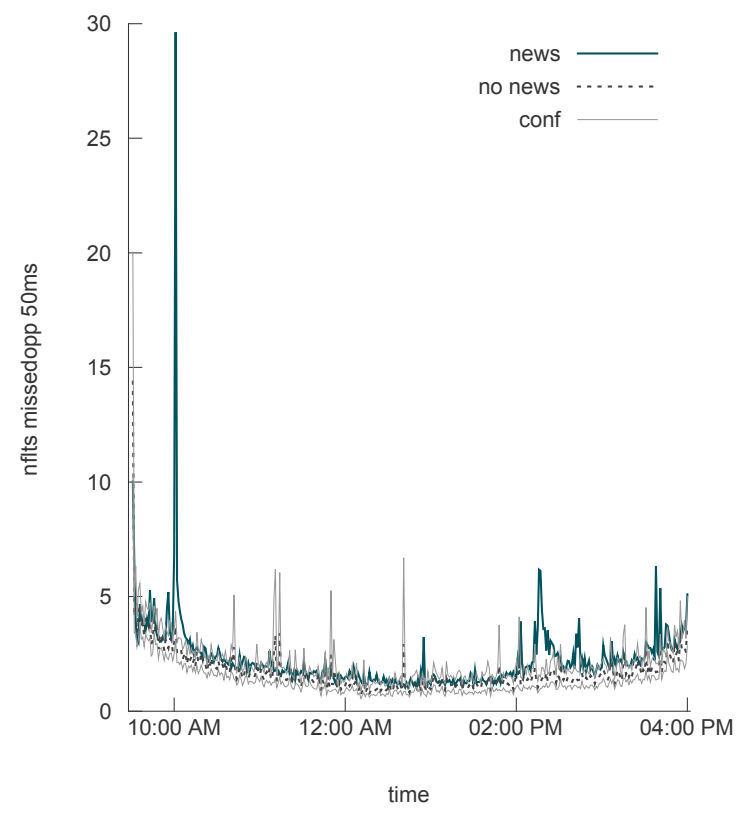

(b) 10:00 AM

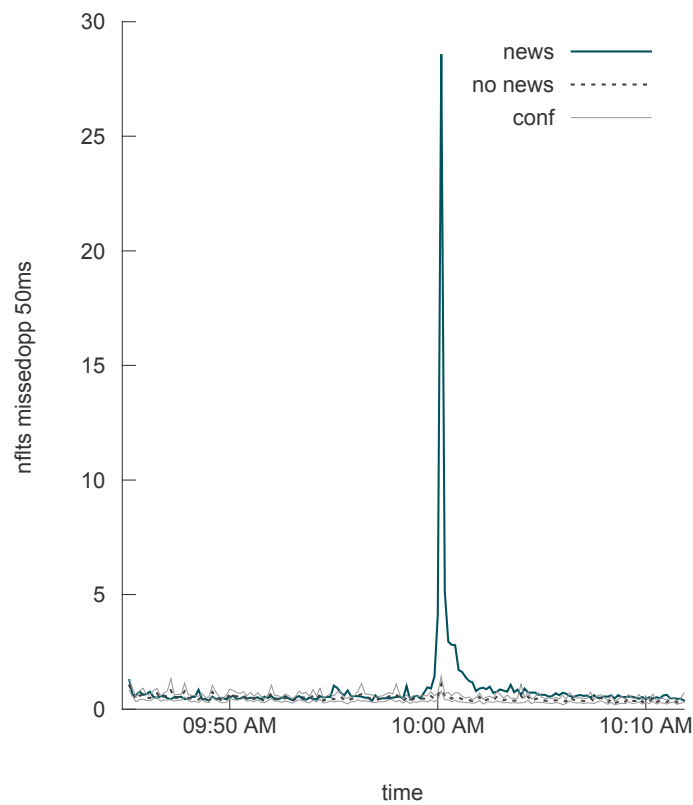

Figure A.16: The average aggregate number of fleeting orders at the $100 \mathrm{~ms}$ level (NFLT100) per minute over the whole trading day (a) and per 10 seconds around 10:00 a.m. (b). The solid dark line is the NFLT100 on days with news, whereas the dashed line is the NFLT100 on days without news. The light gray lines provide the $90 \%$ confidence level of NFLT100 on no news days. Note that the figure in (a) is constructed without differentiating between news arrival times (a day with news on, for example, 02:00 p.m. is a news day), whereas in (b) we only consider a day as a news day if there is news at 10:00 a.m.

(a) whole day

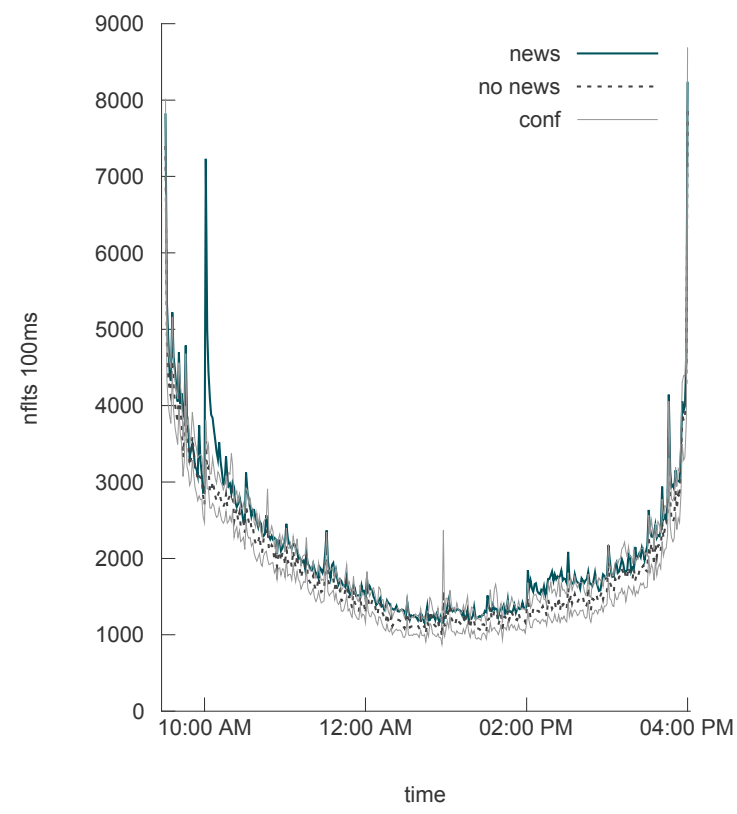

(b) 10:00 AM

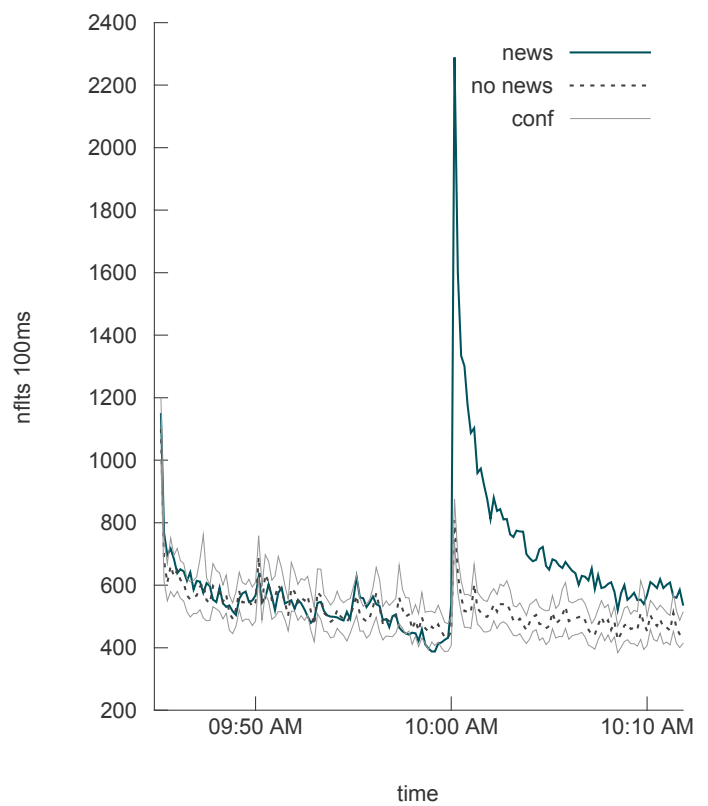


Figure A.17: The average aggregate number of fleeting executions at the $100 \mathrm{~ms}$ level $\left(N F L T 100_{\text {exe }}\right)$ per minute over the whole trading day (a) and per 10 seconds around 10:00 a.m. (b). The solid dark line is the NFLT100exe on days with news, whereas the dashed line is the $N F L T 100_{\text {exe }}$ on days without news. The light gray lines provide the $90 \%$ confidence level of NFLT100 exe on no news days. Note that the figure in (a) is constructed without differentiating between news arrival times (a day with news on, for example, 02:00 p.m. is a news day), whereas in (b) we only consider a day as a news day if there is news at 10:00 a.m.

(a) whole day

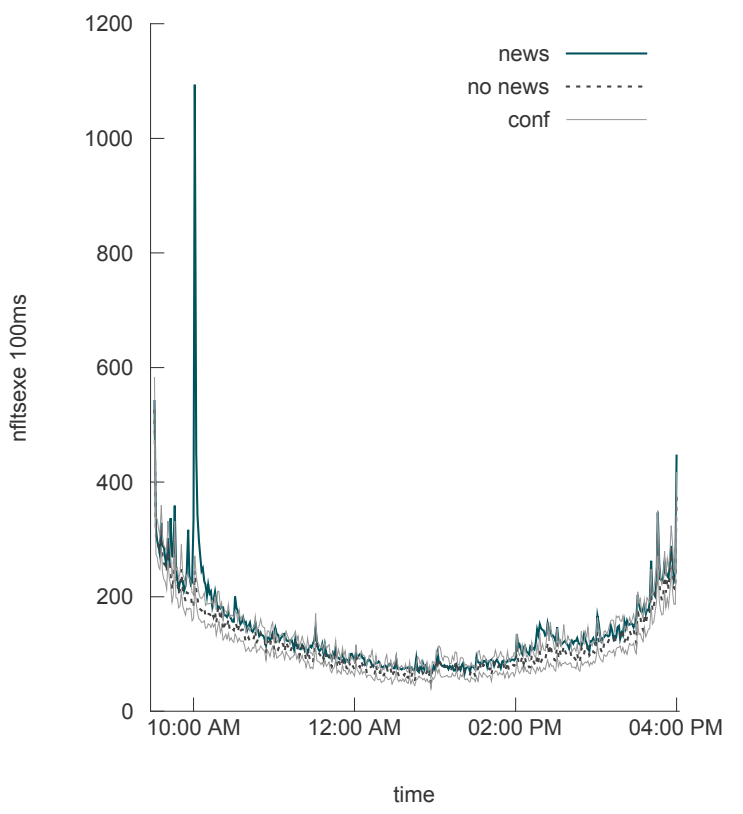

(b) 10:00 AM

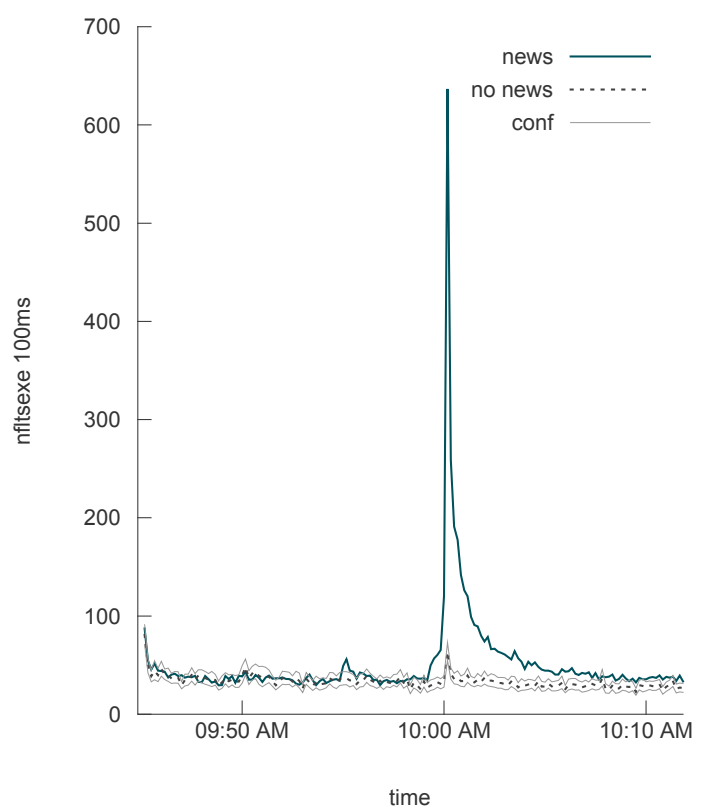

Figure A.18: The average aggregate number of fleeting orders that improve upon the best bid or ask quote at the 100 ms level $\left(N F L T 100_{b a}\right)$ per minute over the whole trading day (a) and per 10 seconds around 10:00 a.m. (b). The solid dark line is the $N F L T 100_{b a}$ on days with news, whereas the dashed line is the $N F L T 100_{b a}$ on days without news. The light gray lines provide the $90 \%$ confidence level of $N F L T 100_{b a}$ on no news days. Note that the figure in (a) is constructed without differentiating between news arrival times (a day with news on, for example, 02:00 p.m. is a news day), whereas in (b) we only consider a day as a news day if there is news at 10:00 a.m.

(a) whole day

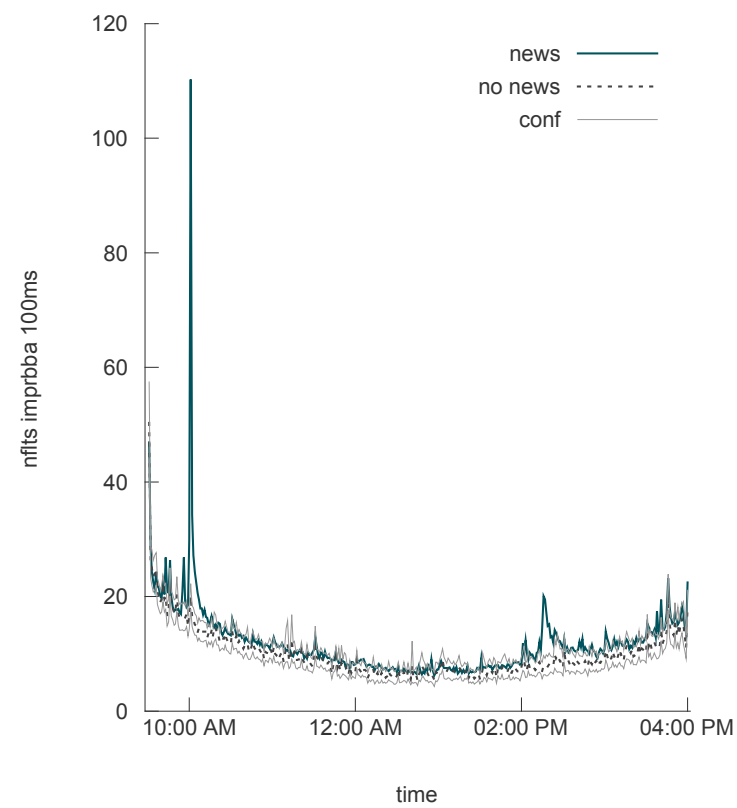

(b) 10:00 AM

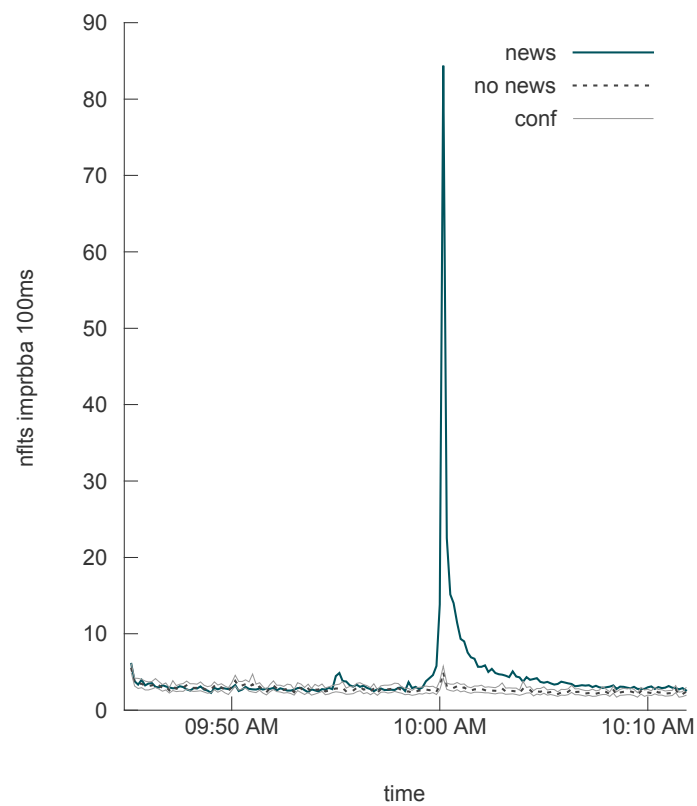


Figure A.19: The average aggregate number of missed opportunities at the $100 \mathrm{~ms}$ level (NFLT100 mo $)$ per minute over the whole trading day (a) and around 10:00 a.m. (b). The solid dark line is the NFLT100 mo on days with news, whereas the dashed line is the $N F L T 100_{m o}$ on days without news. The light gray lines provide the $90 \%$ confidence level of $N F L T 100_{m o}$ on no news days. Note that the figure in (a) is constructed without differentiating between news arrival times (a day with news on, for example, 02:00 p.m. is a news day), whereas in (b) we only consider a day as a news day if there is news at 10:00 a.m.

(a) whole day

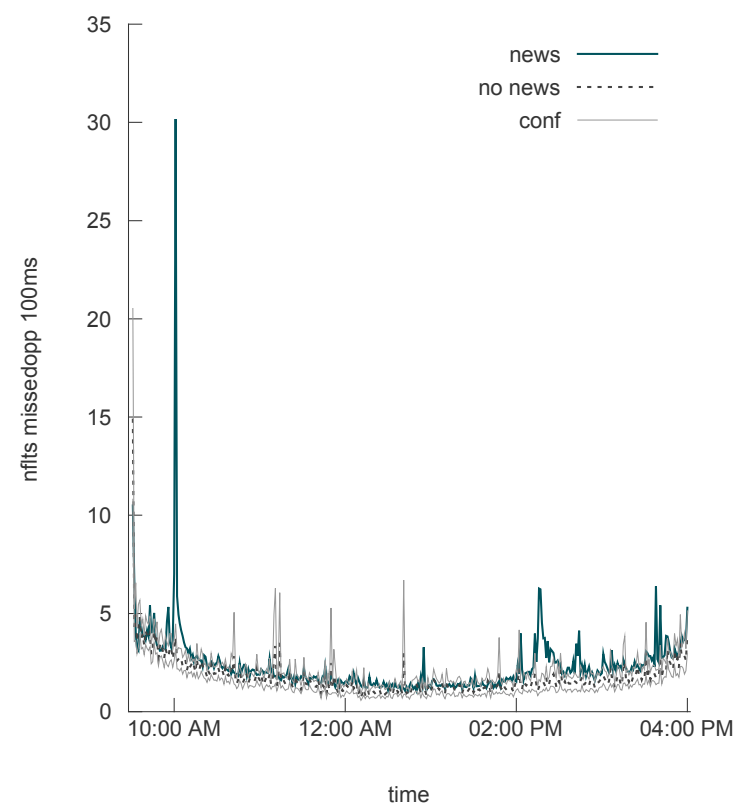

(b) 10:00 AM

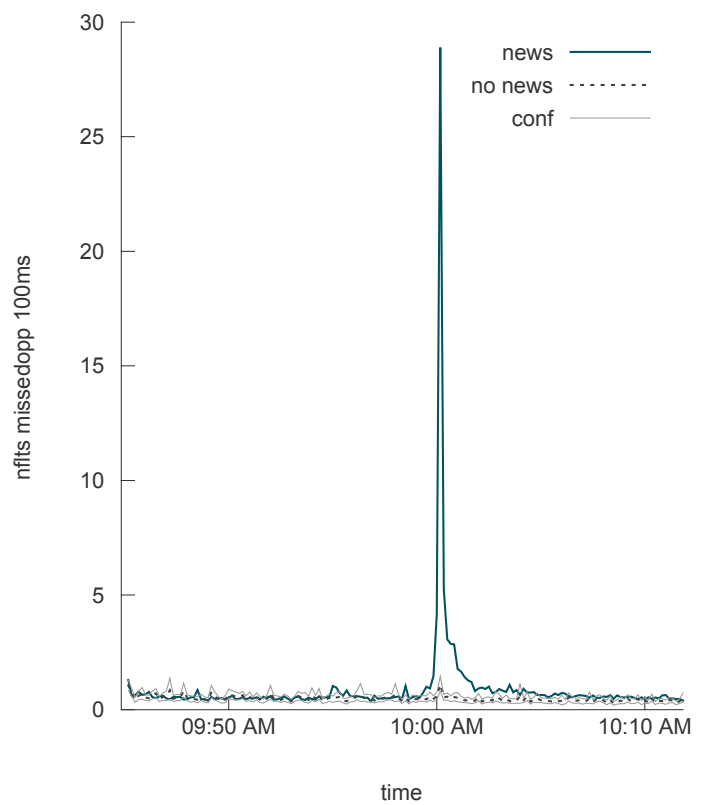

Figure A.20: The importance of speed during macroeconomic news announcements for the different years in the sample period and the year 2009 separate for the period with (June 5, 2009 to August 31, 2009) and without (from January 6, 2009 to June 4, 2009 and from September 1, 2009 to December 31, 2009) flash orders (a) and the importance of speed for the different years, only considering medium volatility days (b). The medium volatility days are determined by sorting the maximum intraday VIX values of all announcement days in ascending order from which we select the announcements in the second and third quartile. The importance of speed is calculated by comparing the average return of executing the perfect foresight strategy instantaneously with the average returns of executing the perfect foresight strategy with the delay levels provided on the x-axis. In case the importance of speed is significant at the $10 \%, 5 \%$, or $1 \%$ level this is indicated by means of a $*, \odot$, and $\bullet$, respectively.

(a) imp. of speed per year, flash orders (f.o.) separate

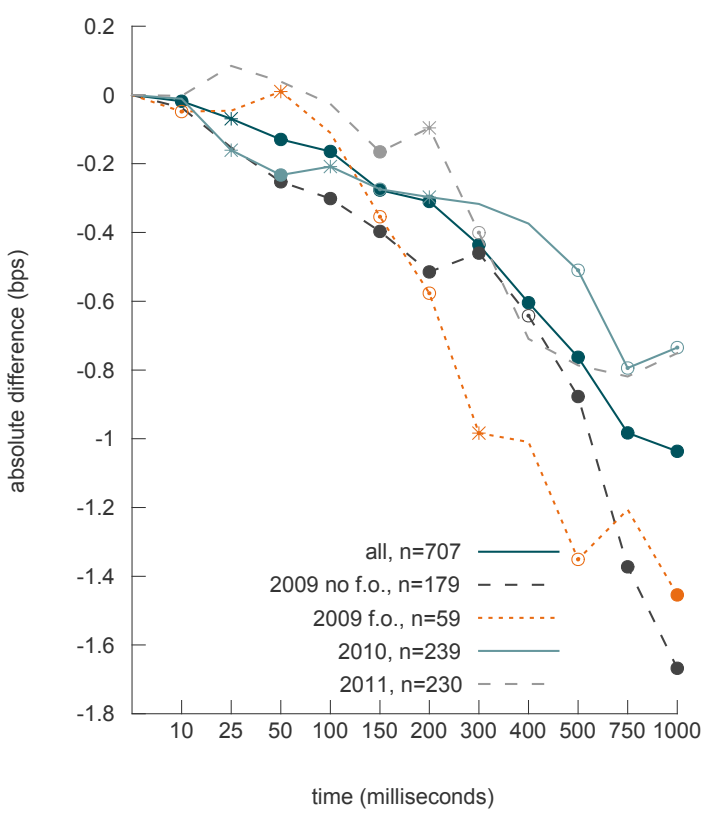

(b) imp. of speed per year mid vol days

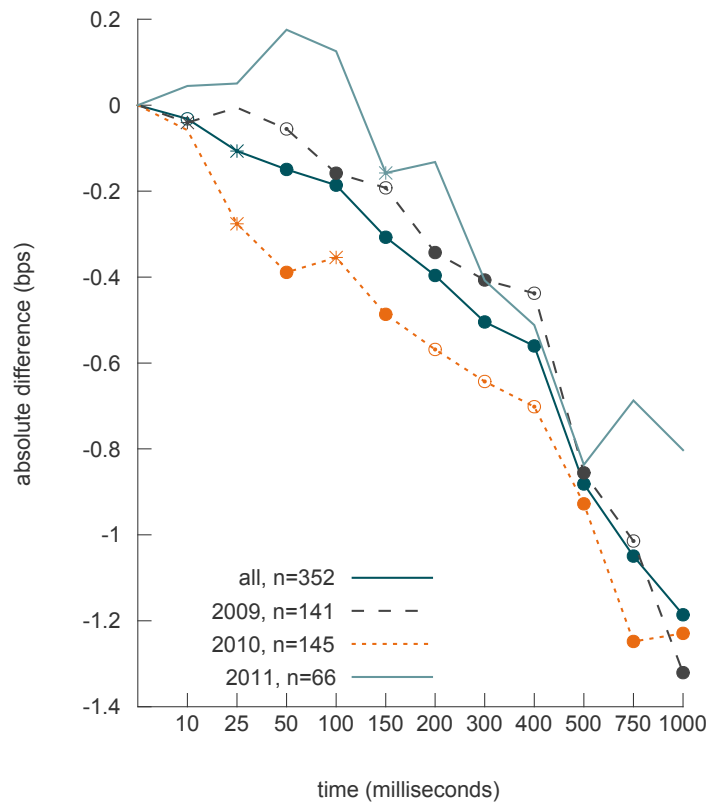


Figure A.21: The importance of speed during macroeconomic news announcements for the different years, only considering low volatility days (a) and only considering high volatility days (b). The low (high) volatility days are determined by sorting, in ascending order, the maximum intraday VIX values of all announcement days from which we select the announcements in the first and second (third and fourth) quartile. The importance of speed is calculated by comparing the average return of executing the perfect foresight strategy instantaneously with the average returns of executing the perfect foresight strategy with the delay levels provided on the x-axis. In case the importance of speed is significant at the $10 \%, 5 \%$, or $1 \%$ level this is indicated by means of a $*, \odot$, and $\bullet$, respectively.

(a) imp. of speed per year low vol days

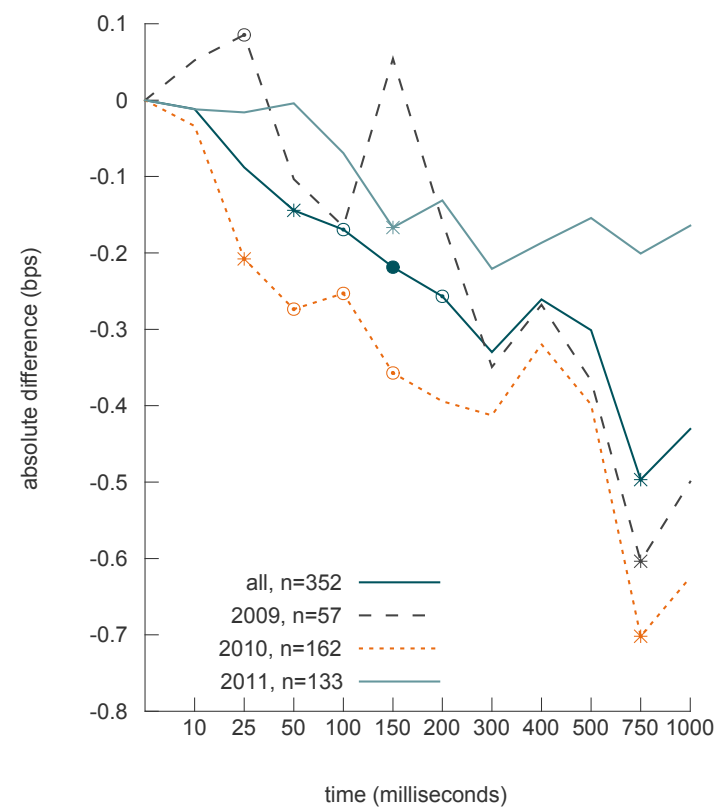

(b) imp. of speed per year high vol days

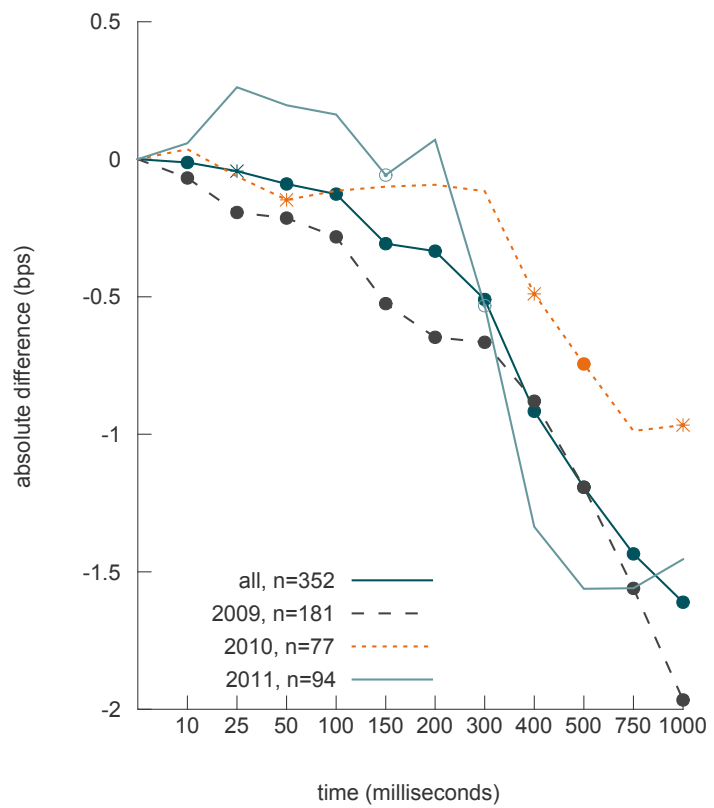

Figure A.22: Scaled 1 second log returns (in bps) over the interval from the official announcement time up to the SIRCA news arrival time (IV0) plotted against the return over the interval of the same length following the SIRCA arrival time (IV1) for all news announcements (a) and news at 10:00 a.m. (b). Because the intervals have different lengths returns are all rescaled to 1 second returns. Dark (light) dots correspond to returns that have the same (different) signs in IV0 and IV1. The legend also provides the mean absolute log return (mar) in IV0 and IV1, respectively. The p-val (z-val) in the title of subplot (a) and (b) correspond to a t-test (Wilcoxon rank-sum test) with the null hypothesis of equal means (medians) in IV0 and IV1.
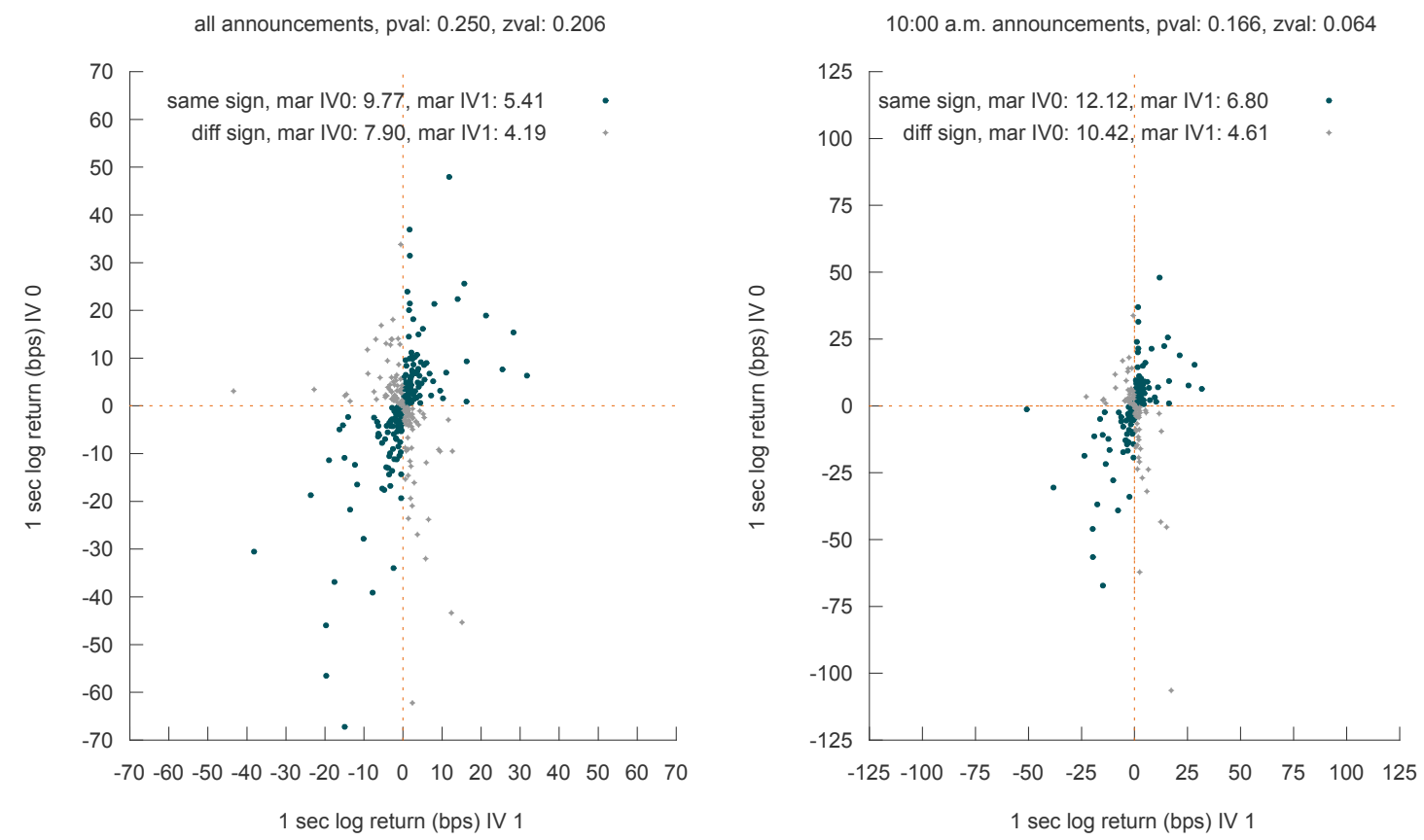
Figure A.23: Subplot (a) provides the percentage of announcements for which the sign of the return over the interval from the official announcement time to SIRCA announcement time (interval 0) matches the sign of subsequent intervals of the same length (\# future periods), excluding the no announcements with a zero return in interval 0 (the number of excluded announcements, n0, is provided in the legend) for announcements where the SIRCA time is within 0-250, 250-500, 500-750, and 750-1000 $\mathrm{ms}$ of the official announcement time. Hit ratios significantly (higher) lower than one would expect based on randomness are marked by means of a $\bullet$ and ( $\mathbf{\square})$. Cumulative returns per event of trading strategies based on the hit ratios in (a) are provided in (b).

(a) hit ratios using info in IV0 excl. zeros

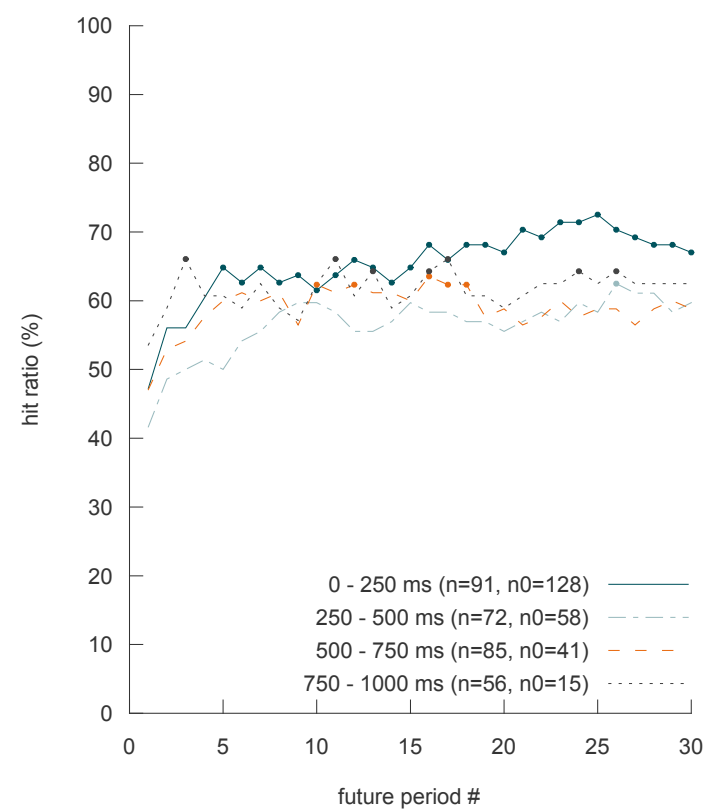

(b) profit using info in IV0 excl. zeros

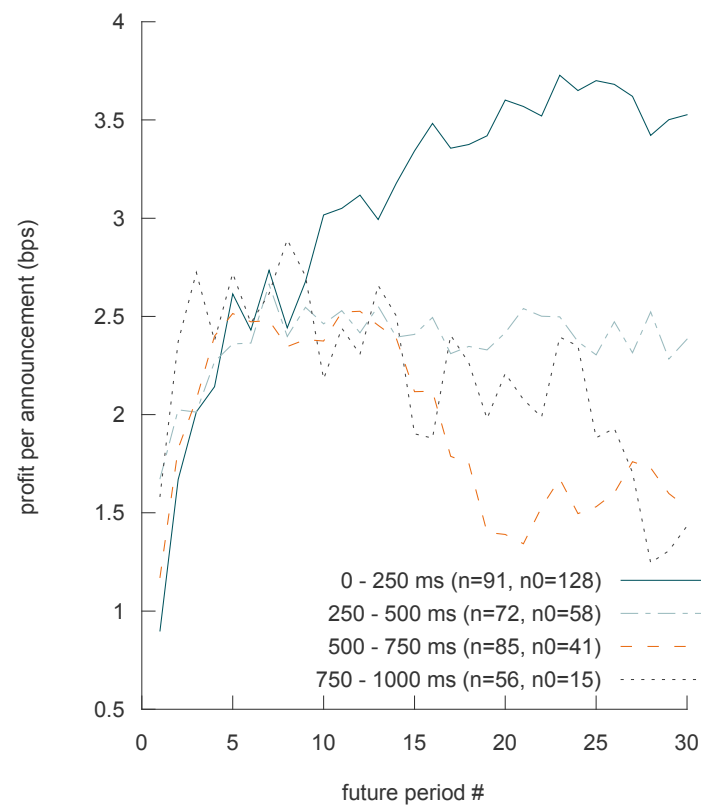

Figure A.24: Subplot (a) provides the percentage of announcements for which the sign of the return over the interval from the official announcement time to SIRCA announcement time (interval 0) matches the sign of subsequent intervals of the same length (\# future periods), including announcements with a zero return in interval 0, for announcements where the SIRCA time is within 0-250, 250-500, 500-750, and 750-1000 ms of the official announcement time. Hit ratios significantly (higher) lower than one would expect based on randomness are marked by means of a $\bullet$ and ( $)$. Cumulative returns per event of trading strategies based on the hit ratios in (a) are provided in (b).

(a) hit ratios using info in IVO incl. zeros

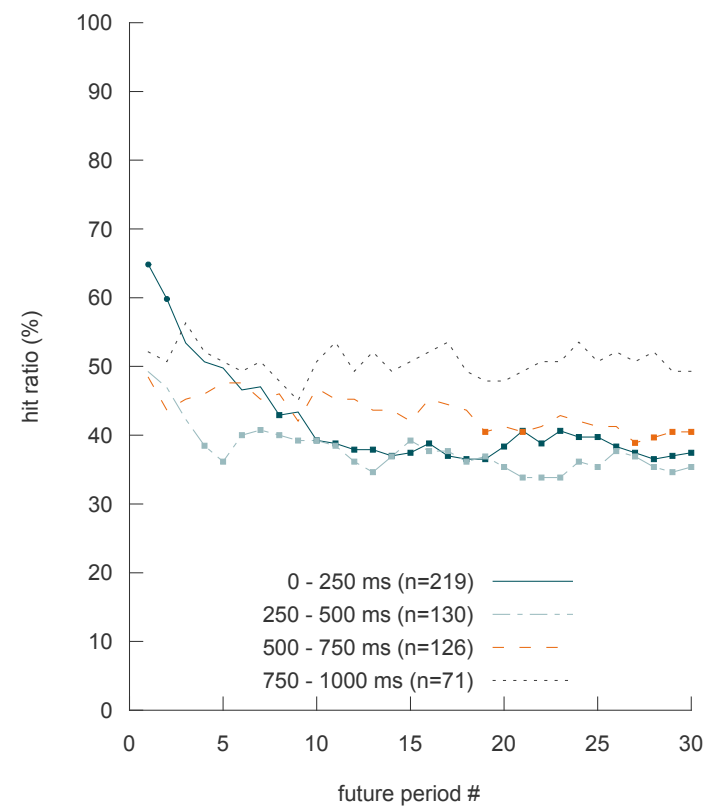

(b) profit using info in IVO incl. zeros

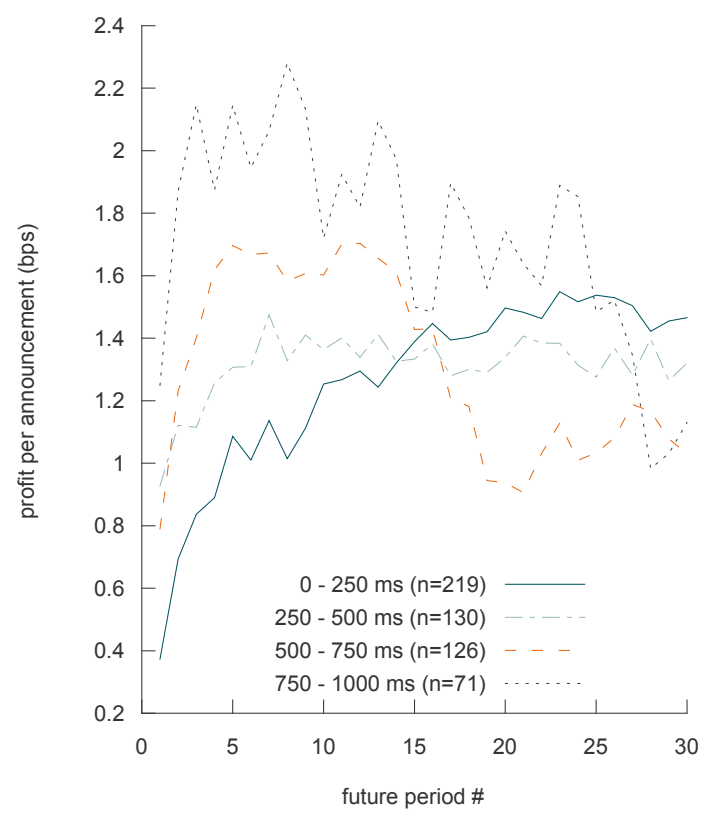


Figure A.25: Subplot (a) provides the percentage of announcements for which the sign of the return over the $\mathrm{x}=50$, $\mathrm{x}=100, \mathrm{x}=150$, and $\mathrm{x}=200 \mathrm{~ms}$ intervals before the official announcement time (OAT) matches the sign of subsequent 30 intervals of length $\mathrm{x}$ following the OAT, excluding announcements with a zero return in the initial interval (the number of excluded announcements, n0, is provided in the legend). Hit ratios significantly (higher) lower than one would expect based on randomness are marked by means of a $\bullet$ and $(\mathbf{\square})$. Cumulative returns per event of trading strategies based on the hit ratios in (a) are provided in (b).

(a) HR using $x$ ms before OAT on OAT excl. zeros

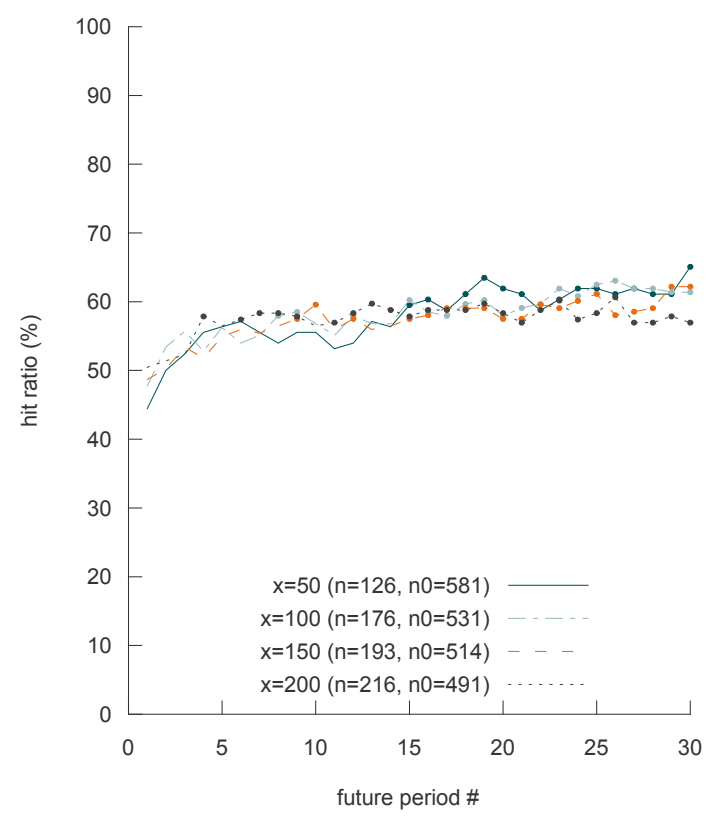

(b) profit using $\mathrm{x}$ ms before OAT on OAT excl. zeros

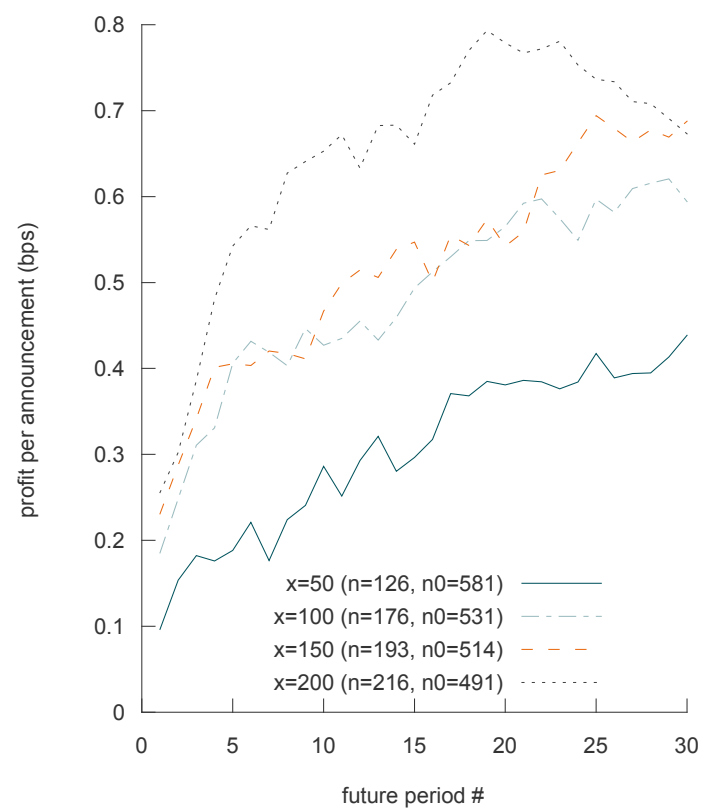

Figure A.26: Subplot (a) provides the percentage of announcements for which the sign of the return over the $\mathrm{x}=50$, $\mathrm{x}=100, \mathrm{x}=150$, and $\mathrm{x}=200 \mathrm{~ms}$ intervals before the official announcement time (OAT) matches the sign of subsequent 30 intervals of length $\mathrm{x}$ following the SIRCA news arrival time, excluding announcements with a zero return in the initial interval (the number of excluded announcements, $\mathrm{n} 0$, is provided in the legend). Hit ratios significantly (higher) lower than one would expect based on randomness are marked by means of a $\bullet$ and ( $\mathbf{\bullet})$. Cumulative returns per event of trading strategies based on the hit ratios in (a) are provided in (b).

(a) HR using $x$ ms before OAT on SIRCA time excl. zeros

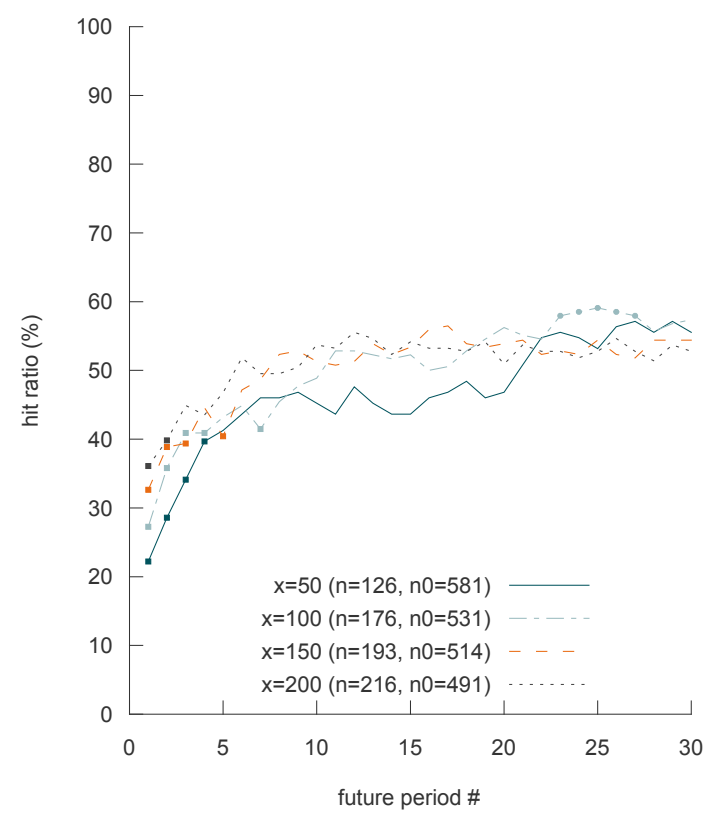

(b) profit using $\mathrm{x}$ ms before OAT on SIRCA time excl. zeros

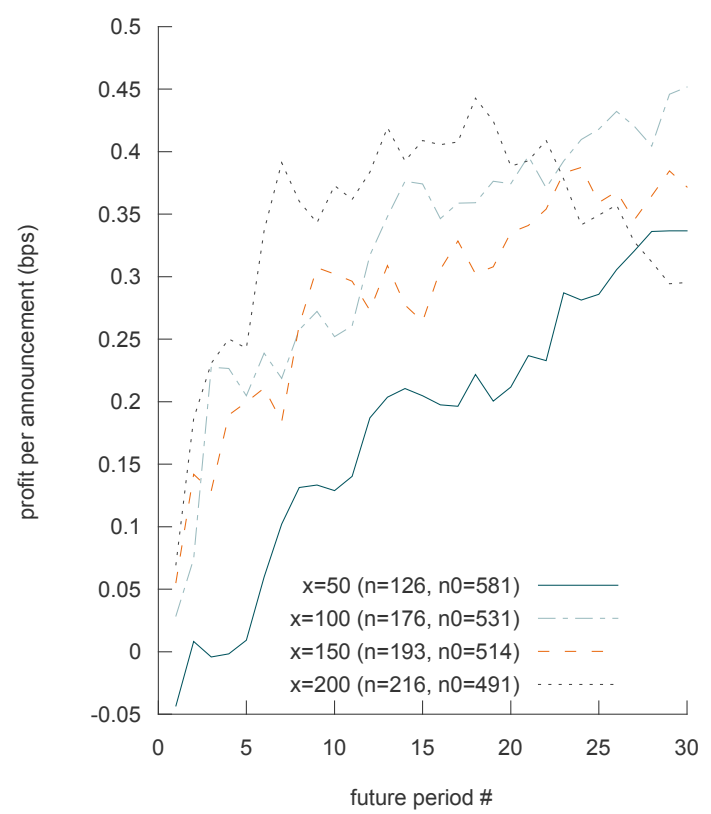


Figure A.27: Subplot (a) provides the percentage of announcements for which the sign of the return over the $\mathrm{x}=50$, $\mathrm{x}=100, \mathrm{x}=150$, and $\mathrm{x}=200 \mathrm{~ms}$ intervals before the SIRCA arrival time matches the sign of subsequent 30 intervals of length $x$ following the SIRCA news arrival time, excluding announcements with a zero return in the initial interval (the number of excluded announcements, n0, is provided in the legend). Hit ratios significantly (higher) lower than one would expect based on randomness are marked by means of a $\bullet$ and ( $\bullet$ ). Cumulative returns per event of trading strategies based on the hit ratios in (a) are provided in (b).

(a) HR using $x$ ms before SIRCA on SIRCA time excl. zeros

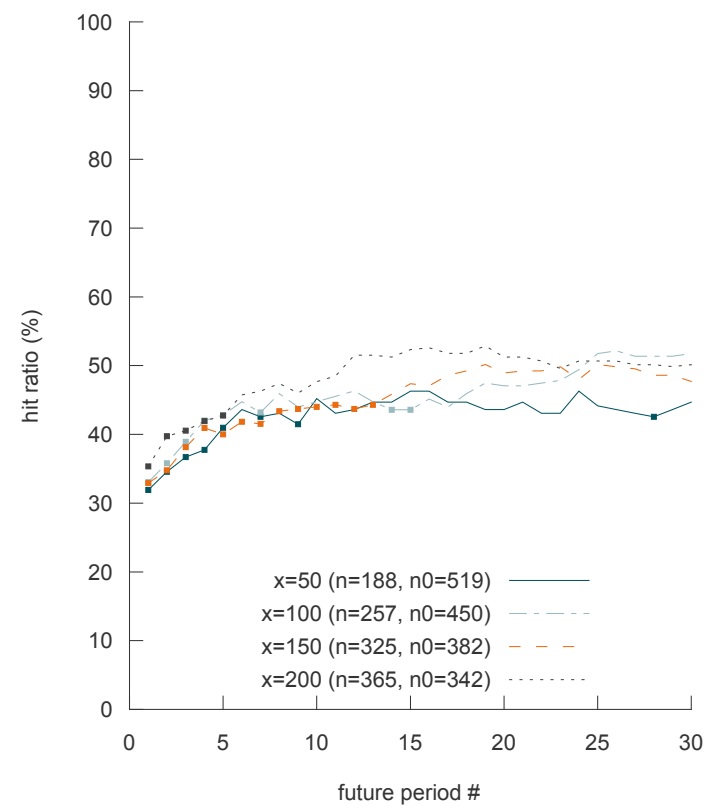

(b) profit using $\mathrm{x}$ ms before SIRCA on SIRCA time excl. zeros

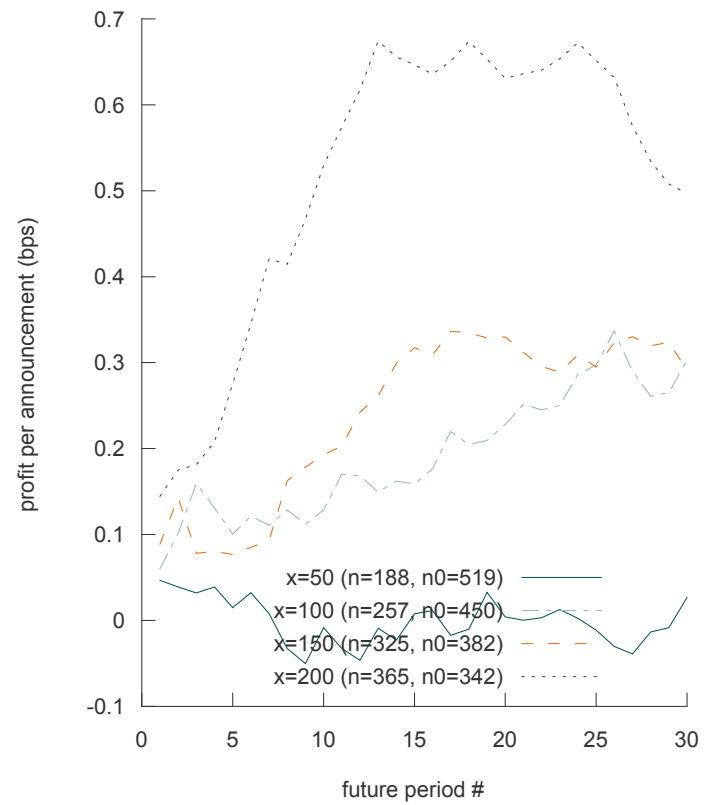

